$1 / 1 / 22^{2196980}$

Background Chemistry for Chemical Warfare Agents and Decontamination Processes in Support of Delisting Waste Streams at the U.S. Army Dugway Proving Ground, Utah

Environmental Assessment Division Argonne National Laboratory

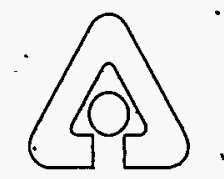

Operated by The University of Chicago, under Contract $W-31-109-E n g-38$, for the United States Department of Energy 


\section{Argonne National Laboratory}

Argonne National Laboratory, with facilities in the states of Iilinois and Idaho, is owned by the United States Government, and operated by the University of Chicago under the provisions of a contract with the Department of Energy.

This technical memo is a product of 'Argonne's Environmental Assessment Division (EAD). For information on the division's scientific and engineering activities, contact:

Director, Environmental Assessment Division

Argonne National Laboratory

Argonne, Illinois 60439-4815

Telephione (708) 252-3107

Presented in this technical memo are preliminary results of ongoing work or work that is more limited in scope and depth than that described in formal reports issued by the EAD.

Publishing support services were provided by Argònne's Information and Publishing Division (for more information, see IPD's home page: http://wwww.jpd.anl.gov/).

\section{Disclaimer}

$$
\text { i }
$$

This report was prepared as an account of work sponsored by an agency of the United States Government. Neither the United States Govemment nor any agency thereof, nor any of their employees, makes any warranty, express or implied, or assumes. any legal liability or responsibility for the accuracy, completeness, or usefulness of any information, apparatus, product, or process disclosed, or represents that its use would nót infringe privately owned rights. Reference herein to any specific commercial product, process, or service by trade name, trademark, manufacturer, or otherwise, does'not necessarily constitute or imply its endorsement, recommendation, or favoring by the United States Government or any agency thereof. The views and opinions of authors expressed herein do not necessarily state or reflect those of the United States Government or any agency thereof.

Reproduced directly from the best available copy.

Available to DOE and DOE contractors from the Office of Scientific and Technical Information, P.O. Box 62, Oak Ridge, TN 37831; prices available from (423) $576-8401$.

Available to the public from the National Technical Information Service, U.S. Department of Commerce, 5285 Port Royal Road, Springfield, VA 22161. 


\section{Background Chemistry for Chemical Warfare Agents and Decontamination Processes in Support of Delisting Waste Streams at the U.S. Army Dugway Proving Ground, Utah}

by D.H. Rosenblatt, ${ }^{*}$ M.J. Small, T.A. Kimmell, and A.W. Anderson

Environmental Assessment Division,

Argonne National Laboratory, 9700 South Cass Avenue, Argonne, Illinois 60439

April 1996

Work sponsored by U.S. Army Test and Evaluation Command, Environmental Quality Office

${ }^{\star}$ Rosenblatt is affiliated with Argonne's Energy Systems Division. 
This report is printed on recycled paper. 


\section{DISCLAIMER}

Portions of this document may be illegible in electronic image products. Images are produced from the best available original document. 


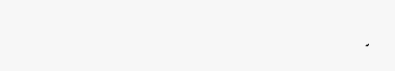




\section{CONTENTS}

FOREWORD $\ldots \ldots \ldots \ldots \ldots \ldots \ldots \ldots \ldots \ldots \ldots \ldots \ldots \ldots \ldots \ldots \ldots \ldots \ldots \ldots$ vii

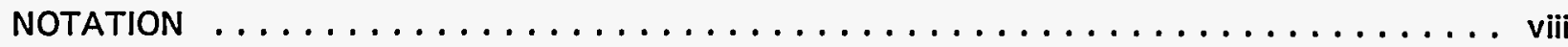

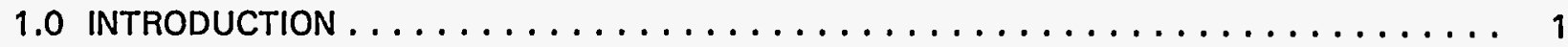

2.0 SCOPE AND CONCEPTS $\ldots \ldots \ldots \ldots \ldots \ldots \ldots \ldots \ldots \ldots \ldots \ldots \ldots \ldots \ldots \ldots \ldots$

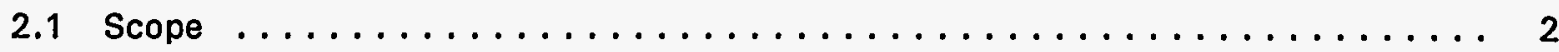

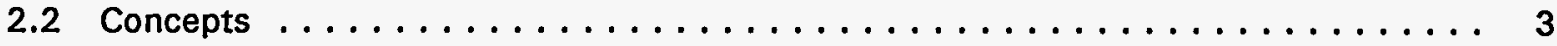

3.0 PHYSICOCHEMICAL PROPERTIES OF THE AGENTS OF CONCERN $\ldots \ldots \ldots \ldots \ldots$

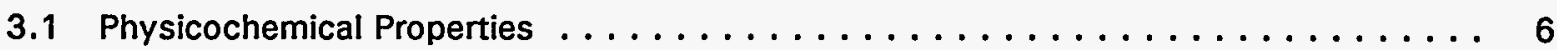

3.1 .1 Vapor Pressure . . . . . . . . . . . . . . . . . . . . 6

3.1.2 Log Octanol/Water Partition Coefficient ................. 6

3.1.3 Henry's Law Constant . . . . . . . . . . . . . . . . . . . . . . 7

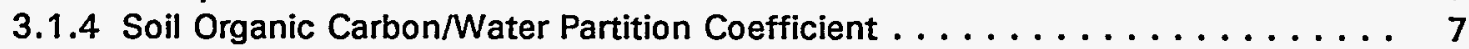

3.2 GB (Sarin or Isopropyl Methylphosphonofluoridate);

CAS Reg. No. 107-44-8 .......................... 8

3.3 GD (Soman or Pinacolyl Methylphosphonofluoridate);

CAS Reg. No. 96-64-0 . . . . . . . . . . . . . . . . . . . . . 11

3.4 VX 10-Ethyl S-[2-Diisopropylaminoethyl]

Methylphosphonothioate); CAS Reg. No. 50782-69-9 . . . . . . . . . . . . . 13

3.5 HD/H (Sulfur Mustard or Mustard Gas or Bis[2-Chloroethyl]

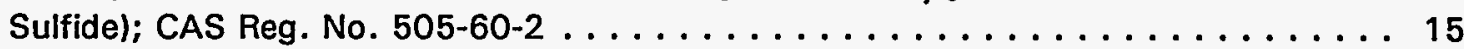

3.5.1 HD (Distilled Mustard or Distilled Sulfur Mustard) $\ldots \ldots \ldots \ldots \ldots \ldots \ldots 15$

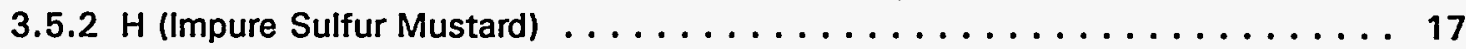

4.0 CONCEPTS OF CONTAMINATION AND REACTIVE DECONTAMINATION $\ldots \ldots \ldots \ldots$

4.1 Exposure of Materials to Vapor-State and Liquid Agents . . . . . . . . . 21

4.2 Interactions between Agents-on-Substrates and Decontaminant Solutions . . . . . 22

5.0 MAJOR REACTIVE SYSTEMS FOR DECONTAMINATION $\ldots \ldots \ldots \ldots \ldots \ldots \ldots$

5.1 Reactions with Aqueous or Aqueous-Alcoholic Alkaline Solutions . . . . . . . 22

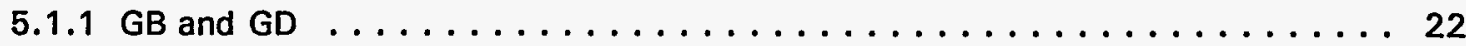

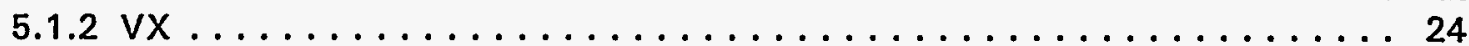

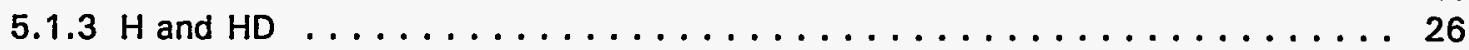

5.2 Reactions with Aqueous Hypochlorite Solutions . . . . . . . . . . . . . . . . 29

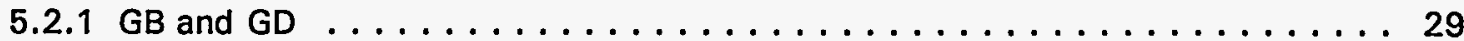

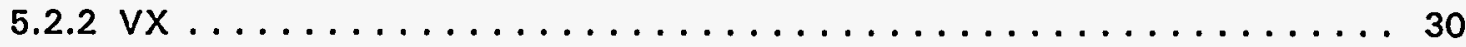

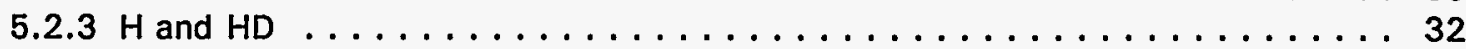

5.3 Significance of Residual Products $\ldots \ldots \ldots \ldots \ldots \ldots \ldots \ldots \ldots \ldots \ldots$

6.0 AlteRnATIVE LIQUID DECONTAMINATION SYSTEMS . . . . . . . . . . . . . 35

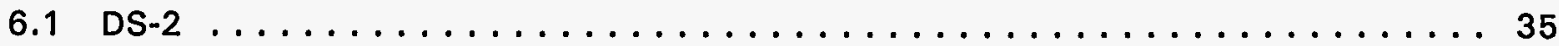


6.2 Oxidizing Systems $\ldots \ldots \ldots \ldots \ldots \ldots \ldots \ldots \ldots \ldots \ldots \ldots \ldots \ldots \ldots \ldots$

6.2.1 Alkaline Hydrogen Peroxide and Peroxy Acids . . . . . . . . . . 37

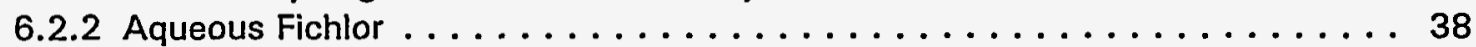

6.2 .3 Aqueous Chlorine Dioxide . . . . . . . . . . . . . . . 38

6.2.4 MCBD Microemulsion and German C8 Emulsion . . . . . . . . . . . 38

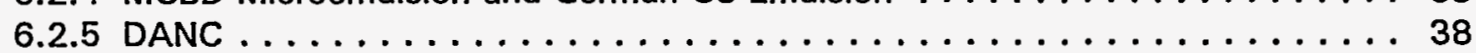

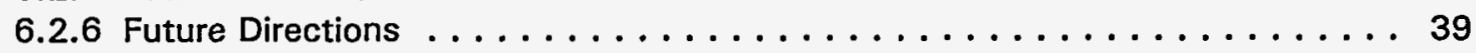

7.0 ADVANTAGES AND DISADVANTAGES OF THE VARIOUS SYSTEMS $\ldots \ldots \ldots \ldots \ldots$

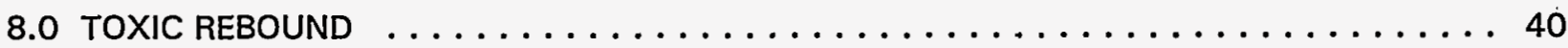

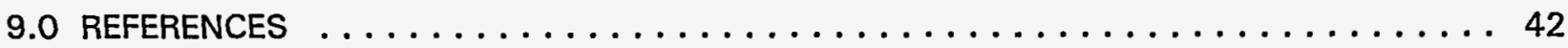

APPENDIX A: Environmental Fate of $G B, V X$, and $H D \ldots \ldots \ldots \ldots \ldots$

APPENDIX B: Absorption and Desorption of Chemical Agents on Polymeric Materials . . . . . . . . . . . . . . . 67

\section{TABLES}

1 Environmentally Relevant Properties of GB $\ldots \ldots \ldots \ldots \ldots \ldots \ldots \ldots \ldots$

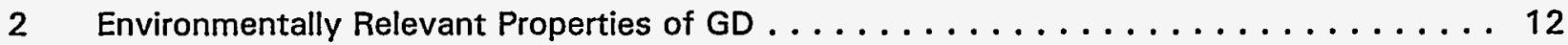

3 Environmentally Relevant Properties of $v x \ldots \ldots \ldots \ldots \ldots \ldots \ldots \ldots \ldots \ldots$

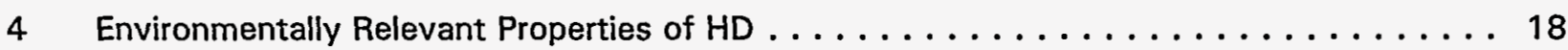

5 Composition of a World War I Sample of $\mathrm{H}$ from Spring Valley

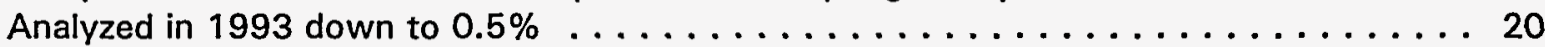

6 Composition of an Old Sample of $H$ Analyzed in $1993 \ldots \ldots \ldots \ldots \ldots$

7 Composition of a Sample of HD from a 1-Ton Container Analyzed in 1993 . . . . . . . 21

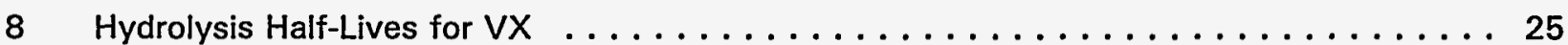

9 Organic Solutes in the Liquid Phase Present in Calcium Hydroxide Hydrolysates of $\mathrm{H}$ (Mustard Gas) . . . . . . . . . . . 28

10 Organic Solutes Identified in the Chloroform Extracts of the Calcium Hydroxide Sludge Hydrolysates of $\mathrm{H}$ (Mustard Gas) . . . . . . . . . . . . . 29

11 Possible Intermediates in the Chlorinolysis of $V x \ldots \ldots \ldots \ldots \ldots \ldots \ldots \ldots \ldots$ 


\section{TABLES (Cont.)}

A-1 Persistence Times Predicted for GB Droplets on Soil $\ldots \ldots \ldots \ldots \ldots \ldots \ldots$

A-2 Percent GB Remaining at Indicated Time after Application $\ldots \ldots \ldots \ldots \ldots \ldots$

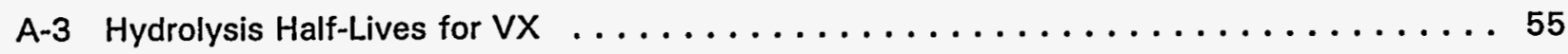

A-4 Persistence Times Predicted for HD Droplets on Soil $\ldots \ldots \ldots \ldots \ldots \ldots \ldots$

A-5 Factors in the Time-Averaged Flux Analysis $\ldots \ldots \ldots \ldots \ldots \ldots \ldots \ldots \ldots$

A-6 Contaminant-Specific Values and Derived 90-Day

Average Flux Rates for a Hypothetical Scenario . . . . . . . . . . . . . 62

B-1 Solubility Parameter Data for Chemical Agents, Solvents, and Polymeric Materials . . . . . . . . . . . . . . . . . . . . 68

B-2 Agent Permeation Estimated for 1-Hour Exposure to Saturated Vapor . . . . . . . 71 


\section{FOREWORD}

The U.S. Army intends to petition the State of Utah, in accordance with Rule R315 of the Utah Administrative Code and the federal Resource Conservation and Recovery Act, to delist certain F999 waste streams generated at the U.S. Army Dugway Proving Ground from Utah's list of hazardous wastes. From 1991 to 1992, the Army conducted a program to gather, evaluate, and document all pertinent agent waste stream and supporting information that existed within Army records systems. As a result of this action, a series of test plans was prepared describing the demonstration testing program to be performed. In June 1993, the Army met with the State of Utah, Division of Solid and Hazardous Waste, and presented its proposed approach to meeting the delisting requirements and filing a formal delisting petition. During this meeting, the State of Utah requested, among other things, that the Army provide a review of agent and agent decontamination chemistry.

This document is intended to fulfill that request. The objective is to provide a comprehensive review of the chemistry of chemical agents and decontamination processes for the agents $H / H D, G B$, GD, and VX. The document reviews the available literature and identifies relevant information on agent and decontaminant by-products, additives, and breakdown products. It also addresses the ability of agents to reform following decontamination (referred to as toxic rebound) and discusses the fate and transport of agents in the environment. Finally, the document discusses absorption and desorption from various types of materials.

As may be expected, the chemistry of agents and decontamination processes is technically complex. Despite this complexity, it is important that the document be understandable to the regulator and, to the extent possible, to the general public. It has therefore been written in layman's terms; it is intended for an audience with a knowledge of general chemistry at the high school level. The document begins with a quick review of basic chemistry as the foundation for the ensuing discussions. Summaries and explanations of the technical information are also provided throughout the document.

The final draft of this document, dated June 6, 1995, was provided to the State of Utah, Division of Solid and Hazardous Waste, for review and comment. In addition, on July 26-27, 1995, a conference was held at the state's offices in Salt Lake City, during which the basic tenets of the document were formally presented by the authors. No written comments on the final draft document were received from the state; moreover, although the state posed a number of questions during the formal presentation, no verbal comments were offered. The Army believes that this final document satisfies the State of Utah's request for information on agent and agent decontamination chemistry. 


\section{NOTATION}

a

Argonne

atm

C

C8

cal

CAS

CFR

CH-TG

d

D

$D_{0}$

DAM

DANC

DDP

DEOH

DEQ

(DES) 2

(DE) ${ }_{2} \mathrm{~S}$

DESH

DIMP

DIPC

DIPU

DPG

DS-2

DSHW

EA 2192

EA 4196

EMPA

EMPS

EPA

foc

F999

$\mathrm{g}$

GB

GC/MS

GD

GLC

constant for a given temperature and polymer-solvent system

Argonne National Laboratory

atmospheres pressure; $1 \mathrm{~atm}$ is equivalent to 760 torr

point concentration

German emulsion (see Section 6.2.4)

calorie

Chemical Abstracts Service

Code of Federal Regulations

$\mathrm{HO}-\mathrm{CH}_{2}-\mathrm{CH}_{2}-\mathrm{S}-\mathrm{CH}_{2}-\mathrm{CH}_{2}-\mathrm{S}^{+}\left(\mathrm{CH}_{2}-\mathrm{CH}_{2}-\mathrm{OH}\right)_{2}$, mustard

chlorohydrin-thiodiglycol complex

day, unit of time; or density in $\mathrm{g} / \mathrm{cm}^{3}$

diffusion coefficient for a specific concentration of permeant in a polymer zero-concentration diffusion coefficient

decontaminating agent, multipurpose

decontaminating agent, noncorrosive

diethyl dimethylpyrophosphonate

2-diisopropylaminoethanol

Department of Environmental Quality (State of Utah)

bis(2-diisopropylaminoethyl) disulfide

bis(2-diisopropylaminoethyl) sulfide

2-diisopropylaminoethanethiol

diisopropyl methylphosphonate

diisopropyl carbodiimide

$N, N^{\prime}$-diisopropylurea

U.S. Army Dugway Proving Ground

decontamination solution 2

Division of Solid and Hazardous Waste (State of Utah)

S-(2-diisopropylaminoethyl) methylphosphonothioic acid

see $(D E S)_{2}$

ethyl methylphosphonic acid

ethyl methylphosphonothioic acid

U.S. Environmental Protection Agency

fraction of organic carbon in a given soil

residues from demilitarization, treatment, and testing of nerve, military, and chemical agents

gram

agent sarin, isopropyl methylphosphonofluoridate

gas chromatography/mass spectrometry, an analytical methodology

agent soman, pinacolyl methylphosphonofluoridate

gas-liquid chromatography 
hour, unit of time

H crude sulfur mustard agent, bis(2-chloroethyl) sulfide

HD distilled sulfur mustard agent

HD-O mustard sulfoxide

$\mathrm{HD}-\mathrm{O}_{2}$ mustard sulfone

$\mathrm{HOCl}$ hypochlorous acid

H-TG Cl- $\mathrm{CH}_{2}-\mathrm{CH}_{2}-\mathrm{S}-\mathrm{CH}_{2}-\mathrm{CH}_{2}-\mathrm{S}^{+}\left(\mathrm{CH}_{2}-\mathrm{CH}_{2}-\mathrm{OH}\right)_{2}$, mustard-thiodiglycol complex

H-2TG $\quad \mathrm{S}\left[\mathrm{CH}_{2}-\mathrm{CH}_{2}-\mathrm{S}^{+}\left(\mathrm{CH}_{2}-\mathrm{CH}_{2}-\mathrm{OH}\right)_{2}\right]_{2}$, mustard- bis(thiodiglycol) complex

$\mathrm{HTH}$ high-test hypochlorite, $\mathrm{Ca}(\mathrm{OCl})_{2}$

IBX sodium 2-nitro-4-iodoxybenzoate

IMP anion of IMPA

IMPA isopropyl methylphosphonic acid

IRP

Installation Restoration Program

$k_{2}$ second order kinetic rate constant, in units of $M^{-1}$ (time) ${ }^{-1}$

$K_{\mathrm{a}} \quad$ acid dissociation constant

$\mathrm{K}_{\mathrm{H}} \quad$ Henry's Law constant, ratio of the concentration of a compound in the vapor state to its concentration in a solvent (here, water) in a system at equilibrium

$k_{\text {obs }} \quad$ observed first order kinetic rate constant, in units of (time) $)^{-1}$

$K_{\text {oc }}$

soil organic carbon/water partition coefficient, ratio of concentration of a compound in soil organic carbon to its concentration in water in a system at equilibrium

Kow

$\mathrm{K}_{\mathrm{w}} \quad$ ion product of water (about $10^{-14}$ at $25^{\circ} \mathrm{C}$ )

L liter; or thickness of a polymer parallel to the direction of diffusion

LDPE low-density polyethylene

log logarithm to base 10

$\mathrm{m} \quad$ meter, a fundamental unit of length

M molar, concentration of a substance in a given medium, expressed in moles per liter

$M^{-1} \quad$ liters per mole

MCBD multipurpose chemical, biological decontaminant (a microemulsion)

$\mathrm{mg}$

$\min$

milligram, one-thousandth of a gram

$\mathrm{mm}$ millimeter, one-thousandth of a meter

mol mole, number of molecules in one gram-molecular weight of a substance,

$6.022 \times 10^{23}$

$\mathrm{MPa} \quad$ millipascal

MPA methylphosphonic acid

MW gram molecular weight

NMR nuclear magnetic resonance (a spectrometric method of chemical analysis)

obs observed 


\begin{tabular}{|c|c|}
\hline $\mathbf{P}$ & vapor pressure \\
\hline $\mathrm{pH}$ & $\begin{array}{l}\text { negative logarithm of the hydrogen ion activity (or concentration) in a solution: } \\
\text { the higher the } \mathrm{pH} \text {, the less acidic (more basic) is the solution }\end{array}$ \\
\hline $\begin{array}{l}\mathrm{pK}_{\mathrm{a}} \\
\text { PMPA }\end{array}$ & $\begin{array}{l}\text { negative logarithm of } \mathrm{K}_{\mathrm{a}} \\
\text { pinacolyl methylphosphonic acid }\end{array}$ \\
\hline PVC & polyvinyl chloride \\
\hline QA/OC & Quality Assurance/Quality Control \\
\hline RCRA & Resource Conservation and Recovery Act \\
\hline s & second, unit of time \\
\hline S & solubility \\
\hline SBR & styrene-butadiene rubber \\
\hline SOC & soil organic content \\
\hline $\mathrm{t}$ & temperature, degrees Celsius; $t=T-273.16$ \\
\hline$T$ & temperature, degrees Kelvin; or ton \\
\hline $\begin{array}{l}\text { TECOM } \\
\text { torr } \\
\text { tsat }\end{array}$ & $\begin{array}{l}\text { U.S. Army Test and Evaluation Command } \\
\text { unit of pressure }=1 \mathrm{~mm} \text { of mercury } \\
\text { pseudosaturation time }\end{array}$ \\
\hline$t_{1 / 2}$ sat & $1 / 2$ tsat \\
\hline$v X$ & O-ethyl S-(2-diisopropylaminoethyl) methylphosphonothioate \\
\hline $\mathrm{x}$ & Flory interaction parameter \\
\hline$[\mathrm{X}]$ & concentration of chemical $X$ in a particular medium \\
\hline$\delta$ & solubility parameter for a liquid in a polymer \\
\hline$\mu \mathrm{g}$ & microgram, one-millionth of a gram \\
\hline
\end{tabular}




\title{
BACKGROUND CHEMISTRY FOR CHEMICAL WARFARE AGENTS AND DECONTAMINATION PROCESSES IN SUPPORT OF DELISTING WASTE STREAMS AT THE U.S. ARMY DUGWAY PROVING GROUND, UTAH
}

\author{
by \\ D.H. Rosenblatt, M.J. Small, T.A. Kimmell, and A.W. Anderson
}

\subsection{INTRODUCTION}

The State of Utah, Department of Environmental Quality (DEQ), Division of Solid and Hazardous Waste (DSHW), has declared residues resulting from the demilitarization, treatment, cleanup, and testing of military chemical agents to be hazardous wastes. These residues have been designated as corrosive, reactive, toxic, and acute hazardous (Hazardous Waste No. F999). These residues are listed as hazardous waste by the State of Utah and several other states, but they are not listed under the U.S. Environmental Protection Agency (EPA) regulations promulgated pursuant to the Resource Conservation and Recovery Act (RCRA), the primary law governing management of hazardous waste in the United States. The RCRA regulations (40 Code of Federal Regulations [CFR] 260-280), the Utah Administrative Code (R-315), and other state hazardous waste programs list specific wastes as hazardous but allow generators to petition, the regulator to "delist," if it can be demonstrated that such wastes are not hazardous. The U.S. Army Test and Evaluation Command (TECOM) believes that certain categories of F999 residues are not hazardous and has obtained assistance from Argonne National Laboratory (Argonne) to make the delisting demonstration.

The objective of this project is to delist chemical agent decontaminated residues resulting from materials testing activities and to delist a remediation residue (e.g., contaminated soil). To delist these residues, it must be demonstrated that the residues (1) do not contain hazardous quantities of the listed agents; (2) do not contain hazardous quantities of constituents listed in 40 CFR Part 261, Appendix VIII; (3) do not exhibit other characteristics that could define the residues as hazardous; and (4) do not fail a series of acute toxicity tests.

The TECOM Chemical Agent Decontaminated Residue and Remediation Waste Delisting Program (Delisting Program) will be implemented in phases so that subsequent efforts can benefit from the documentation and experience obtained in earlier phases. The first phase will focus on a subset of the F999 wastes generated at the U.S. Army Dugway Proving Ground (DPG), where the Army tests the effects of military chemical agents and agent-decontamination procedures on numerous military items. This effort is identified as Phase I of the Delisting Program. Subsequent phases will address other DPG chemical agent decontaminated residues and remediation wastes and similar residues at other installations.

The first major objective of Phase 1 is to conduct analytical method validation studies. The second major objective is to review and revise, as necessary, a series of test plans prepared previously to support the delisting effort and to develop a Quality Assurance/Quality Control (QA/QC) Plan. The test plans and QA/QC Plan will be implemented, and a Delisting Test Report will be prepared. These and other documents will form the basis of the Delisting Petition.

The Phase l effort will target two residues generated at DPG for delisting, including a decontaminated substrate residue and the decontamination fluid used to decontaminate that substrate. In addition, an agentcontaminated remediation waste (e.g., contaminated soil) will be addressed. These wastes will contain one 
or more of the chemical agents $H / H D, G B, G D$, and VX. The Phase I effort is expected to last approximately 3.5 years, including the postpetition submittal period.

Analytical laboratories at DPG will be used to conduct agent and related analyses. Once samples have passed screening analyses for the absence of agents, they will be sent off-site to a commercial laboratory for RCRA testing. The analytical laboratory at DPG will only be able to support the Delisting Program during the winter months because the laboratory is expected to be busy performing analyses to support DPG's Installation Restoration Program (IRP) during the rest of the year. Hence, analytical method validation will be performed during the 1995-1996 winter period, and the delisting demonstration will be performed during the 1996-1997 winter period.

The objective of this document is to provide a comprehensive review of chemical agent chemistry and the chemistry of decontamination processes for the agents $H / H D, G B, G D$, and VX. It presents a review of the available literature and identifies relevant information on agent and decontaminant by-products, additives, and breakdown products. The document also addresses the ability of agents to reform following decontamination (referred to as toxic rebound) and discusses the fate and transport of agents in the environment. Finally, it discusses absorption and desorption of agents from various types of materials.

\subsection{SCOPE AND CONCEPTS}

\subsection{Scope}

This review considers chemical interactions between certain liquid decontamination systems and a selected group of chemical agents. The agents of interest are GB (sarin), GD (soman), VX, H (sulfur mustard), and HD (distilled sulfur mustard). These agents are tested at DPG to determine the interaction of chemical agents and decontaminants with military equipment and the efficacy of decontaminants for decontamination of contaminated materials.

In a typical experiment or test arrangement, a given amount of an agent would be applied to the surface of an engineered material (e.g., stainless steel or rubber). Then the surface would be contacted with a chosen liquid decontaminant under prescribed conditions for a specified time. At the end of that time, the decontaminating solution and the engineered material would be subjected to chemical and other analyses.

In addition to waste streams that result from the controlled decontamination of military equipment, DPG soil may have been contaminated through past operations or exercises with $G B, V X$, and $H / H D$ (but historically not with GD) and through disposal of decontaminated materials. The contaminants in soils, assuming they were . present initially, are expected to have undergone weathering, so they are no longer in the same chemical state as they were originally. It is therefore necessary to review what is known or believed regarding the environmental fate of $G B, V X$, and $H / H D$, as well as of other hazardous substances that might be present. This topic is reviewed separately in Appendix $A$ of this document.

The interaction between polymeric substrate materials and the agents (the kinetics and equilibria of absorption and desorption) is discussed in Appendix B. 


\subsection{Concepts}

This subsection discusses certain basic chemistry concepts to help the reader better understand the report.

Atoms, Molecules, and lons. The simplest form of matter that the chemist deals with is the atom; the atom consists of a positively charged nucleus surrounded by negatively charged electrons. The nucleus, with virtually all the atom's mass, can contain within it a large number of units of positive charge, whereas each electron carries a single unit of negative charge. When atoms or groups of atoms have equal amounts of positive and negative charges, they are said to be "neutral." If there are more negative than positive charges, the (atom or) group of atoms is called an anion; if there are more positive charges, it is a cation. An element may exist as isolated atoms, for example, helium. Most elements, however, tend to combine in simple or complex ways with other atoms. Oxygen is illustrative; it is mainly present in the air, or dissolved in water, as a molecule consisting of two atoms, $\mathrm{O}_{2}$. A small fraction of the world's elemental oxygen exists in groups of three oxygen atoms, $\mathrm{O}_{3}$, known as ozone; this "trimer" of oxygen has properties much different from those of the more commonplace "dimer," $\mathrm{O}_{2}$. An example of an anion is the hydroxide ion, the symbol for which is $\mathrm{OH}^{-}$; the minus sign denotes the negative charge. The sodium ion, $\mathrm{Na}^{+}$, is positively charged, and thus a cation. Sodium hydroxide, $\mathrm{NaOH}$, contains an equal number of anions and cations.

Structure of Molecules. Neutral molecules, generally speaking, are held together by "covalent" bonds; these are usually "single" bonds, but can be "double" or "triple" bonds, or other types. An example of the single bond is that in a chlorine molecule, $\mathrm{Cl}_{2}$, or $\mathrm{Cl}-\mathrm{Cl}$ (where the dash stands for a pair of electrons that constitute the covalent bond and that are shared between the two chlorine atoms). Carbon dioxide, $\mathrm{O}=\mathrm{C}=\mathrm{O}$, has two double bonds. Organic compounds (compounds containing at least one carbon atom) can consist of a few or a great number of atoms linked mainly by covalent bonds.

Phases. The idea of phases is best expressed by example. If one tries to mix sand and water, the sand soon settles out as a solid phase, and the water becomes clear again as a liquid phase. If one attempts to dissolve oil in water, these separate into two liquid phases (though less rapidly if an emulsifying agent is added, as is often done with a salad dressing). A gaseous phase may be caused to dissolve in a liquid phase, as with a carbonated beverage, only to escape when the bottle is opened and the pressure reduced. One may dissolve sugar in hot tea; here two phases interact to become a single phase. The capacity of a substance to be accepted (dissolved) by a particular phase under a specified set of conditions, such as temperature and pressure, is referred to as the solubility of the substance in that phase under those conditions. When as much of the dissolved material (solute) is dissolved as the solvent can hold under the conditions, the solution is said to be "saturated."

Molecules and lons in Solution. When a substance is dissolved in a solvent, its structure may be affected by the presence of the solvent. (The solvent is also affected by the dissolved substance - the solute.) One example is the tendency of a substance to dissociate. For example, when water is added to ethyl alcohol the concentration of ethoxide ions increases. This is simplistically expressed by the following:

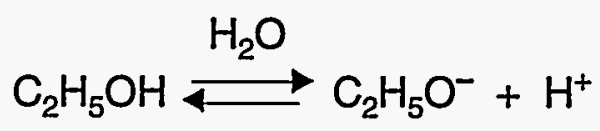

Concentration in Solution. The concentration of a substance, in units of moles per liter, $M$, is expressed by enclosing the identifying symbol in square brackets (e.g., [GB]). 
pH of Aqueous (Water) Solutions. Neutral water $\left(\mathrm{pH} 7\right.$ at $25^{\circ} \mathrm{C}$ ) has equal concentrations (denoted with square brackets) of hydroxide ions $\left(\mathrm{OH}^{-}\right)$and protons $\left(\mathrm{H}^{+}\right)$, namely, $\left[\mathrm{OH}^{-}\right]=\left[\mathrm{H}^{+}\right]=10^{-7} \mathrm{M}$. M stands for molar or moles per liter. If a solution is alkaline (basic), $\left[\mathrm{OH}^{-}\right]$exceeds $10^{-7}$, with $\left[\mathrm{H}^{+}\right]$being correspondingly lower (and vice versa for an acidic solution), such that the ion product, $\mathrm{K}_{\mathrm{W}}=\left[\mathrm{OH}^{-}\right] \times\left[\mathrm{H}^{+}\right]$, is always $10^{-14} \mathrm{M}^{2}$. In simple terms, one defines $\mathrm{pH}$ as $\left(-\log \left[\mathrm{H}^{+}\right]\right)$; the $\mathrm{pH}$ of a neutral solution would be 7 . Any solution with a pH above 7 is alkaline; that with a pH below 7 is acidic. Because $\mathrm{pH}$ is on a logarithmic scale, a drop of one unit in pH indicates a 10-fold increase in acidity (hydrogen ion activity). The pH is often an important determinant of chemical reactivity in aqueous solutions.

$\mathrm{pK}_{2}$ of an Acidic Solute. If a solute, generically symbolized by $\mathrm{HA}$, dissociates in water to furnish protons, i.e., $\mathrm{HA} \rightleftarrows \mathrm{H}^{+}+\mathrm{A}^{-}$, we may express the degree to which this takes place as $\mathrm{K}_{\mathrm{a}}=\left[\mathrm{H}^{+}\right]\left[\mathrm{A}^{-}\right] /[\mathrm{HA}]$. The greater the magnitude of $K_{a}$, the more acidic $H A$ is said to be. The related term, $p K_{a}=-\log K_{a}$, is the way in which the property is usually expressed. The smaller $\mathrm{pK}_{a}$, the more acidic is HA. The $\mathrm{pH}$ at which $[\mathrm{HA}]=\left[\mathrm{A}^{-}\right]$is approximately equivalent to the $\mathrm{pK}_{\mathrm{a}}$.

Chemical Reactions, Mechanisms. Chemical reactions typically involve the breaking and making of chemical bonds, or the loss or gain of electrons. The step or steps that occur in such a process are known, collectively, as a reaction mechanism. Frequently, the parts of a molecule that do not change during the course of a reaction are represented generically in chemical shorthand by a symbol such as $R$. Thus the hydrolysis (cleavage by water) of chloromethane $\left(\mathrm{CH}_{3} \mathrm{Cl}\right)$, chloroethane $\left(\mathrm{C}_{2} \mathrm{H}_{5} \mathrm{Cl}\right)$, or other chlorinated hydrocarbons could be represented generically by the following:

$$
\mathrm{R}-\mathrm{Cl}+\mathrm{H}_{2} \mathrm{O} \rightarrow \mathrm{R}-\mathrm{OH}+\mathrm{HCl}
$$

Here, a bond between a carbon in the group " $R$ " and a chlorine atom was broken, and a bond between that carbon and part of a water molecule (i.e., $\mathrm{OH}$ ) was formed. Hydrolysis reactions take many forms. They are frequently catalyzed (accelerated) by acid (such as $\mathrm{H}^{+}$) or base (such as $\mathrm{OH}$ ), but the range of possible catalysts is quite broad and includes such entities as soil minerals and enzymes.

Oxidation-reduction (redox) reactions are characterized by the loss and gain of electrons or of electron-rich atoms like oxygen or chlorine. As an example of electron transfer, the reaction between iron ( $\mathrm{Fe}$ ) and chlorine $\left(\mathrm{Cl}_{2}\right)$ to produce ferrous chloride requires the transfer of two electrons from the iron to a chlorine molecule:

$$
\mathrm{Fe}+\mathrm{Cl}_{2} \rightarrow \mathrm{Fe}^{++}+2 \mathrm{Cl}^{-}
$$

The superscript + or - signs denote units of nuclear or electronic charge. The reaction of ozone $\left(\mathrm{O}_{3}\right)$ with sulfur dioxide exemplifies the transfer of an oxygen; the sulfur dioxide is oxidized to sulfur trioxide, and the ozone is reduced to $\mathrm{O}_{2}$ ("dioxygen"):

$$
\mathrm{SO}_{2}+\mathrm{O}_{3} \rightarrow \mathrm{SO}_{3}+\mathrm{O}_{2}
$$

The reaction of sulfur dioxide with chlorine to form sulfuryl chloride is also considered an oxidation, with chlorine being the oxidant:

$$
\mathrm{SO}_{2}+\mathrm{Cl}_{2} \rightarrow \mathrm{SO}_{2} \mathrm{Cl}_{2}
$$


Reagents. A reagent is a substance introduced into a system to react with other substances. Conventionally, all reagents are "reactants," but the reverse is not necessarily true.

Nucleophiles and Electrophiles. The term "nucleophile" refers to a class of reagents that have a special affinity for centers of positive charge other than $\mathrm{H}^{+}$(such as the phosphorus atoms in the nerve agents); hypochlorite ion $\left(\mathrm{ClO}^{-}\right)$and hydroperoxide ion $\left(\mathrm{HOO}^{-}\right)$are nucleophiles. At the opposite extreme, many oxidizing agents, such as $\mathrm{Cl}_{2}$, are called "electrophiles" because they seek out accessible electrons.

Kinetics. This term encompasses various factors influencing the speed with which chemical reactions take place. In some reactions, all the molecules or ions that can find each other react almost as soon as the reacting materials are mixed; in other cases, reactions proceed at an extremely slow pace, with few encounters producing a chemical change. For a chemical reaction to occur, the reactants have to be sufficiently close to each other, be in the correct orientation towards each other, and possess sufficient energy to overcome forces of repulsion that might keep them from reacting. Allowing for exceptions, one may say that (1) the higher the concentration of each reactive species, the higher the reaction rate, and (2) the higher the temperature, the faster the reaction (because the reactants possess more kinetic energy).

Half-Life of a Reaction. As a reaction proceeds, the starting materials (reactants) get used up. If one reactant is originally in excess, its concentration ratio increases with time. Eventually, only the reactant that was in excess remains. A large excess of one reactant may be used intentionally, even at the beginning of the process. Often, when some of the reagents are in large excess, the time interval for any given concentration of the reactant not in excess to fall to half that concentration is constant. For example, the initial concentration of the low-concentration reactant is $800 \mathrm{mg} / \mathrm{L}$ (milligrams per liter) and decreases in $10 \mathrm{~min}$ to $400 \mathrm{mg} / \mathrm{L}$. In the next $10 \mathrm{~min}$ it falls to $200 \mathrm{mg} / \mathrm{L}$. The "half-life" of the reaction in this example is $10 \mathrm{~min}$. If such a reaction is allowed to proceed for seven half-lives, the low-concentration (or "limiting") reactant will have been diminished to less than $1 \%$ of its original concentration within $70 \mathrm{~min}$ in the present example. Study of the reaction kinetics may make it possible to select conditions under which the concentration of the reactant of concern may be decreased to a desired level in a given length of time.

Multistep Reactions. Often, one deals with a sequence of reactions rather than with a single reaction. One such type of sequence is conceptually visualized as:

(1) $A+B \rightarrow C$ and possibly other products

(2) $A+C \rightarrow D$ and possibly other products

(3) $A+D \rightarrow E$ and possibly other products

And so forth

If the amount of compound $A$ is much larger than that of compound $B$ and step (1) is rapid compared to step (2), compound $C$ can accumulate before being eventually consumed. If the initial quantity of compound $A$ is equal to that of compound $B$ and step (2) is very fast compared to step (1), then only half of compound $B$ will be consumed and compound $\mathrm{C}$ will not accumulate. Such examples illustrate the complexity and variety of phenomena associated with multistep reactions. Moreover, the same reagents may produce two or more sets of products (in competing reactions). 
Role of Chemical Analysis. To deduce the mechanisms and determine the kinetic factors used to predict the kinds and amounts of reaction products for chosen conditions, the chemist must analyze the compositions of experimental reaction mixtures at intervals during the course of reaction. Sometimes this can be done with essentially noninvasive techniques such as spectrophotometry, nuclear magnetic resonance (NMR) spectrometry, or the measurement of $\mathrm{pH}$. At other times, it may be necessary to stop ("quench") the reaction by chilling or neutralizing a sample of the reaction mixture before conducting complex manipulations, such as chromatography. The choice of sensitive analytical tools has increased dramatically over the past 50 years, but some of the most valuable analytical information about the reactions of chemical agents is about half a century old.

Decontamination. Decontamination refers to the effective removal of a contaminant, such as a chemical agent, from a given medium. Decontamination may consist primarily of physical removal, involving transfer of the contaminant to another medium without altering its chemical identity. In this review, however, attention is paid to the chemical reactions that convert the organic contaminants of interest to compounds of quite different identities and properties and, in some cases, to inorganic end products.

Solubility. Solubility is an important determinant of the feasibility of conducting chemical decontamination under a given set of conditions. Chemical reactions occur most readily when the reactants are dissolved in the same phase. If a chemical agent is not rapidly dissolved in a liquid decontaminant, the reaction is confined to the interface between phases and is usually a rather slow process. Low solubility tends to be a particular problem for decontaminating sulfur mustard (H/HD) with aqueous decontaminants.

\subsection{PHYSICOCHEMICAL PROPERTIES OF THE AIGENTS OF CONCERN}

Selected properties of the agents addressed in this document are recorded in Tables 1-4, and other information is presented and discussed in the text.

\subsection{Physicochemical Properties}

\subsubsection{Vapor Pressure (P)}

Vapor pressure is the pressure at which a liquid (or solid) and its vapor, at a given temperature, are in equilibrium. The vapor pressure of a compound is commonly given for the state - solid or liquid - in which the substance is likely to occur under ambient conditions, typically $25^{\circ} \mathrm{C}$. If vapor pressures have been determined for a range of temperatures, the data may be presented as the constants of Antoine equations, $\log P=A-B /(C+t)$, where the temperature, $t$, is in degrees Celsius $\left({ }^{\circ} \mathrm{C}\right)$. (Note that the equation is equivalent to a Clausius-Clapeyron equation when $C=273.16$.) Units for the value $P$ are in torr ( $\mathrm{mm}$ of mercury). $A$ high vapor pressure indicates that a substance can easily evaporate if exposed to the atmoshere.

\subsubsection{Log Octanol/Water Partition Coefficient $\left(\mathrm{K}_{\mathrm{ow}}\right)$}

The octanol/water partition coefficient, $\mathrm{K}_{\mathrm{ow}}$, is the ratio between the concentration of the compound of interest in the octanol phase to its concentration in the aqueous phase when the two phases are in equilibrium. This 
parameter is commonly expressed as its logarithm, $\log \mathrm{K}_{\mathrm{ow}}$. Though $\mathrm{K}_{\mathrm{ow}}$ is an indicator of relative lipophilicity (affinity towards fats), it is primarily used as a starting point to estimate such properties as bioconcentration factors, aqueous solubilities, and coefficients of adsorption to soil and sediment. Experimental values for numerous compounds have been reported for $\log \mathrm{K}_{\mathrm{ow}}$, and these should be used if they are available and reliable. Otherwise, values are calculated from fragment constants and structural factors, or from other solvent-water partition coefficients through linear regression equations (Lyman et al. 1990). High values of $K_{o w}$ (or $\log \mathrm{K}_{\mathrm{ow}}$ ) indicate that a substance will tend to concentrate in soil organic matter or in fatty tissue rather than in water.

\subsubsection{Henry's Law Constant $\left(\mathbf{K}_{\mathbf{H}}\right)$}

The Henry's Law constant, here applied to the aqueous solutions in contact with air, is a measure of the ratio of the concentration of a compound in the gaseous state to its concentration (as a nonionic species) in solution. $K_{H}$ is commonly estimated as a ratio of vapor pressure at a particular temperature to the saturation solubility at the same temperature. For most of the data presented below, the following equation was used to calculate $K_{H}$ from the vapor pressure $P$ (torr or mm of mercury) of the pure solute, gram molecular weight (MW), and solubility $S(\mathrm{mg} / \mathrm{L})$ of the solute in the solvent:

\section{$\mathrm{K}_{\mathrm{H}}\left(\mathrm{atm} \cdot \mathrm{m}^{3} / \mathrm{mol}\right)=(\mathrm{P} \times \mathrm{MW}) /(\mathrm{S} \times 760)$}

Because environmental concerns are usually related to exposures to low concentrations of potentially toxic materials, namely to the Henry's Law constant at infinite dilution, this kind of estimation is most valid for compounds of low solubility. It cannot be used at all for substances miscible in all proportions (such as GB, in which case the ratio of a measured pair of concentration values at equilibrium was used for the calculation).

The higher the value of $\mathrm{K}_{\mathrm{H}}$, the more an organic solute will tend to volatilize from an aqueous solution.

If $K_{H}$ is expressed in torr $M^{-1}$, it may be converted to (atm $\cdot \mathrm{m}^{3} / \mathrm{mol}$ ) through division by 760,$000 ;$ also, if $\mathrm{K}_{H}$ is expressed in the latter units, multiplication by the constant $40.88 \mathrm{~mol} /\left(\mathrm{m}^{3} \cdot \mathrm{atm}\right)$ converts it to the dimensionless form for $25^{\circ} \mathrm{C}$.

\subsubsection{Soil Organic Carbon/Water Partition Coefficient $\left(K_{o c}\right)$}

The soil organic carbon/water partition coefficient, $\mathrm{K}_{\mathrm{oc}}$, is defined as $\mu \mathrm{g}$ adsorbed chemical per $\mathrm{g}$ organic carbon) $/\left(\mu \mathrm{g}\right.$ chemical per $\mathrm{mL}$ of solution). Estimating the actual partition coefficient, $K_{d}$, of a chemical between soil and water from this value is based on the assumption that the soil's organic content is the only determinant of the sorption of a compound from water to soil. Thus, $K_{d}=f_{o c} \times K_{o c}$, where $f_{o c}$ is the fraction of organic carbon in the soil. The organic matter content, as opposed to organic carbon content, may be converted to $f_{o c}$ by multiplying it by 0.58 . Log $K_{o c}$ was calculated from $\log K_{o w}$ by the following equation (Lyman and Loreti 1987):

$$
\log K_{o c}=0.824 \log K_{o w}+0.328
$$


The greater the value of $\log K_{o c}$, the greater the tendency of a substance will be to stick to the organic matter in soil and not to migrate with the groundwater or to vaporize into the air.

\subsection{GB (Sarin or Isopropyl Methylphosphonofluoridate); CAS Reg. No. 107-44-8}

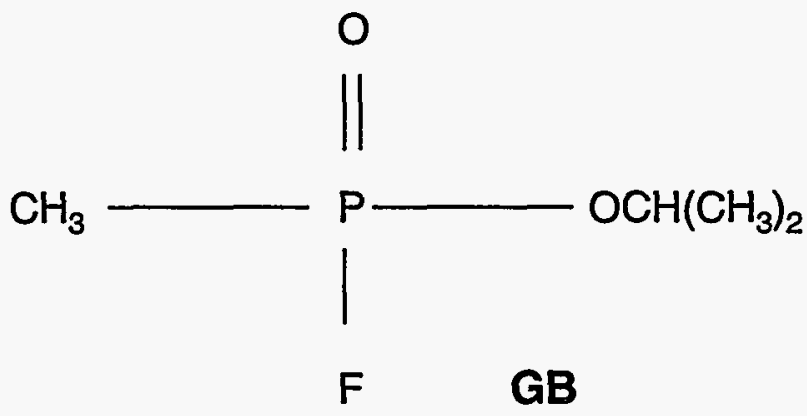

$\mathrm{GB}$, or sarin, is a relatively nonpersistent nerve agent. For instance, at $25^{\circ} \mathrm{C}$ and a loading of $3.33 \mathrm{mg} / \mathrm{cm}^{2}$, it persisted on concrete for only $2 \mathrm{~h}$ (Cooper 1990). Experiments showed $99 \%$ disappearance of GB from pulverized or intact concrete in $30 \mathrm{~min}$ or less (Carpenter and Hill 1988). It evaporates at about the same rate as water (Headquarters, Departments of the Army, Navy, and Air Force 1990). Its hydrolytic half-life is longest in the $\mathrm{pH}$ range of 4 to 6 , about $160 \mathrm{~h}$ at $\mathrm{pH} 5$ and $25^{\circ} \mathrm{C}$, and decreases outside that range in either more alkaline or more acidic solutions (Clark 1989). The second order rate constant for hydroxyl ion-catalyzed hydrolysis is:

$$
\log k_{2}\left(M^{-1} \min ^{-1}\right)=9.8507-(1,985.4 / T[K])
$$

where

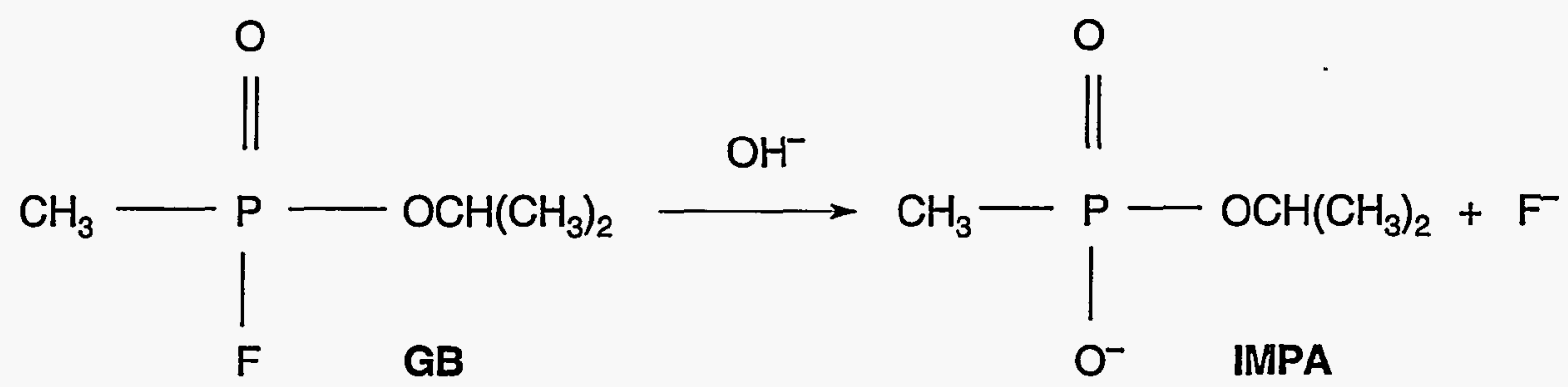

This gives a value of $1,543 \mathrm{M}^{-1} \mathrm{~min}^{-1}$ at $25^{\circ} \mathrm{C}$. Hence, the estimated pseudo-first order rate constant at $\mathrm{pH} 10$ is $0.1543 \mathrm{~min}^{-1}$, and the half-life at that $\mathrm{pH}$ is $5 \mathrm{~min}$. Hydrolysis of GB produces two far less toxic products, hydrofluoric acid and isopropyl methylphosphonic acid (IMPA). In the presence of a base such as hydroxyl ion, these acids are deprotonated to the corresponding anions. When large amounts of $G B$ are added to distilled 
water, the observed hydrolysis rate constant first decreases but increases once the $\mathrm{pH}$ has dropped through the minimum reaction rate range and acid catalysis begins to take effect.

In addition to the environmentally relevant data in Table 1, the following temperature relationships were reported for GB:

Vapor pressure, $\log \mathrm{P}$ (torr) $=7.48160-1,773.82 /\left(227.9+\mathrm{t}\left[{ }^{\circ} \mathrm{C}\right]\right) \quad$ (Samuel et al. 1983)

Density, $d=1.1182-\left(0.00118 \mathrm{t}\left[{ }^{\circ} \mathrm{C}\right]\right)$

(Samuel et al. 1983)

To summarize, GB is rather volatile, infinitely soluble in water, and subject to both acid- and base-catalyzed hydrolysis.

Because of the sensitivity of GB to hydrolysis and to acid-catalyzed decomposition, $N, N$-diisopropylcarbodiimide and/or tributylamine have been added as stabilizers for weapons-grade GB. The requirement for N,N'-diisopropylcarbodiimide in $1.50 \%$ excess was spelled out in specification documents (Edgewood Arsenal 1968; U.S. Army 1969); according to these documents, the GB had to be at least $93 \%$ pure, and up to $0.5 \%$ methylphosphonic difluoride would be an acceptable component. Tributylamine is referred to by Epstein et al. (1977) and in specifications (U.S. Army 1969). GB may also contain some diisopropyl methylphosphonate (DIMP) as an impurity. $N, N^{\prime}$-Diisopropylurea is a hydrolysis product of $N, N$ !diisopropyl carbodiimide.

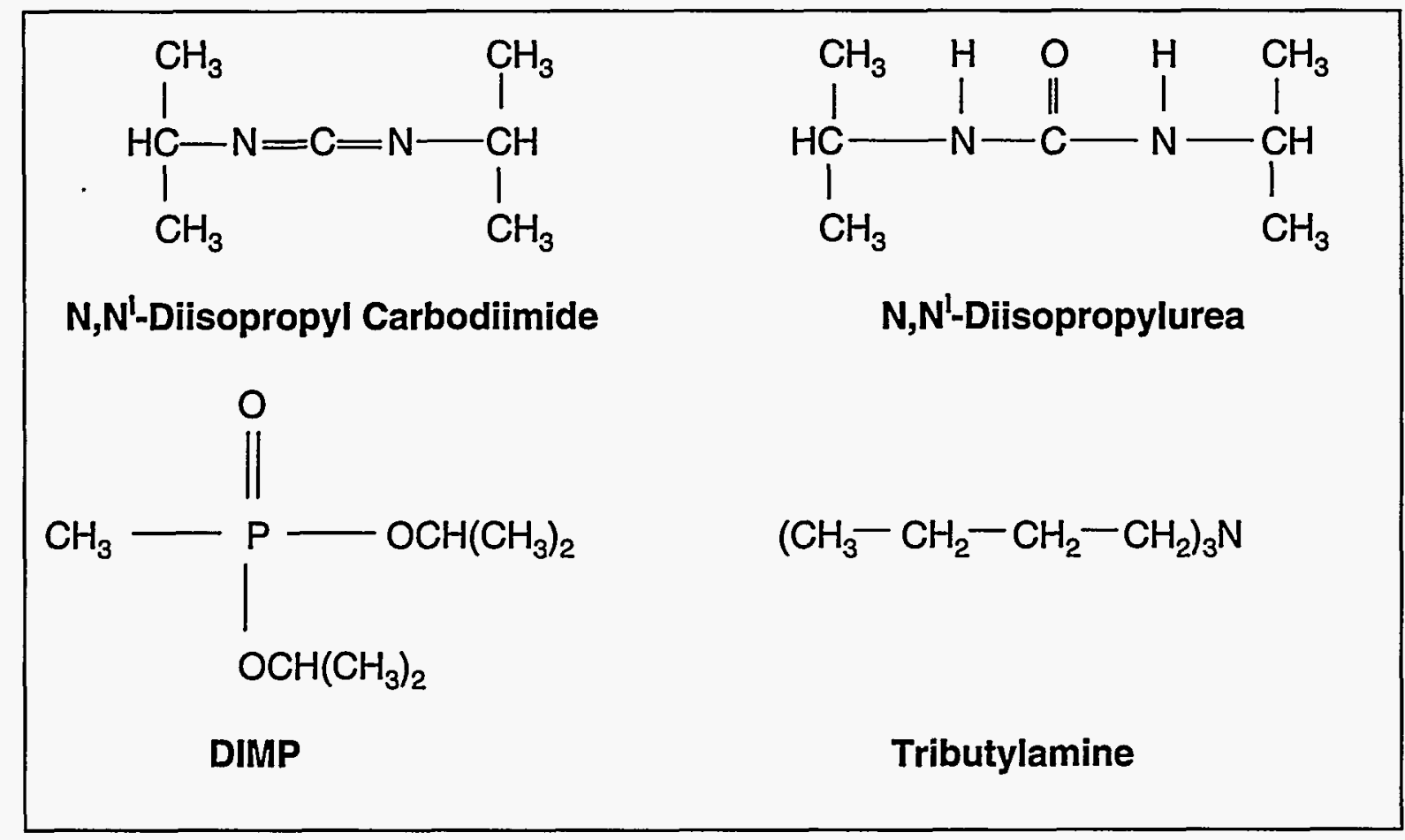




\section{Table 1. Environmentally Relevant Properties of GB}

\begin{tabular}{|c|c|c|c|}
\hline Property & Data & $\begin{array}{l}\text { Data } \\
\text { Quality }\end{array}$ & Reference \\
\hline Empirical Formula & $\mathrm{C}_{4} \mathrm{H}_{10} \mathrm{FO}_{2} \mathrm{P}$ & Not Applicable & \\
\hline $\begin{array}{l}\text { Molecular Weight } \\
\text { (MW) (g/mol) }\end{array}$ & 140.1 & Not Applicable & \\
\hline Density ( $\mathrm{g} / \mathrm{mL})$ & $1.0887 / 25^{\circ} \mathrm{C}$ & Good & Samuel et al. (1983) \\
\hline Melting Point $\left({ }^{\circ} \mathrm{C}\right)$ & -56.9 & Fair & Samuel et al. (1983) \\
\hline Boiling Point $\left({ }^{\circ} \mathrm{C}\right)$ & 157.8 & Good & Samuel et al. (1983) \\
\hline $\begin{array}{l}\text { Heat of Vaporiza- } \\
\text { tion (cal/g) }\end{array}$ & 80.66 & Good & Samuel et al. (1983) \\
\hline $\begin{array}{l}\text { Vapor Pressure at } \\
25^{\circ} \mathrm{C} \text { (torr). }\end{array}$ & 2.94 & Good & Samuel et al. (1983) \\
\hline Log $K_{\text {ow }}$ & $0.15^{\mathrm{a}}$ & Poor & Britton and Grant (1988) \\
\hline Aqueous Solubility (g/L) & $\begin{array}{l}\text { Miscible in all } \\
\text { proportions }\end{array}$ & Good & $\begin{array}{l}\text { Headquarters, Departments } \\
\text { of the Army, Navy, and Air } \\
\text { Force (1990) }\end{array}$ \\
\hline $\mathrm{K}_{\mathrm{H}}\left(\mathrm{atm} \cdot \mathrm{m}^{3} / \mathrm{mol}\right)$ & $4.0 \times 10^{-7} / 25^{\circ} \mathrm{C}$ & Poor & $\begin{array}{l}\text { Prestop and Starrock } \\
(1993)\end{array}$ \\
\hline $\begin{array}{l}\text { Diffusion Coefficient } \\
\text { (air) }\left(\mathrm{cm}^{2} / \mathrm{s}\right)\end{array}$ & $0.061 / 25^{\circ} \mathrm{C}$ & Fair & Samuel et al. (1983) \\
\hline $\log K_{o c}$ & 0.45 & Poor & c \\
\hline
\end{tabular}

a The authors of the present report estimated $\log K_{\text {ow }}$ by regression equations (see Section 3.1.2) involving distribution coefficients for four solvents (Rosenthal et al. 1956), with $\log K_{\text {ow }}$ values ranging from 0.12 to 1.30 and a mean of 0.74 .

b Based on an estimated vapor pressure of $0.136 \mathrm{kPa}$ for 0.1 mole fraction (about $3.34 \mathrm{M}$ ) of GB in water, $K_{H}=0.00134 \mathrm{~atm} /\left(3,340 \mathrm{~mol} / \mathrm{m}^{3}\right)$ from Fig. 2 .

c Authors' estimate (see Section 3.1.4). Small (1984) estimated 1.8. 


\subsection{GD (Soman or Pinacolyl Methylphosphonofluoridate); CAS Reg. No. 96-64-0}

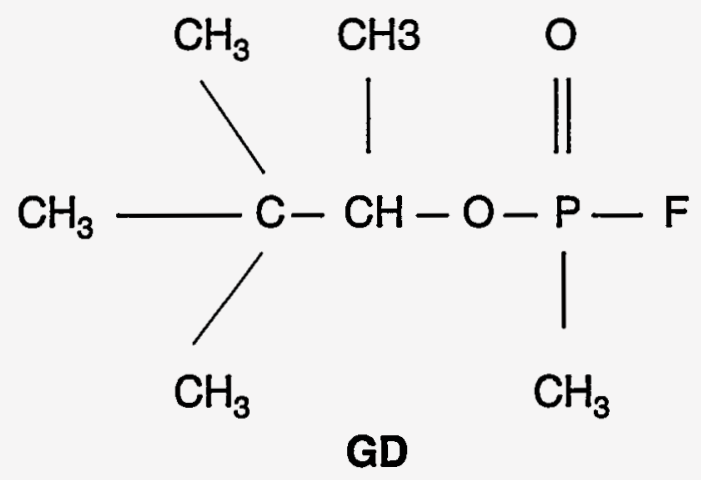

$\mathrm{GD}$, or soman, was designed as a somewhat more persistent nerve agent than GB. It evaporates at about onefourth the rate of water. Its hydrolytic half-life is longest in the $\mathrm{pH}$ range of 4 to 7 , about $144 \mathrm{~h}$ at $\mathrm{pH} 5$ and $20^{\circ} \mathrm{C}$, and increases outside that range in either more alkaline or more acidic solutions (Clark 1989). The observed hydrolysis rate constant at $25^{\circ} \mathrm{C}$, exclusive of buffer effects (Healy 1948), is $\mathrm{k}_{\text {obs }}\left(\mathrm{h}^{-1}\right)=0.0047+$ $33\left[\mathrm{H}_{3} \mathrm{O}^{+}\right]+5 \times 10^{4}\left[\mathrm{OH}^{-}\right]$. Hydrolysis of $\mathrm{GD}$ produces two far less toxic acids as products, hydrofluoric and pinacolyl methylphosphonic acids. In the presence of a base such as hydroxyl ion, these acids are deprotonated to the corresponding anions. When large amounts of GD are added to distilled water, the observed hydrolysis rate constant first decreases but increases once the $\mathrm{pH}$ has dropped through the minimum reaction rate range and acid catalysis begins to take effect.

In addition to the environmentally relevant data in Table 2, the following temperature relationships were reported for GD:

$$
\begin{array}{ll}
\text { Vapor pressure, } \log P(\text { torr })=7.47060-1,903.10 /\left(216.9+t\left[{ }^{\circ} \mathrm{C}\right]\right) & \text { (Samuel et al. 1983) } \\
\text { Density, } d=1.0456-\left(0.00093 \mathrm{t}\left[{ }^{\circ} \mathrm{C}\right]\right) & \text { (Samuel et al. 1983) }
\end{array}
$$

In conclusion, GD may be compared to GB in its behavior but is considerably less water soluble and less volatile. 


\section{Table 2. Environmentally Relevant Properties of GD}

\begin{tabular}{|c|c|c|c|}
\hline Property & Data & $\begin{array}{l}\text { Data } \\
\text { Quality }\end{array}$ & Reference \\
\hline Empirical Formula & $\mathrm{C}_{7} \mathrm{H}_{16} \mathrm{FO}_{2} \mathrm{P}$ & Not Applicable & \\
\hline $\begin{array}{l}\text { Molecular Weight } \\
(\mathrm{MW})(\mathrm{g} / \mathrm{mol})\end{array}$ & 182.18 & Not Applicable & \\
\hline Density ( $(\mathrm{g} / \mathrm{mL})$ & $1.0223 / 25^{\circ} \mathrm{C}$ & Good & Samuel et al. (1983) \\
\hline Melting Point $\left({ }^{\circ} \mathrm{C}\right)$ & -42 & Fair & Samuel et al. (1983) \\
\hline Boiling Point $\left({ }^{\circ} \mathrm{C}\right)$ & 197.8 & Good & Samuel et al. (1983) \\
\hline $\begin{array}{l}\text { Heat of Vaporiza- } \\
\text { tion }(\mathrm{cal} / \mathrm{g})\end{array}$ & 72.5 & Good & Samuel et al. (1983) \\
\hline $\begin{array}{l}\text { Vapor Pressure at } \\
25^{\circ} \mathrm{C} \text { (torr) }\end{array}$ & $\begin{array}{l}0.40 / 25^{\circ} \mathrm{C} \\
0.274 / 20^{\circ} \mathrm{C}\end{array}$ & $\begin{array}{l}\text { Good } \\
\text { Good }\end{array}$ & Samuel et al. (1983) \\
\hline Log $K_{\text {ow }}$ & $1.02^{b}$ & Poor & Britton and Grant (1988) \\
\hline $\begin{array}{l}\text { Aqueous Solubility } \\
(g / L)\end{array}$ & $\begin{array}{l}34 / 0^{\circ} \mathrm{C} \\
21 / 20^{\circ} \mathrm{C}\end{array}$ & $\begin{array}{l}\text { Fair } \\
\text { Fair }\end{array}$ & $\begin{array}{l}\text { Edgewood Arsenal (1974) } \\
\text { Samuel et al. (1983) }\end{array}$ \\
\hline $\mathrm{K}_{\mathrm{H}}\left(\mathrm{atm} \cdot \mathrm{m}^{3} / \mathrm{mol}\right)$ & $3.1 \times 10^{-6} / 20^{\circ} \mathrm{C}$ & Poor & $\begin{array}{l}\text { Authors' estimate } \\
\text { (see Section 3.1.3) }\end{array}$ \\
\hline $\begin{array}{l}\text { Diffusion Coefficient } \\
\text { (air) }\left(\mathrm{cm}^{2} / \mathrm{s}\right)\end{array}$ & $0.047 / 25^{\circ} \mathrm{C}$ & Fair & Samuel et al. (1983) \\
\hline $\log K_{o c}$ & 1.17 & Poor & $\begin{array}{l}\text { Authors' estimate } \\
\text { (see Section 3.1.4) }\end{array}$ \\
\hline
\end{tabular}

a From the Antoine equation (see text).

b The present authors estimated log $K_{\text {ow }}$ with regression equations (see Section 3.1.2), by using distribution coefficients for two solvents (Rosenthal et al. 1956) to obtain $\log K_{o w}=1.79$ and 1.60. 


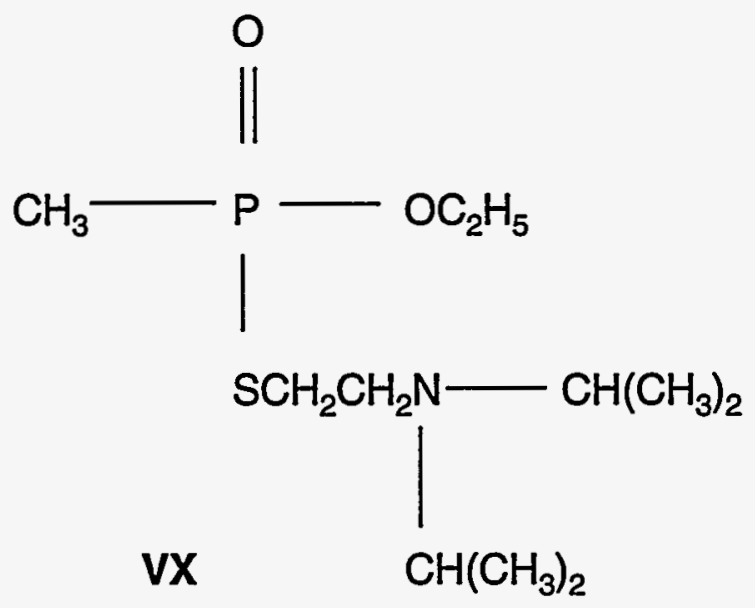

VX, a nerve agent that penetrates skin easily, is more persistent than G-agents because of its low vapor pressure; its evaporation rate is about 1/1,500 that of water (Headquarters, Departments of the Army, Navy, and Air Force 1990). Nevertheless, the literature indicates that, most conservatively, $90 \%$ of VX applied to soil would be lost in 15 days (Small 1983). When 0.25-inch concrete coupons were spiked with $1.8 \mathrm{mg} / \mathrm{g}$ of $\mathrm{VX}$ and allowed to stand for $2 \mathrm{~h}$, no VX could be recovered from the headspace after heating at $140^{\circ} \mathrm{C}$ (Carpenter and Hill 1988). VX hydrolysis rates tend to be slower than those of the G-agents; thus, at $\mathrm{pH} 10$ and $25^{\circ} \mathrm{C}$, the halflife in water is 2,432 min (converted data from Epstein et al. [1974]), compared to $5 \mathrm{~min}$ for GB. At pH 5 and $25^{\circ} \mathrm{C}$, the half-life was reported as $2,342 \mathrm{~h}$ (Clark 1989). VX is not subject to acid-catalyzed hydrolysis but does undergo water-mediated and hydroxyl ion-catalyzed hydrolysis. According to Epstein et al. (1974), watercatalyzed hydrolysis below $\mathrm{pH} 7$ and alkaline hydrolysis above $\mathrm{pH} 10$ result in $\mathrm{P}$-S cleavage, to give ethyl methylphosphonic acid (EMPA) and 2-diisopropylaminoethanethiol (DESH). Complex mixtures of hydrolysis products are formed in the $\mathrm{pH}$ range 7-10; these involve ethoxy cleavage from the phosphorus as well as $\mathrm{C}-\mathrm{S}$ and P-S cleavage at the sulfur (Epstein et al. 1974). One of the products of P-S cleavage, the mercaptan DESH, readily undergoes air oxidation to (DES) $)_{2}(E A 4196)$ (see structures below) (Small 1983). Some of the products may be toxic. The product of ethoxy cleavage, S-(2-diisopropylaminoethyl) methylphosphonothioic acid (EA 2192), is comparatively stable towards hydrolysis and almost as toxic as VX (Sage and Howard 1989). Contrary to Epstein, Yang et al. (1990, 1992, 1993a, see Section 5.1.2) show that ethoxy cleavage occurs significantly at $\mathrm{pH}$ levels much higher than 10.

In addition to the environmentally relevant data in Table 3, the following temperature relationships were reported for VX:

Vapor pressure, $\log \mathrm{P}$ (torr) $=7.28100-2,072.10 /\left(172.5+\mathrm{t}\left[{ }^{\circ} \mathrm{C}\right]\right) \quad$ (Samuel et al. 1983)

Density, $\left.d=1.0290-\left(0.00083+{ }^{\circ} \mathrm{C}\right]\right)$

(Samuel et al. 1983)

The $\mathrm{pK}_{\mathrm{a}}$ of protonated $\mathrm{VX}$ at $25^{\circ} \mathrm{C}$ has been given as 8.60 (Epstein et al. 1974) or 9.1 (Demek et al. 1970). $\mathrm{VX}$ is much more soluble in the protonated form (below a pH of about 7 or 8 ) than it is in the unprotonated (free base) form. 
Table 3. Environmentally Relevant Properties of VX

\begin{tabular}{|c|c|c|c|}
\hline Property & Data & $\begin{array}{l}\text { Data } \\
\text { Quality }\end{array}$ & Reference \\
\hline Empirical Formula & $\mathrm{C}_{11} \mathrm{H}_{26} \mathrm{NO}_{2} \mathrm{PS}$ & Not Applicable & \\
\hline $\begin{array}{l}\text { Molecular Weight } \\
\text { (MW) (g/mol) }\end{array}$ & 267.38 & Not Applicable & \\
\hline Density $(\mathrm{g} / \mathrm{mL})$ & $1.0083 / 25^{\circ} \mathrm{C}$ & Good & Samuel et al. (1983) \\
\hline Melting Point $\left({ }^{\circ} \mathrm{C}\right)$ & -50 & Fair & Samuel et al. (1983) \\
\hline Boiling Point $\left({ }^{\circ} \mathrm{C}\right)$ & 298.4 & Good & Samuel et al. (1983) \\
\hline $\begin{array}{l}\text { Heat of Vaporiza- } \\
\text { tion (cal/g) }\end{array}$ & 80.8 & Good & Samuel et al. (1983) \\
\hline $\begin{array}{l}\text { Vapor Pressure } \\
\text { (torr) }\end{array}$ & $6.2 \times 10^{-4} / 25^{\circ} \mathrm{C}$ & Good & Samuel et al. (1983) \\
\hline $\log K_{\text {ow }}$ & $\begin{array}{l}2.36 \text { (estimate) } \\
2.09 \text { (estimate) } \\
1.992 \text { (estimate) }\end{array}$ & $\begin{array}{l}\text { Poor } \\
\text { Poor } \\
\text { Poor }\end{array}$ & $\begin{array}{l}\text { Britton and Grant (1988) } \\
\text { Small (1984) } \\
\text { Sage and Howard (1989) }\end{array}$ \\
\hline $\begin{array}{l}\text { Aqueous Solubility } \\
\text { (g/L) }\end{array}$ & $30 / 25^{\circ} \mathrm{C}$ & Fair & Edgewood Arsenal (1974) \\
\hline $\mathrm{K}_{\mathrm{H}}\left(\mathrm{atm} \cdot \mathrm{m}^{3} / \mathrm{mol}\right)$ & $7.2 \times 10^{-9} / 25^{\circ} \mathrm{C}$ & Poor & $\begin{array}{l}\text { Authors' estimate } \\
\text { (see Section 3.1.3) }\end{array}$ \\
\hline $\begin{array}{l}\text { Diffusion Coefficient } \\
\text { (air) }\left(\mathrm{cm}^{2} / \mathrm{s}\right)\end{array}$ & $0.034 / 25^{\circ} \mathrm{C}$ & Fair & Samuel et al. (1983) \\
\hline $\log K_{o c}$ & $1.18^{a}$ & Poor & Sage and Howard (1989) \\
\hline
\end{tabular}

a Small (1984) estimated a value of 2.5 . 
In summary, VX is quite persistent and not very water soluble in basic aqueous solution but much more so in acidic solution. It is hydrolyzed by base, and more slowly in neutral or acidic solution, but not nearly as rapidly as $\mathrm{GB}$ or $\mathrm{GD}$ under comparable conditions. Complex mixtures of hydrolysis products are formed.

Because of the sensitivity of VX to hydrolysis, diisopropyl carbodiimide or dicyclohexyl carbodiimide have been added as stabilizers for weapons-grade VX (U.S. Army 1964; Durst et al. 1988).

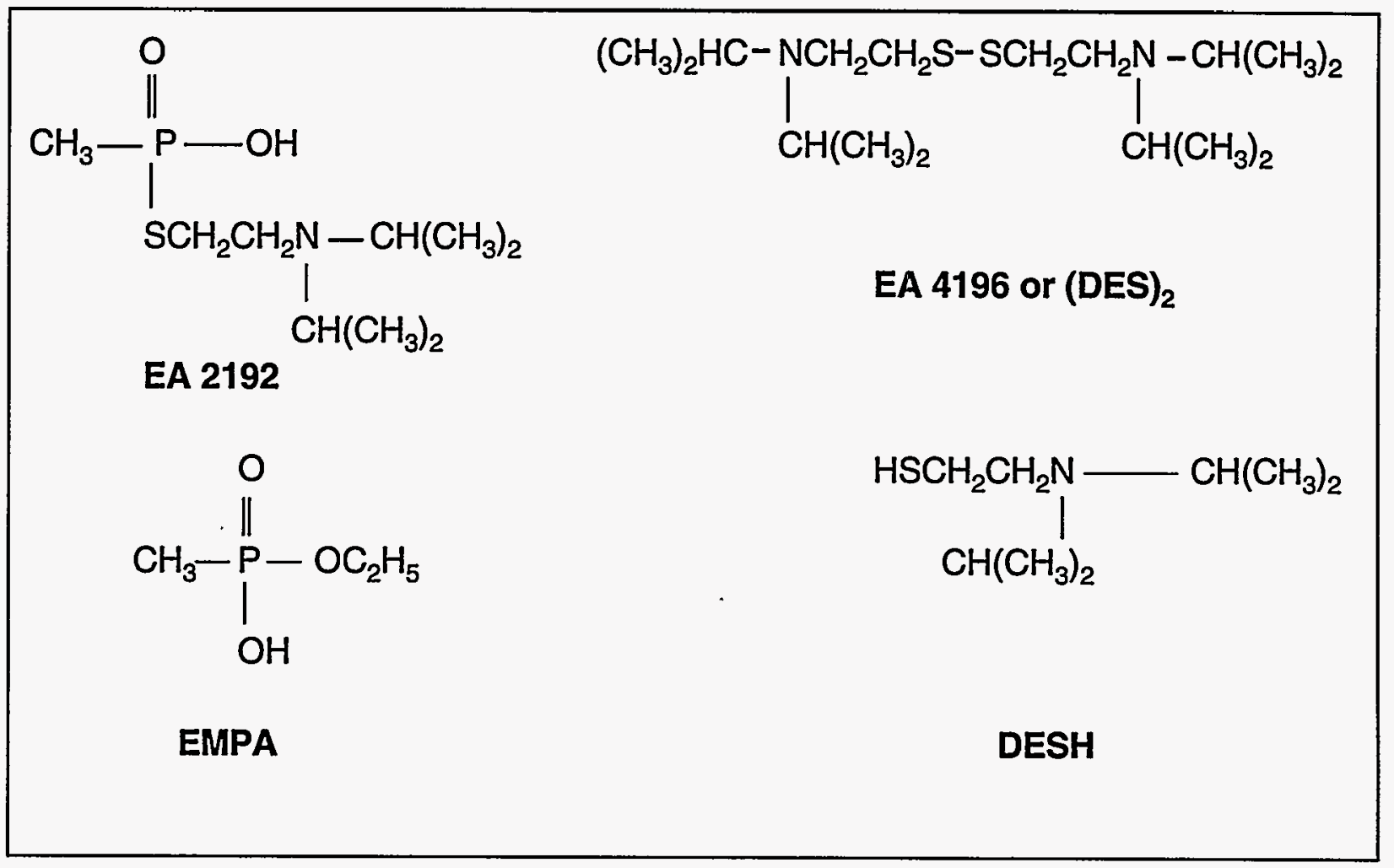

3.5 HD/H (Sulfur Mustard or Mustard Gas or Bis[2-Chloroethyl] Sulfide); CAS Reg. No. 505-60-2

$$
\mathrm{Cl}-\mathrm{CH}_{2}-\mathrm{CH}_{2}-\mathrm{S}-\mathrm{CH}_{2}-\mathrm{CH}_{2}-\mathrm{Cl}
$$

$H$ differs from $H D$ in that $H$ contains certain impurities normally absent from $H D$; however, there is no standard composition for $\mathrm{H}$.

\subsubsection{HD (Distilled Mustard or Distilled Sulfur Mustard)}

Virtually all available physicochemical information on what is commonly known as "mustard gas," a blister agent, has been determined on the relatively pure material, HD. This compound has a low solubility in water 
and a low rate of solution. According to Dacre and Burrows (1988), a pool of HD at the bottom of a water body, relatively undisturbed by currents, would diminish in depth by $1 \mathrm{~cm}$ every 100 days at $20^{\circ} \mathrm{C}$. For these reasons, $\mathrm{HD}$ is difficult to decontaminate by aqueous hydrolysis (to thiodiglycol) despite the relatively high first-order rate constant of the reaction once the HD is in solution (see Section 5.1.3). As discussed in Section 3.5.2, largescale hydrolysis in the presence of lime (to neutralize the hydrochloric acid that was produced) gave mainly thiodiglycol; however, significant amounts of 1,4-oxathiane, 1,4-dithiane, 2-vinylthioethanol, and in some cases mustard chlorohydrin were found in the hydrolysate, along with lesser amounts of other organics (D'Agostino and Provost 1985). Sludge formed in this process contained a number of organic compounds, among them bis(2-chloroethyl) trisulfide; many of the products were unidentified (D'Agostino and Provost 1985).

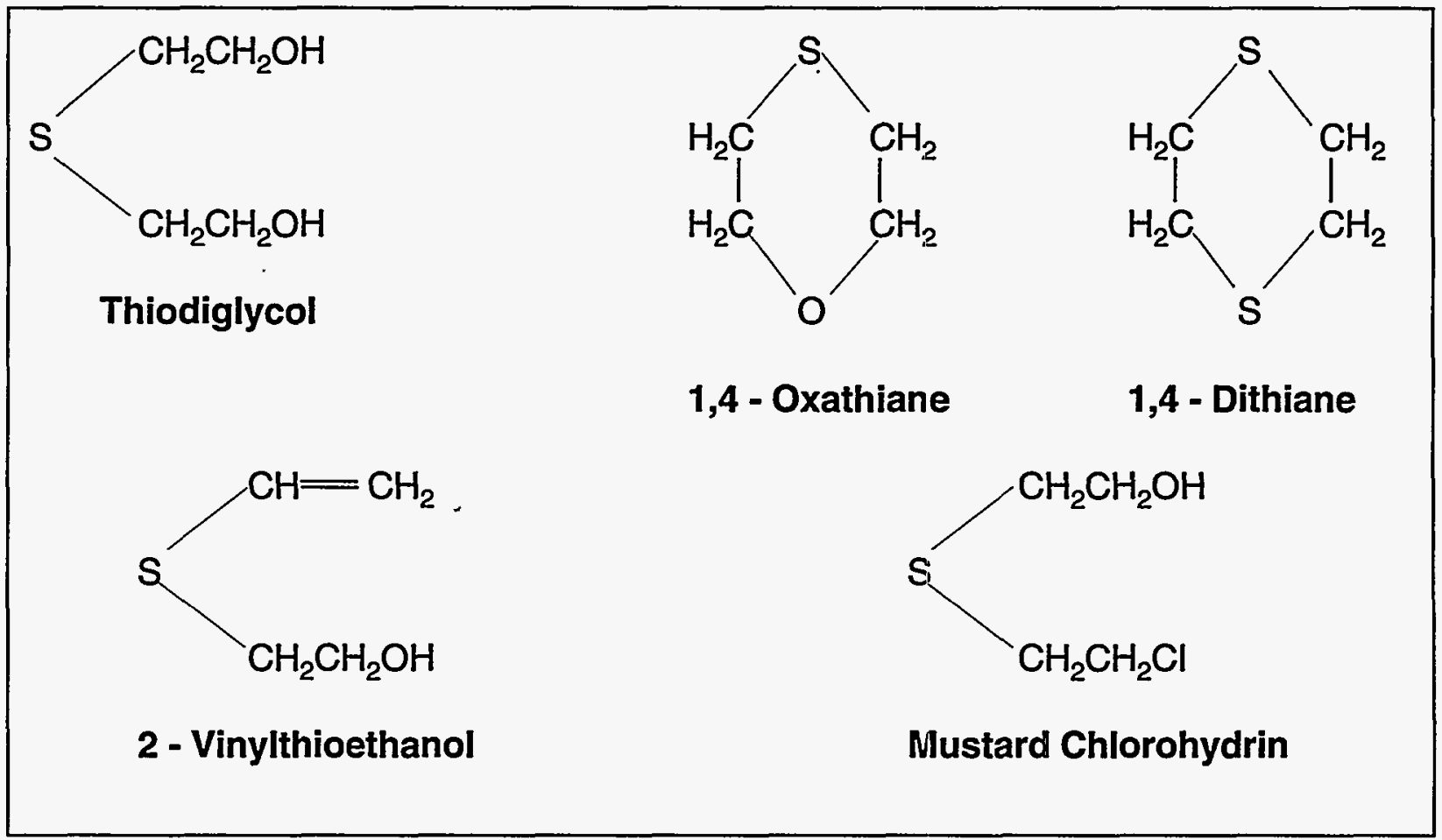

The gas chromatographic analytical procedures used in the foregoing work (D'Agostino and Provost 1985) would not have detected ionic products such as<smiles>OCC[S+]1CCSCC[S+]1CCO</smiles>

H-2TG 
This ion, as determined by NMR spectrometry, was the main organic constituent of the aqueous phase of a twophase mixture of equal volumes of HD and water that had been allowed to stand for 2 months; ions of this type retain much of the toxicity of mustard, including its vesicancy (Yang et al. 1987). Thus, reaction of HD with limited volumes of water can result in the loss of HD without corresponding loss of toxicity.

The fact that bulk HD (or $\mathrm{H}$ ) can persist deep in the soil or under relatively quiescent water for years may be due to the formation of oligomeric degradation products of limited hydrolysis, such as that shown above; presumably these coat the surface of the HD mass. In another sort of scenario, HD films on or near the soil surface would volatilize or hydrolyze within about 3 weeks (Small 1984). Under calm dry conditions at $0^{\circ} \mathrm{C}$, an original heavy soil loading of $50,000 \mathrm{mg} / \mathrm{m}^{2}$ is predicted to decay to $33 \mathrm{mg} / \mathrm{m}^{2}$ in $1,530 \mathrm{~h}$, some $2 \mathrm{months}$; the time is reduced to $41.5 \mathrm{~h}$ at $25^{\circ} \mathrm{C}$ (Small 1984). When 0.25 -inch concrete coupons were spiked with $1.8 \mathrm{mg} / \mathrm{g}$ of $\mathrm{HD}$ and let stand for $24 \mathrm{~h}$, no HD could be recovered from the headspace after heating at $140^{\circ} \mathrm{C}$ (Carpenter and Hill 1988).

In addition to the environmentally relevant data in Table 4, the following temperature relationships were reported for HD:

$$
\text { Vapor pressure, } \log \mathrm{P} \text { (torr) }=7.4749753-1,940.711 /\left(204.6712+\mathrm{t}\left[{ }^{\circ} \mathrm{C}\right]\right) \quad \text { (Penski1993) }
$$

$$
\text { Density, } \left.d=1.2954-\left(0.00107 t{ }^{\circ} \mathrm{C}\right]\right)
$$

To conclude, mustard agent ( $H$ or $H D$ ) is fairly persistent. It is difficult to dissolve mustard agent in water, but, once dissolved, it is quick to hydrolyze to thiodiglycol. Large masses of mustard can become coated with intermediate hydrolysis products that tend to prevent further hydrolysis and preserve the agent for long periods.

\subsubsection{H (Impure Sulfur Mustard)}

The symbol $H$ has probably been used in various ways to designate unpurified (in particular undistilled) mustard made by any process and to refer to distilled mustard $(H D)$ that has been stored under conditions permitting significant degradation. The latter could be caused by the presence of oxygen or water or simply by thermal decomposition over time. Storage in steel containers, especially in conjunction with other factors (e.g., moisture), has probably contributed to such degradation. $\mathrm{H}$ is likely to be more viscous than $\mathrm{HD}$ and to contain suspended solids.

Mustard was synthesized for military use mainly by the Levinstein process (Fuson et al. 1946a), and distillation was not initially used but was later adopted to improve the agent's storage stability. The Levinstein process is shown in the simplest terms as a reaction between sulfur monochloride and ethylene:

$$
\mathrm{S}_{2} \mathrm{Cl}_{2}+2 \mathrm{CH}_{2}=\mathrm{CH}_{2} \rightarrow \mathrm{Cl}-\mathrm{CH}_{2}-\mathrm{CH}_{2}-\mathrm{S}-\mathrm{CH}_{2}-\mathrm{CH}_{2}-\mathrm{Cl}+\mathrm{S}
$$

\section{Mustard}

\section{Elemental} Sulfur 
Table 4. Environmentally Relevant Properties of HD

\begin{tabular}{|c|c|c|c|}
\hline Property & Data & $\begin{array}{l}\text { Data } \\
\text { Quality }\end{array}$ & Reference \\
\hline Empirical Formula & $\mathrm{C}_{4} \mathrm{H}_{8} \mathrm{Cl}_{2} \mathrm{~S}$ & Not Applicable & \\
\hline $\begin{array}{l}\text { Molecular Weight } \\
(\mathrm{MW})(\mathrm{g} / \mathrm{mol})\end{array}$ & 159.08 & Not Applicable & \\
\hline Density $(\mathrm{g} / \mathrm{mL})$ & $1.2685 / 25^{\circ} \mathrm{C}$ & Good & Samuel et al. (1983) \\
\hline Melting Point $\left({ }^{\circ} \mathrm{C}\right)$ & 14.445 & Good & Penski (1993) \\
\hline Boiling Point $\left({ }^{\circ} \mathrm{C}\right)$ & 217.5 & Good & Samuel et al. (1983) \\
\hline $\begin{array}{l}\text { Heat of Vaporiza- } \\
\text { tion }(\mathrm{cal} / \mathrm{g})\end{array}$ & 94.3 & Good & Samuel et al. (1983) \\
\hline $\begin{array}{l}\text { Vapor Pressure } \\
\text { (torr) }\end{array}$ & $\begin{array}{l}0.082 / 22^{\circ} \mathrm{C}^{\mathrm{a}} \\
0.1059 / 25^{\circ} \mathrm{C}^{\mathrm{a}}\end{array}$ & $\begin{array}{l}\text { Good } \\
\text { Good }\end{array}$ & $\begin{array}{l}\text { Samuel et al. (1983) } \\
\text { Samuel et al. (1983) }\end{array}$ \\
\hline $\log K_{\text {ow }}$ & $\begin{array}{l}1.37 \\
2.026\end{array}$ & $\begin{array}{l}\text { Good } \\
\text { Fair }\end{array}$ & $\begin{array}{l}\text { b } \\
\text { Sage and Howard (1989) }\end{array}$ \\
\hline $\begin{array}{l}\text { Aqueous Solubility } \\
(\mathrm{g} / \mathrm{L})\end{array}$ & $0.92 / 22^{\circ} \mathrm{C}$ & Fair & Edgewood Arsenal (1974) \\
\hline $\mathrm{K}_{H}\left(\mathrm{~atm} \cdot \mathrm{m}^{3} / \mathrm{mol}\right)$ & $\begin{array}{l}1.87 \times 10^{-5} \\
2.57 \times 10^{-5}\end{array}$ & Fair & $\begin{array}{l}\text { Authors' estimate } \\
\text { (see Section 3.1.3) } \\
\text { Sage and Howard (1989) }\end{array}$ \\
\hline $\begin{array}{l}\text { Diffusion Coefficient } \\
\text { (air) }\left(\mathrm{cm}^{2} / \mathrm{s}\right)\end{array}$ & $0.060 / 25^{\circ} \mathrm{C}$ & Fair & Samuel et al. (1983) \\
\hline $\log K_{\alpha c}$ & $2.0-2.1$ & Poor & Sage and Howard (1989) \\
\hline
\end{tabular}

a From the Antoine equation (see text).

b Authors' estimate from fragment constants (see Section 3.1.2) in agreement with Small (1984) and the U.S. Environmental Protection Agency (1986). 
The excess sulfur in Levinstein mustard may react in various ways to form polysulfide impurities, such as the trisulfide $\mathrm{Cl}-\mathrm{CH}_{2}-\mathrm{CH}_{2}-\mathrm{S}-\mathrm{S}-\mathrm{S}-\mathrm{CH}_{2}-\mathrm{CH}_{2}-\mathrm{Cl}$ and a pentasulfide formed by attaching two sulfur atoms to the middle sulfur of the trisulfide. Depending on conditions, even more sulfurs can be attached (as chains of sulfur hanging on to the middle sulfur). Very little disulfide is formed (Fuson et al. 1946a, 1946c). The proportions of polysulfides with various numbers of sulfurs, and of free sulfur, depend on formation temperatures and the age of the crude mixtures. The middle sulfur - and any sulfurs attached to it - would appear to be quite labile.

When $H D$ was heated in a sealed tube at $180^{\circ} \mathrm{C}$ for $18 \mathrm{~h}$, the products of reaction were 1,4-dithiane and 1,2-dichloroethane $\left(\mathrm{Cl}-\mathrm{CH}_{2}-\mathrm{CH}_{2}-\mathrm{Cl}\right)$ in high yield (Bell et al. 1927). (1,4-Dithiane is a mustard impurity frequently found in groundwater near mustard disposal sites.) The reverse reaction, conversion of 1,4-dithiane plus excess 1,2-dichloroethane in a sealed tube at $180^{\circ} \mathrm{C}$ to mustard, was demonstrated by the same authors (though a small yield must be presumed). When $H D$ was held at $137^{\circ}$ to $145^{\circ} \mathrm{C}$ in an atmosphere of nitrogen, with $1,2-$ dichloroethane allowed to escape, some 1,4-dithiane was formed; the following compounds were also identified among the products (Fuson et al. 1946b):

$$
\mathrm{Cl}-\mathrm{CH}_{2}-\mathrm{CH}_{2}-\mathrm{S}-\mathrm{CH}_{2}-\mathrm{CH}_{2}-\mathrm{S}-\mathrm{CH}_{2}-\mathrm{CH}_{2}-\mathrm{Cl}
$$

\section{1,2-Bis(2-chloroethylthio)ethane}

and<smiles>SCCSCCSCCCl</smiles>

Bis[2-(2-chloroethylthio)ethyl] sulfide

In addition, evidence existed that higher polymeric materials were present. With small amounts of water, HD (or H) would form some of the hydrolysis intermediates discussed in Section 3.5.1.

It has not been possible to find a listing for the composition of a "typical" sample of $\mathrm{H}$; such an entity may not exist. It is instructive, however, to consider two old samples of $\mathrm{H}$ (probably Levinstein mustard) that were recently analyzed. In the first instance, a 75-mm projectile dating from the World War I era was discovered in Spring Valley, Washington, D.C.; it was subjected to proton NMR spectrometry and found to contain sulfur mustard of the composition (peak area of NMR spectrum down to $0.5 \%$, with less abundant constituents not recorded here) shown in Table 5 (Brooks et al. 1994). Aside from HD, the main constituents correspond to Levinstein mustard impurities, products of thermal decomposition, and products of reaction with limited amounts of water described above. 


\section{Table 5. Composition of a World War I Sample of H from Spring Valley Analyzed in 1993 Down to $0.5 \%$}

\begin{tabular}{|c|c|}
\hline Analyte & NMR Peak Area \% \\
\hline $\mathrm{HD}\left(\mathrm{Cl}-\mathrm{CH}_{2}-\mathrm{CH}_{2}-\mathrm{S}-\mathrm{CH}_{2}-\mathrm{CH}_{2}-\mathrm{Cl}\right)$ & 64.2 \\
\hline $\mathrm{HD}$ Disulfide $\left(\mathrm{Cl}-\mathrm{CH}_{2}-\mathrm{CH}_{2}-\mathrm{S}-\mathrm{S}-\mathrm{CH}_{2}-\mathrm{CH}_{2}-\mathrm{Cl}\right)$ & 11.8 \\
\hline 1,4-Dithiane $\left(\mathrm{C}_{4} \mathrm{H}_{8} \mathrm{~S}_{2}\right)$ & 9.7 \\
\hline HD Trisulfide $\left(\mathrm{Cl}-\mathrm{CH}_{2}-\mathrm{CH}_{2}-\mathrm{S}-\mathrm{S}-\mathrm{S}-\mathrm{CH}_{2}-\mathrm{CH}_{2}-\mathrm{Cl}\right)$ & 3.7 \\
\hline 1,2-Bis(2-chloroethylthio)ethane & \\
\hline$\left(\mathrm{Cl}-\mathrm{CH}_{2}-\mathrm{CH}_{2}-\mathrm{S}-\mathrm{CH}_{2}-\mathrm{CH}_{2}-\mathrm{S}-\mathrm{CH}_{2}-\mathrm{CH}_{2}-\mathrm{Cl}\right)$ & 3.7 \\
\hline 1,2,3-Trithiolane $\left(\mathrm{C}_{2} \mathrm{H}_{4} \mathrm{~S}_{3}\right)$ & 1.4 \\
\hline 1,4-Thioxane $\left(\mathrm{C}_{4} \mathrm{H}_{8} \mathrm{OS}\right)$ & 1.1 \\
\hline 1,2,5-Trithiepane $\left(\mathrm{C}_{4} \mathrm{H}_{8} \mathrm{~S}_{3}\right)$ & 0.9 \\
\hline 1,2,3,4-Tetrathiane $\left(\mathrm{C}_{2} \mathrm{H}_{4} \mathrm{~S}_{4}\right)$ & 0.8 \\
\hline $\mathrm{Cl}-\mathrm{CH}_{2}-\mathrm{CH}_{2}-\mathrm{S}-\mathrm{CH}_{2}-\mathrm{CH}_{2}-\mathrm{O}-\mathrm{CH}_{2}-\mathrm{CH}_{2}-\mathrm{Cl}$ & 0.7 \\
\hline
\end{tabular}

The second sample, from an old chemical munition of undisclosed origin, was analyzed in July 1993 by gas chromatography/mass spectrometry (GC/MS); peak areas were measured, as shown in Table 6 (Rohrbaugh 1994).

HD stored in a 1-ton container (No. HD-U-2296-CTF-N), probably dating to after World War II, was also sampled and analyzed in July 1993 by GC/MS. Results are shown in Table 7 (Rohrbaugh 1994).

\section{Table 6. Composition of an Old Sample of H Analyzed in 1993}

\section{Analyte}

$\mathrm{HD}\left(\mathrm{Cl}-\mathrm{CH}_{2}-\mathrm{CH}_{2}-\mathrm{S}-\mathrm{CH}_{2}-\mathrm{CH}_{2}-\mathrm{Cl}\right)$

HD Disulfide ( $\left.\mathrm{Cl}-\mathrm{CH}_{2}-\mathrm{CH}_{2}-\mathrm{S}-\mathrm{S}-\mathrm{CH}_{2}-\mathrm{CH}_{2}-\mathrm{Cl}\right)$

1,4-Dithiane $\left(\mathrm{C}_{4} \mathrm{H}_{8} \mathrm{~S}_{2}\right)$

HD Trisulfide ( $\mathrm{Cl}-\mathrm{CH}_{2}-\mathrm{CH}_{2}-\mathrm{S}-\mathrm{S}-\mathrm{S}-\mathrm{CH}_{2}-\mathrm{CH}_{2}-\mathrm{Cl}$ )

1,2-Bis(2-chloroethylthio)ethane

( $\mathrm{Cl}-\mathrm{CH}_{2}-\mathrm{CH}_{2}-\mathrm{S}-\mathrm{CH}_{2}-\mathrm{CH}_{2}-\mathrm{S}-\mathrm{CH}_{2}-\mathrm{CH}_{2}-\mathrm{Cl}$ )

1,2,3-Trithiolane $\left(\mathrm{C}_{2} \mathrm{H}_{4} \mathrm{~S}_{3}\right)$

1,4-Thioxane $\left(\mathrm{C}_{4} \mathrm{H}_{8} \mathrm{OS}\right)$

1,2,5-Trithiepane $\left(\mathrm{C}_{4} \mathrm{H}_{8} \mathrm{~S}_{3}\right)$

1,2,3,4-Tetrathiane $\left(\mathrm{C}_{2} \mathrm{H}_{4} \mathrm{~S}_{4}\right)$

$\mathrm{Cl}-\mathrm{CH}_{2}-\mathrm{CH}_{2}-\mathrm{S}-\mathrm{CH}_{2}-\mathrm{CH}_{2}-\mathrm{O}-\mathrm{CH}_{2}-\mathrm{CH}_{2}-\mathrm{Cl}$

1,2-Dichloroethane $\left(\mathrm{Cl}-\mathrm{CH}_{2}-\mathrm{CH}_{2}-\mathrm{Cl}\right)$

HD Tetrasulfide ( $\left.\mathrm{Cl}-\mathrm{CH}_{2}-\mathrm{CH}_{2}-\mathrm{S}-\mathrm{S}-\mathrm{S}-\mathrm{S}-\mathrm{CH}_{2}-\mathrm{CH}_{2}-\mathrm{Cl}\right)$

$\mathrm{Cl}-\mathrm{CH}_{2}-\mathrm{CH}_{2}-\mathrm{S}-\mathrm{CH}_{2}-\mathrm{CH}_{2}-\mathrm{CH}_{2}-\mathrm{Cl}$ or isomer

$\mathrm{Cl}-\mathrm{CH}_{2}-\mathrm{CH}_{2}-\mathrm{S}-\mathrm{CH}_{2}-\mathrm{CH}_{2}-\mathrm{CH}_{2}-\mathrm{CH}_{2}-\mathrm{Cl}$ or isomers

$\mathrm{Cl}-\mathrm{CH}_{2}-\mathrm{CH}_{2}-\mathrm{S}-\mathrm{CH}_{2}-\mathrm{CH}_{2}-\mathrm{S}-\mathrm{S}-\mathrm{CH}_{2}-\mathrm{CH}_{2}-\mathrm{Cl}$

Tetrachloroethene $\left(\mathrm{Cl}_{2} \mathrm{C}=\mathrm{CCl}_{2}\right)$

Sulfur $\left(S_{8}\right)$

\section{GC/MS Peak Area \%}

62.2

10.9

3.2

9.6

2.6

2.4

0.1

0.9

1.4

0.4

3.2

0.6

0.3

0.8

0.2

0.3

0.5 
Analyte

$\mathrm{HD}\left(\mathrm{Cl}-\mathrm{CH}_{2}-\mathrm{CH}_{2}-\mathrm{S}-\mathrm{CH}_{2}-\mathrm{CH}_{2}-\mathrm{Cl}\right)$

$\mathrm{HD}$ Disulfide ( $\mathrm{Cl}-\mathrm{CH}_{2}-\mathrm{CH}_{2}-\mathrm{S}-\mathrm{S}-\mathrm{CH}_{2}-\mathrm{CH}_{2}-\mathrm{Cl}$ )

1,4-Dithiane $\left(\mathrm{C}_{4} \mathrm{H}_{8} \mathrm{~S}_{2}\right)$

1,2-Bis(2-chloroethylthio)ethane

$$
\text { (Cl- } \mathrm{CH}_{2}-\mathrm{CH}_{2}-\mathrm{S}-\mathrm{CH}_{2}-\mathrm{CH}_{2}-\mathrm{S}-\mathrm{CH}_{2}-\mathrm{CH}_{2}-\mathrm{Cl} \text { ) }
$$

1,2,5-Trithiepane $\left(\mathrm{C}_{4} \mathrm{H}_{8} \mathrm{~S}_{3}\right)$

1,2-Dichloroethane $\left(\mathrm{Cl}-\mathrm{CH}_{2}-\mathrm{CH}_{2}-\mathrm{Cl}\right)$

$\mathrm{Cl}-\mathrm{CH}_{2}-\mathrm{CH}_{2}-\mathrm{S}-\mathrm{CH}_{2}-\mathrm{CH}_{2}-\mathrm{CH}_{2}-\mathrm{Cl}$ or isomer

Four $\mathrm{Cl}-\mathrm{CH}_{2}-\mathrm{CH}_{2}-\mathrm{CH}_{2}-\mathrm{S}-\mathrm{CH}_{2}-\mathrm{CH}_{2}-\mathrm{CH}_{2}-\mathrm{Cl}$ isomers
GC/MS Peak Area \%

89.2

0.1

1.2

4.7

0.1

2.4

0.4

1.7

To summarize, chemically impure mustard $(H)$ behaves more or less like the distilled product $(H D)$ but contains a much higher proportion of impurities and is likely to be more viscous than HD. The toxicity and environmental fate of most of the impurities have not been thoroughly characterized.

\subsection{CONCEPTS OF CONTAMINATION AND REACTIVE DECONTAMINATION}

The following subsections of this document often refer to interactions between agents and "substrates." The U.S. Army frequently tests the effects of chemical agents on various types of military equipment, followed by decontamination solutions and procedures to decontaminate the various materials tested. The materials tested are referred to as "substrates."

\subsection{Exposure of Materials to Vapor-State and Liquid Agents}

The exposure of impermeable, chemically unreactive substrates (such as stainless steel or glass) to $H D, G B, G D$, and VX in the vapor state will result in very little sorption of the agents. Aeration will lead to very rapid loss of any residual agent following decontamination. By contrast, painted metal is expected to absorb a small amount of agent vapors; plastics and elastomers would absorb more, depending to a considerable degree on the time of exposure preceding decontamination. For a detailed discussion of agent sorption/desorption in organic matrices, see Appendix B.

Exposure of substrates to liquid agents would permit higher loadings than exposure to vapors. A fairly volatile agent, such as $G B$, deposited on a nonporous unreactive surface, would evaporate quickly even without decontamination; whereas an agent of low vapor pressure, such as VX, would tend to persist. Permeable polymeric substrates would tend to absorb agents, especially those of low volatility, making the agents largely inaccessible to decontaminants. The longer the delay between application of agent to substrate and application of decontaminant (especially for agents of low volatility), the more deeply penetrating the agent would be. 


\subsection{Interactions between Agents-on-Substrates and Decontamiraant Solutions}

The solubility of an agent in a decontaminating solution strongly affects the ease of decontamination. Thus, GB, which is infinitely miscible with water, should be easily and rapidly rernoved from an impermeable surface such as stainless steel. $H$ or $H D$, being relatively insoluble, might require lengthy contact with decontaminant solution to achieve decontamination of such a surface. If the agent has been absorbed by a permeable substrate, such as paint, time will be required for it to diffuse out to the decontaminant. Most active decontaminant ingredients do not penetrate the material to attack the agent within. From a practical point of view, the time of contact between permeable substrates and decontaminant solutions has to be prolonged to effect complete decontamination where the rate of reaction is limited by the rate of diffusion of the agent back out of the substrate.

Once agent and reactive decontaminants have been brought together in the decontaminating solution, speed and efficacy of decontamination are controlled by the reaction rates (kinetics).

\subsection{MAJOR REACTIVE SYSTEMS FOR DECONTAMINATION}

\subsection{Reactions with Aqueous or Aqueous-Alcoholic Alkaline Solutions}

\subsubsection{GB and GD}

$\mathrm{GB}$ and $\mathrm{GD}$ are rapidly hydrolyzed by water at high $\mathrm{pH}$ through reaction with hydroxide ion:<smiles>CC(O)CC(C)P(=O)([O-])OC(C)C(C)F</smiles><smiles>CC(C)OP(=O)([O-])OC(C)C(C)C(C)C(C)C</smiles>

As reported in Section 3.2, the half-life of $\mathrm{GB}$ at $\mathrm{pH} 10$ (a reasonable $\mathrm{pH}$ for a sodium carbonate solution) is approximately $5 \mathrm{~min}$; one may estimate the half-life for GD (see Section 3.3) at the same $\mathrm{pH}$ as $8.3 \mathrm{~min}$ (or, accepting the value from Yang et al. [1992], $12 \mathrm{~min}$ ). Thus, in an hour, five or more half-lives would elapse, and 
the concentration of agent would be no more than $3 \%$ of its original value. In $4 \mathrm{~h}$ at $\mathrm{pH} 10$, the concentration of either of these agents would be less than one millionth of its original concentration. The reaction rate would be a thousandfold greater at $\mathrm{pH} 13$ (the approximate $\mathrm{pH}$ of $0.4 \%$ sodium hydroxide) than at $\mathrm{pH} 10$. Whereas $\mathrm{GB}$ is infinitely miscible with water, GD is soluble only to the extent of about $2 \%$. The solubility of GD can be increased by using a solvent mixture consisting of a small proportion of water with a large proportion of methanol (or another alcohol); the alcohol does not appear to depress the reactivity of $G$-agents with sodium hydroxide in the solution to a significant degree. The decontaminating solution, in this case, contains not only hydroxide ion but also methoxide ion. Alcoholysis of GD by the latter occurs, to some degree, in parallel with the hydrolysis reaction depicted above, to form methyl pinacolyl methylphosphonate, an ester:<smiles>COP(=O)(C[CH-][18CH3])OC(C)C(C)(C)C</smiles>

This ester would eventually undergo hydrolysis to form pinacolyl methylphosphonic acid and perhaps some methyl methylphosphonic acid.

Methylphosphonic difluoride, a potential impurity of GB and GD, would rapidly hydrolyze to methylphosphonic acid (MPA) and its anions on exposure to water, especially at high $\mathrm{pH}$.<smiles>CP(=O)(F)PCCOP(=O)(O)[18F]</smiles>

Also present as impurities in the G-agents are dialkyl methylphosphonates such as DIMP. Such esters undergo relatively slow basic hydrolysis to salts of alkyl methylphosphonic acids. Alkyl methylphosphonic acids, which are also the phosphorus-containing hydrolysis products of GB or GD, are extremely resistant to basic hydrolysis, although they are slowly hydrolyzed in strong acid at elevated temperatures (Kingery and Allen 1994, 1995). These alkyl methylphosphonic acids can undergo catalyzed hydrolysis, biologically or in the presence of reactive soils, to form MPA (Kingery and Allen 1994, 1995). Kingery and Allen also showed that the latter is chemically quite stable although subject to slow biodegradation. Aqueous methylphosphonic and alkyl methylphosphonic acids can be routinely analyzed in water down to a level of $0.5 \mu \mathrm{g} / \mathrm{L}$ by ion chromatography (Kingery and Allen 1993).

To sum up, alkaline aqueous or alcoholic solutions rapidly hydrolyze GB and GD; the presence of an alcohol enhances the solubility of GD. 
The diisopropyl carbodiimide added as a stabilizer for weapons-grade GB would be converted completely to $\mathrm{N}, \mathrm{N}$ '-diisopropylurea by the strongly basic aqueous decontaminant (see Appendix A). The tributylamine stabilizer is unreactive towards base.

\subsubsection{VX}

The hydrolytic reactions of VX are complex and involve multiple pathways. Rates and products depend on pH (Epstein et al. 1974; Yang et al. 1990, 1992, 1993a, 1994; Szafraniec et al. 1993), temperature, and VX concentration (Yang et al. 1994). VX is not subject to acid-catalyzed hydrolysis but does undergo water-and hydroxyl ion-catalyzed hydrolysis. The major products under most conditions are those of P-S cleavage, giving ethyl methyiphosphonic acid and DESH. DESH, especially under alkaline conditions, is easily oxidized by oxygen to form EA 4196.

Contrary to the report by Epstein et al. (1974) that $\mathrm{P}$-S cleavage is the only reaction at $\mathrm{pH}>10$, it now appears that formation of the products of ethoxy (i.e., C-O) cleavage, namely ethanol and EA 2192, is significant at both neutral and alkaline $\mathrm{pH}$. Thus, at $22^{\circ} \mathrm{C}$, Yang et al. $(1992,1993 \mathrm{a})$ report a $13 \%$ yield of EA 2192 from $0.01 \mathrm{M}$ VX in aqueous $0.1 \mathrm{M}$ sodium hydroxide; at $23^{\circ} \mathrm{C}$, Szafraniec et al. (1993) report the following molar sodium hydroxide concentrations and EA 2192 yields: $0.25,11 \% ; 1.25,16 \%$; and 2.0, 17\%. Further, Yang et al. (1990) report a 22\% yield of EA 2192 for $0.05 \mathrm{MVX}$ in $2 \mathrm{M}$ sodium hydroxide dissolved in water containing $10 \%$ by volume of 2-propanol (to solubilize the VX). It is important to recognize that the still quite toxic EA 2192 is quite resistant to hydrolysis, as will be seen below.

A third set of hydrolysis products was reported for the neutral $\mathrm{pH}$ range, namely those arising through nitrogenassisted C-S cleavage and producing diisopropylaminoethyl sulfide and O-ethyl methylphosphonothioic acid as the major (but probably not only) products (Epstein et al. 1974; Yang et al. 1990).

While the C-O cleavage products have been seen under very alkaline conditions in strictly aqueous solution, studies with the simulant O,S-diethyl methylphosphonothioate have indicated that presence of a preponderance of an alcoholic solvent along with the alkali favors P-S cleavage. Thus, it is inferred that VX could be rapidly decontaminated by such strongly basic (e.g., with $0.15 \mathrm{M}$ added $\mathrm{NaOH}$ ) methyl or propyl alcoholic solutions without forming the product EA 2192 . This holds true even when as much as $10 \%$ of water by volume is present. The enhanced and selective reactivity of VX in such solutions is a result of the high nucleophilic reactivity of the alkoxides formed by reaction between the alcohols and the added hydroxide ion; the effect is not due to decreased solvent polarity (Yang et al. 1993b). From these results with the simulant, it is predicted that, following reaction with VX, such alcoholic decontamination fluids would be free of EA 2192.

Concern for the presence of EA 2192 stems from reports of its toxicity. EA 2192 is nearly as toxic as VX by the intravenous route, although considerably less so by the oral route, and is apparently not absorbed through the skin; its extremely low vapor pressure precludes it from being hazardous by inhalation (Durst et al. 1988).

The half-lives for disappearance of $\mathrm{VX}$ at $25^{\circ} \mathrm{C}$ in aqueous solution have been reported by Epstein et al. (1974) as shown in Table 8 (some of the values were actually determined for the diethylamino analog of VX that has virtually identical hydrolytic behavior). Durst et al. (1988) cited a reported half-life at $\mathrm{pH} 14$ of $1.3 \mathrm{~min}(0.022 \mathrm{~h}$, no temperature given). 


\section{Table 8. Hydrolysis Half-Lives for VX}

\begin{tabular}{|c|c|}
\hline $\mathrm{pH}$ & Half-Life (hours), $25^{\circ} \mathrm{C}$ \\
\hline 2.0 & 2,520 \\
\hline 4.0 & 2,257 \\
\hline 6.0 & 2,381 \\
\hline 7.0 & 996 \\
\hline 8.0 & 184 \\
\hline 9.0 & 63 \\
\hline 10.0 & 40.5 \\
\hline 11.0 & 15 \\
\hline (approximately $0.01 \mathrm{M} \mathrm{NaOH}$ ) & 2.5 \\
\hline 12.65 & 0.525 \\
\hline 12.9 & 0.279 \\
\hline 13.5 & 0.0529 \\
\hline
\end{tabular}

Source: Epstein et al. (1974)

For $22^{\circ} \mathrm{C}$ and $0.1 \mathrm{M}$ aqueous sodium hydroxide, Yang et al. (1993a) reported a half-life for $\mathrm{VX}$ of $31 \mathrm{~min}(0.517 \mathrm{~h})$. At the same temperature, with 10 times the concentration of sodium hydroxide, the half-life of EA 2192 was 7.4 days $(178 \mathrm{~h})$.

Under very alkaline conditions, the half-life of VX (in minutes) can be expressed (Szafraniec et al. 1993) as:

$$
t_{1 / 2}=2.17 /\left(\left[\mathrm{OH}^{-}\right]^{1.2}\right)
$$

The half-life for EA 2192 can be expressed (in minutes) as:

$$
t_{1 / 2}=835 /\left(\left[\mathrm{OH}^{-}\right]^{1.6}\right)
$$

Because VX is a base, the $\mathrm{pH}$ resulting from its dissolution in water is sufficient to initiate its own hydrolysis. However, the acid generated by that reaction would gradually lower the $\mathrm{pH}$, so that the apparent half-life would decrease with time. Yang et al. (1990) estimate $80 \mathrm{~h}$ as the "half-life for the spontaneous hydrolysis" of VX at $20^{\circ} \mathrm{C}$. Szafraniec et al. (1990) made a $0.5 \%$ solution of VX in unbuffered water; the initial pH was 9.0 , and this dropped to 7.5 in the course of hydrolysis. The overall first-order rate constant was $0.0121 \mathrm{~h}^{-1} 1$, so that the half-life was $57 \mathrm{~h}$. Cleavage fractions are P-O, 0.54 (product EA 2192); P-S, 0.36; and S-C, 0.10. Thus, cleavage to produce EA 2192 was dominant under these conditions.

As seen in Section 3.4, the hydrolysis rate for $\mathrm{VX}$ at $\mathrm{pH} 10$ and $25^{\circ} \mathrm{C}$ is about 375 times slower than for $\mathrm{GB}$, and this holds more or less true at higher $\mathrm{pH}$ levels. Moreover, ordinary alkaline aqueous hydrolysis sufficient to destroy all the VX would not completely eliminate the toxicity (because of EA 2192). One hydrolysis product of VX, EMPA, has an environmental fate very similar to that of other alkyl methylphosphonates (see Section 5.1.1). 
In sum, the hydrolysis chemistry of VX is complex. Hydrolysis is fastest under basic conditions and is enhanced by the presence of alcohols, which help to avoid formation of the undesirable EA 2192. Water-containing decontaminants convert the VX stabilizing agents, diisopropyl carbodiimide and dicyclohexyl carbodiimide, to N,N'diisopropylurea and $\mathrm{N}, \mathrm{N}$-dicyclohexylurea, respectively.

\subsection{3 $\mathrm{H}$ and HD}

$H$ is a mixture of $H D$ with various impurities in differing proportions that depend on the history of the particular lot. (Old samples of "HD" may contain some of those same impurities.) Because it is impractical to characterize the chemistry of $\mathrm{H}$ separately, most studies have involved fairly pure $\mathrm{HD}$. For this reason, emphasis is placed on $\mathrm{HD}$; this report also contains a few qualitative comments (based on best professional judgment) as to the chemical behavior and possible effects of the impurities.

For hydrolysis of HD with predominantly aqueous solutions, the two central facts are (1) dissolution of HD in water is extremely slow, though it can be facilitated by vigorous stirring, and (2) the rate of basic hydrolysis (via the intermediate 2-chloroethyl-2'-hydroxyethyl sulfide or "mustard chlorohydrin") to the predominant product, thiodiglycol, is not affected by the base concentration. The reason for the insensitivity to base concentration is that the formation of the cyclic sulfonium intermediates (I and II) is slow and rate-controlling, and it depends mainly on the nature of the solvent (Rosenblatt et al. 1975). The following reactions are observed almost exclusively when the ratio of water to $H D$ is relatively high:

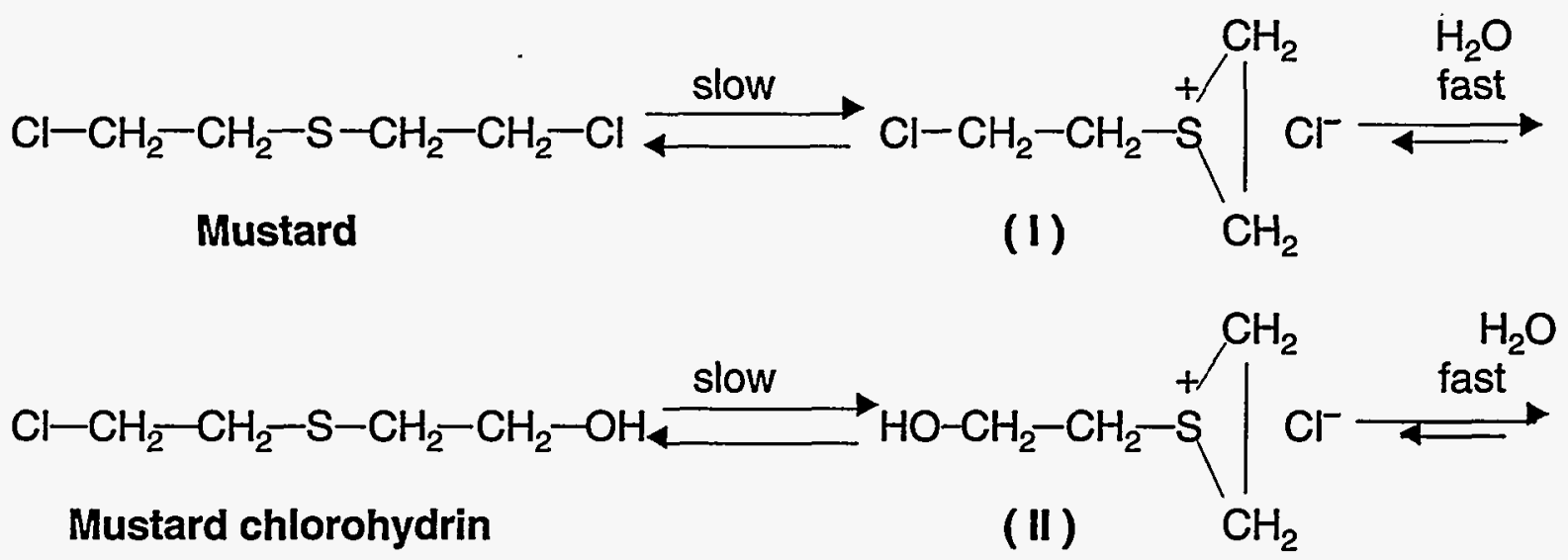<smiles>OCCSCCO</smiles>

Thiodiglycol 
Note that the hydrolysis of mustard chlorohydrin is somewhat faster than that of mustard, so that the chlorohydrin does not tend to accumulate in high concentration. If chloride ion is present, as it is in seawater, for example, the reaction is retarded because chloride ion reacts with the cyclic sulfonium intermediates I and II to reform HD. Strong nucleophiles (e.g., thiosulfate) also react with the intermediates, competing with water or hydroxide for I and II, so that less thiodiglycol is formed (Ogston et al. 1948).

The impurities found in $\mathrm{H}$, such as the polysulfides, might be expected to hinder the already slow dissolution of the agent, and, if they dissolved in water, to react more slowly with water than HD (or not at all). One impurity, 1,2-bis(2-chloroethylthio)ethane, is about five times as vesicant as HD itself; others, such as 1,8-dichloro-3-oxa-6thiaoctane, are probably about as toxic as HD. Yet others, including the HD polysulfides, are considerably less vesicant; thus, the disulfide, $\mathrm{Cl}-\mathrm{CH}_{2} \mathrm{CH}_{2}-\mathrm{S}-\mathrm{S}-\mathrm{CH}_{2} \mathrm{CH}_{2}-\mathrm{Cl}$ is reportedly $1 / 50$ as vesicant as $\mathrm{HD}$, and the trisulfide, $\mathrm{Cl}-\mathrm{CH}_{2} \mathrm{CH}_{2}$-S-S-S- $\mathrm{CH}_{2} \mathrm{CH}_{2}-\mathrm{Cl}$ is not vesicant at all (Kinnear and Harley-Mason 1943).

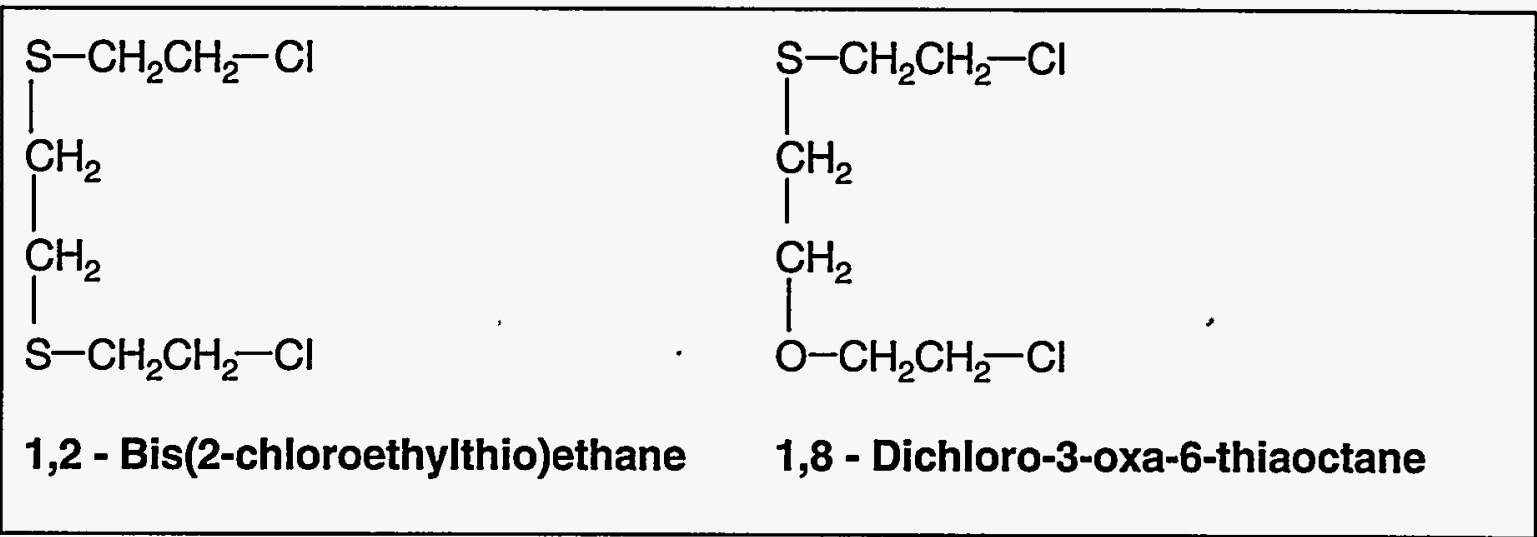

Organic solvents that might be added to water to solubilize HD, so as to facilitate its hydrolysis, often significantly decrease the rates of formation of the sulfonium intermediates (Yang et al. 1986). When a relatively small amount of acetone (5\%) was used to introduce a sample of mustard into water at $25^{\circ} \mathrm{C}$, the rate constant for disappearance of HD was $0.00129 \mathrm{~s}^{-1}$ (Yang et al. 1986, citing Bartlett and Swain 1949). This indicates a half-life of $0.693 /(0.00129 \times 60)=9.0 \mathrm{~min}$. The half-life would be somewhat less in pure water. In short, the concentration of HD could be reduced by a factor of 1 million in $3 \mathrm{~h}$, provided dissolution in water could be effected with the addition of only a very small amount of a suitable solvent. (Note that Bartlett and Swain [1949] reported the initial rate constant for disappearance of $\mathrm{HD}$ as $0.002585^{-1}$.)

Although the hydrolysis reaction occurs rapidly, it seems that a tendency exists in quiescent conditions for HD to polymerize at the HD/water interface, which interferes with transfer of HD to the aqueous solution and thus shields the bulk agent from hydrolysis reactions (MacNaughton and Brewer 1994). The Committee on Alternative Demilitarization Technologies (1993) states: "The chemical problem is that the intermediate products are cyclic or oligomeric sulfonium salts, which are relatively unreactive and which moreover have the potential for slowly reforming mustard." Yang et al. (1987) write that "the enduring toxicity of mustard gas in the environment can hardly be explained unless additional transformations of mustard gas into stable products of similar toxicity exist." They note the toxic effects of H-2TG (see structure in Section 3.5.1) and the less stable H-TG to bolster this argument. As evidence, one may cite an experiment that sought oligomeric sulfonium salts under conditions in which a limited amount of water was in contact with HD for a moderately long period. Equal volumes of $H D$ and water (as a two-phase system) were allowed to stand; after two months at least $50 \%$ of the original HD phase was 
still present. NMR spectrometry indicated that the aqueous phase contained a preponderance of the $\mathrm{H}-2 \mathrm{TG}$ dication, a small amount of thiodiglycol, and a smaller amount of CH-TG cation (Yang et al. 1987).

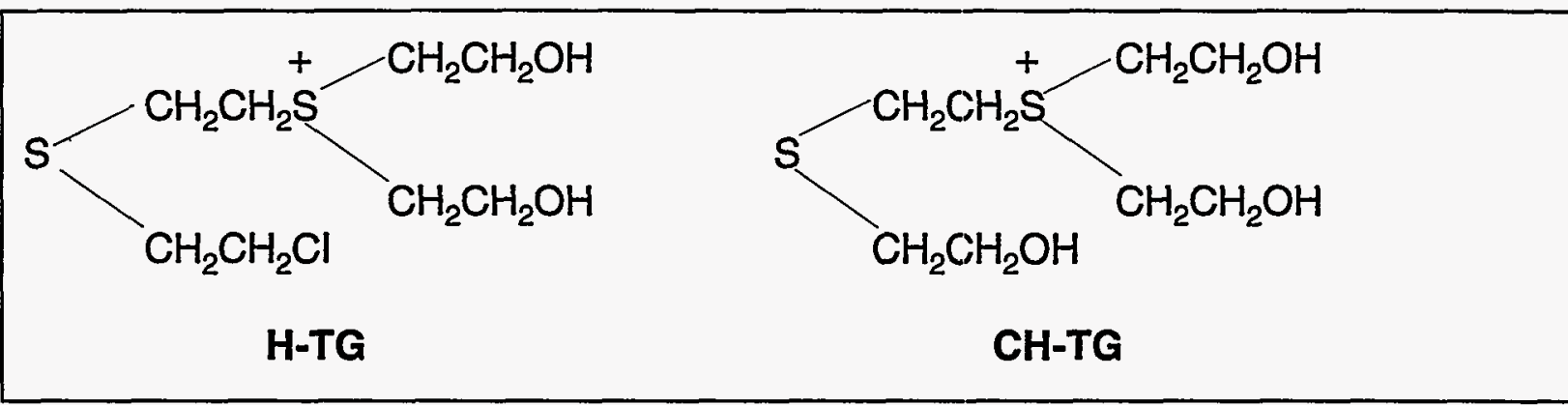

A somewhat different picture is presented by the analysis of products of bulk decontamination of mustard stocks. After 1,000-gallon batches of $H$ stored by the Canadian government were each hydrolyzed with 5,000 pounds of calcium hydroxide and 2,500 gallons of water at $100^{\circ} \mathrm{C}$, they were allowed to stand for several years. Each batch separated into two layers: a colorless to pale yellow fluid and a paste-like yellow-brown sludge. The liquid layers contained five nonionic species (no analytical methods were applied to detect anions such as H-2TG or CH-TG) (Table 9) (D'Agostino and Provost 1985). The sludge contained a large number of sulfur compounds (at least 25 compounds), but most could not be identified; those that were characterized are listed in Table 10. The fact that such compounds survived may indicate that they are less reactive than HD itself. Because cations such as H-2TG, CH-TG, and H-TG could not have been identified by the methods employed, one should not conclude that these toxic entities were absent.

It is not clear how high the ratio of water to HD would have to be to ensure that toxic cations (such as H-2TG, H-TG, $\mathrm{CH}-\mathrm{TG}$, or others not yet identified) would be eliminated by hydrolysis and that HD could not form again. It is likely, however, that use of alkaline aqueous solutions under conditions of decontamination, where the aqueous decontaminant is in large excess, would completely transform HD to essentially nonhazardous products, provided contact times were sufficiently long (e.g., hours).

\title{
Table 9. Organic Solutes in the Liquid Phase Present in Calcium Hydroxide Hydrolysates of $\mathbf{H}$ (Mustard Gas)
}

\author{
Thiodiglycol $\left(\mathrm{C}_{4} \mathrm{H}_{10} \mathrm{O}_{2} \mathrm{~S}\right)$ \\ 1,4-Oxathiane $\left(\mathrm{C}_{4} \mathrm{H}_{8} \mathrm{OS}\right)$ \\ (2-Vinylthio)ethanol $\left(\mathrm{C}_{4} \mathrm{H}_{8} \mathrm{OS}\right.$ ) \\ 1,4-Dithiane $\left(\mathrm{C}_{4} \mathrm{H}_{8} \mathrm{~S}_{2}\right)$ \\ Mustard Chlorohydrin $\left(\mathrm{C}_{4} \mathrm{H}_{9} \mathrm{ClOS}\right)$
}




\title{
Table 10. Organic Solutes Identified in the Chloroform Extracts of the Calcium
} Hydroxide Sludge Hydrolysates of $\mathbf{H}$ (Mustard Gas)

\author{
1,4-Oxathiane $\left(\mathrm{C}_{4} \mathrm{H}_{8} \mathrm{OS}\right)$ \\ (2-Vinylthio)ethanol $\left(\mathrm{C}_{4} \mathrm{H}_{8} \mathrm{OS}\right)$ \\ 1,4-Dithiane $\left(\mathrm{C}_{4} \mathrm{H}_{8} \mathrm{~S}_{2}\right)$ \\ $\mathrm{HD}$ Disulfide ( $\mathrm{Cl}-\mathrm{CH}_{2}-\mathrm{CH}_{2}-\mathrm{S}-\mathrm{S}-\mathrm{CH}_{2}-\mathrm{CH}_{2}-\mathrm{Cl}$ ) \\ HD Trisulfide $\left(\mathrm{Cl}-\mathrm{CH}_{2}-\mathrm{CH}_{2}-\mathrm{S}-\mathrm{S}-\mathrm{S}-\mathrm{CH}_{2}-\mathrm{CH}_{2}-\mathrm{Cl}\right)$ \\ 1,2,5-Trithiepane $\left(\mathrm{C}_{4} \mathrm{H}_{8} \mathrm{~S}_{3}\right)$ \\ 2-Methyl-1,3-oxathiolane $\left(\mathrm{C}_{4} \mathrm{H}_{8} \mathrm{OS}\right)$ \\ 5-Oxa-1,2-dithiepane $\left(\mathrm{C}_{4} \mathrm{H}_{8} \mathrm{OS}_{2}\right)$
}

\subsection{Reactions with Aqueous Hypochlorite Solutions}

Hypochlorite solutions (commonly known as bleach) are efficacious decontaminants but are corrosive (Hovanec et al. 1993). Although they meet the requirements of detoxifying an exposed material, the utility of the material may be sacrificed.

\subsection{1 $G B$ and $G D$}

Commercial aqueous sodium hypochlorite solutions, as well as solutions or suspensions containing calcium hypochlorite, are somewhat alkaline, so that G-agents would be hydrolyzed fairly rapidly in such solutions even without the effects of hypochlorite ion (see Section 5.1.1).

Epstein et al. (1956) studied the strong catalytic effect of aqueous hypochlorite ion on the hydrolysis of GB. They determined the second order rate constant to be $600 \mathrm{M}^{-1} \mathrm{~min}^{-1}$ at $25^{\circ} \mathrm{C}$ and cited a $\mathrm{K}_{\mathrm{a}}$ value of $4 \times 10^{-8}$ for hypochlorous acid ( $\mathrm{HOCl}$ ). If one assumes a sodium hypochlorite ( $\mathrm{MW}=75.5$ ) concentration of $3 \%$ in a commercial bleach sample and a pH of 8 , the observed first-order rate constant $\left(k_{o b s}\right)$ for hypochlorite-catalyzed hydrolysis of GB is calculated to be:

$$
(0.03 \times 1000 / 75.5) \times\left(4 \times 10^{-8} /\left[1 \times 10^{-8}+4 \times 10^{-8}\right]\right) \times 600=191 \mathrm{~min}^{-1}
$$

The half-life would be $0.693 / 191=0.00363 \mathrm{~min}$, or $0.218 \mathrm{~s}$. Thus, the concentration would decrease more than a millionfold in less than $5 \mathrm{~s}$. As the $\mathrm{pH}$ decreases, the concentration of hypochlorite ion decreases and that of $\mathrm{HOCl}$ increases. The latter has no effect on $\mathrm{GB}$ hydrolysis, so decreases in $\mathrm{pH}$ to levels below 8 decrease the decontaminant's effectiveness. Although no analogous study has been conducted with $G D$, the rate constants observed with hypochlorite ion are not expected to be appreciably lower than those for GB. 
Therefore, strong commercial bleach, which contains sodium hypochlorite, and slurries of solid bleaches that contain calcium hypochlorite are very effective in catalyzing the hydrolysis of GB (above) and GD (Eskanow 1978).

Hypochlorite solutions that have stood for any length of time contain chlorate ion as a contaminant because of the following disproportionation reaction (Bodek et al. 1988):

$$
2 \mathrm{HOCl}+\mathrm{OCl}^{-} \rightleftarrows \mathrm{ClO}_{3}^{-}+2 \mathrm{H}^{+}+2 \mathrm{Cl}^{-}
$$

Chlorate ion should not be overlooked as a possible toxicant.

\subsubsection{VX}

Aqueous hypochlorite solutions react differently with $\mathrm{VX}$ at low (acidic) $\mathrm{pH}$ than at high (alkaline) $\mathrm{pH}$. At low pH, $V X$ is protonated on the nitrogen (which greatly enhances the agent's water solubility) and is thus protected at that site (Yang et al. 1992). Also, if the acidic (proton-rich) medium contains chloride ion, the very reactive oxidizing species elemental chlorine $\left(\mathrm{Cl}_{2}\right)$ must be present, that is:

$$
\mathrm{HOCl}+\mathrm{H}^{+}+\mathrm{Cl}^{-} \rightleftarrows \mathrm{Cl}_{2}+\mathrm{H}_{2} \mathrm{O}
$$

Under these circumstances, the reaction is:<smiles>CCOP(C)(=O)CCC(C)[N+](CC)(CC)C(C)C</smiles>

Protonated VX

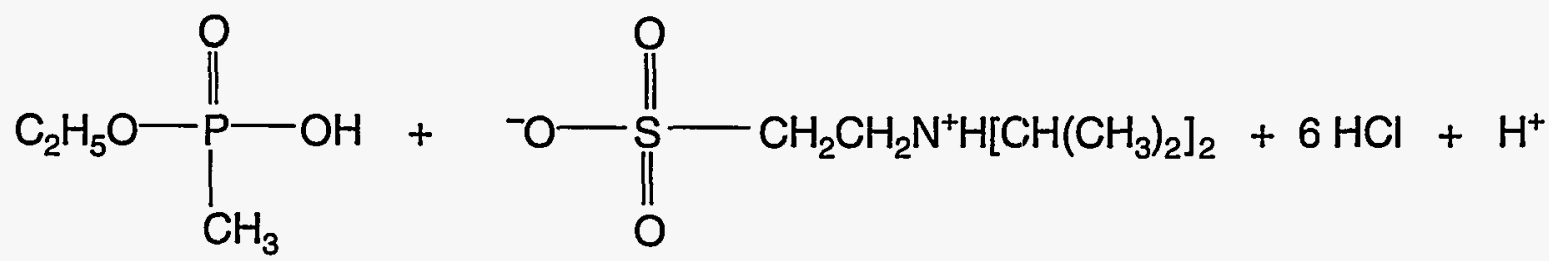

\section{Ethyl methylphosphonic acid EMPA \\ Diisopropyltaurine}


The reaction with gaseous chlorine would probably be useful to destroy VX only on a large scale because facilities would be needed to prevent release of chlorine fumes and to avoid the corrosive effects of that element. In the procedure conducted at Tooele Army Depot (Durst et al. 1988), 100-pound batches of VX were dissolved in $1.5 \mathrm{~N}$ hydrochloric acid (1:3 v/v), and chlorine gas was added (rather than $\mathrm{HOCl}$, as discussed above) until the solution maintained the green color of chlorine. The reaction was rapid and strongly exothermic. The destruction efficiency was determined to be $99.999999 \%$. Among the products found was $\mathrm{N}, \mathrm{N}^{\prime}$-dicyclohexylurea, which was formed from dicyclohexyl carbodiimide, the VX stabilizer mentioned earlier. Even if only $\mathrm{HOCl}$ (and not $\mathrm{Cl}_{2}$ ) is present, the oxidation can proceed in a similar fashion (Yang et al. 1992).

On the moderately basic side, because the unprotonated $\mathrm{VX}$ nitrogen is available, initial oxidative attack by $\mathrm{HOCl}$ (more likely than $\mathrm{OCl}^{-}$) probably occurs preferentially as an electrophilic oxidative attack on the nitrogen. This is logical, because the nitrogen is electron-rich. Unlike other oxidants whose reactions with $\mathrm{VX}$ and model compounds have been examined (Yang et al. 1990), however, the chlorine system (specifically $\mathrm{HOCl} / \mathrm{OCl} / \mathrm{Cl}_{2}$ ) is so complex that the mechanisms involved in chlorinolysis of VX in basic solution have not yet been defined. With sufficient excess hypochlorite, the stoichiometry of the reaction has been reported (Durst et al. 1988) as:

$$
\begin{aligned}
\mathrm{VX}+9 \mathrm{OCl}^{-}+7 \mathrm{OH}^{-} & \rightarrow \mathrm{CH}_{3}-\overbrace{-\mathrm{O}}^{\mathrm{O}}-\mathrm{OC}_{2} \mathrm{H}_{5}+9 \mathrm{Cl}^{-}+5 \mathrm{H}_{2} \mathrm{O} \\
& +\mathrm{NO}_{\mathrm{CH}\left(\mathrm{CH}_{3}\right)_{2}}^{-\mathrm{CH}\left(\mathrm{CH}_{3}\right)_{2}}+2 \mathrm{CO}_{3}=
\end{aligned}
$$

\section{Diisopropylamine}

The reaction was characterized by Durst et al. (1988) as rapid (half-life $=1.5 \mathrm{~min}$ at $\mathrm{pH} 10$ ), having been used for demilitarization of $\mathrm{VX}$. However, it is considered less effective than acid chlorinolysis. The nature of the products is $\mathrm{pH}$-dependent.

With reaction occurring very rapidly in basic chlorinolysis and perhaps in branching sequences, the potential intermediates are numerous, but most might not be stable enough to permit their isolation. Table 11 depicts some intermediates suggested by Yang et al. (1990) with other oxidants. These compounds, about which almost nothing is known, are not likely to explain the formation of diisopropylamine; it would more reasonably have been formed via an $\mathrm{N}$-chlorammonium intermediate in a kind of oxidative fragmentation reaction (Dennis et al. 1967).

It may be concluded that, under appropriate conditions, the diisopropylaminoethylthio moiety of VX can be efficiently and permanently disrupted by chlorinolysis; thus, the $V X$ is completely destroyed. These conditions need to be more precisely defined. 


\section{Table 11. Possible Intermediates in the Chlorinolysîs of VX}<smiles>CCOP(C)(=O)[C-]C[N+]([O-])(C(C)C)C(C)C</smiles><smiles>C=CSP(C)(=O)OCC</smiles><smiles>CC(C)N(O)C(C)C</smiles><smiles>CC(C)[N+]([O-])(O)C(C)C</smiles>

\subsection{3 $\mathrm{H}$ and $\mathrm{HD}$}

The sulfur moiety of HD is readily subject to oxidation. Various forms of hypochlorite-containing materials have been used to effect oxidative reactions, including bleach solution (approximately $3-5 \%$ aqueous sodium hypochlorite, available on grocery shelves); chlorinated lime [approximately $\mathrm{Ca}(\mathrm{Cl})(\mathrm{OCl})$ ]; and "high test hypochlorite" $\left[\mathrm{HTH}\right.$, with the formula $\left.\mathrm{Ca}(\mathrm{OCl})_{2}\right]$. When solid chlorinated lime or HTH are used, reaction with HD may be violently exothermic; with the hypochlorite source in aqueous slurry, reaction is more easily controlled. While the reaction pathway varies with the proportion of reactants and temperature, the mineralization of HD is essentially complete in the presence of a sufficient excess of hypochlorite (Durst et al. 1988):

$$
\left(\mathrm{Cl}-\mathrm{CH}_{2}-\mathrm{CH}_{2}\right)_{2} \mathrm{~S}+14 \mathrm{OCl}^{-} \rightarrow \mathrm{SO}_{4}{ }^{=}+16 \mathrm{Cl}^{-}+4 \mathrm{CO}_{2}+4 \mathrm{H}^{+}+2 \mathrm{H}_{2} \mathrm{O}
$$


Durst et al. (1988) cite an Edgewood Arsenal internal memorandum:

In actual decontamination of HD with calcium hypochlorite, scaled-down amounts, corresponding to ratios of $11.7 \mathrm{lb}$ of HD to $100 \mathrm{lb}$ of HTH in $108 \mathrm{gal}$ of water, were stored for several days at an ambient temperature, treated with sodium thiosulfate to remove excess hypochlorite, and extracted with hexane. The extracts were submitted to GLC [gas-liquid chromatography] with sensitivity of $1 \mathrm{ppm}$ [part per million] of HD in hexane and results indicated essentially complete decontamination.

(Note that a ratio of $19 \mathrm{OCl}: 1 \mathrm{HD}$ was employed here, rather than the minimal 14:1 ratio required by the equation.)

Citing Yurow (1981), MacNaughton and Brewer (1994) point out that, "Theoretically, HD can be completely decomposed to sulfate, chloride and carbon dioxide; however, due to the low solubility of HD in aqueous solutions, poor mixing, or non-stoichiometric proportions, other products such as the sulfoxide or sulfone [see discussion below] are produced." MacNaughton and Brewer go on to say that the reaction of HD is pH-dependent. Reactions in alkaline media "are primarily oxidative, while in acid and neutral solutions, chlorination takes place."

Yang et al. (1992) have also illuminated the subject with a number of observations, as well as a scheme showing some of the early reaction products:

The reactions of chemical agents are so vigorous that ... agents can be converted to less or nontoxic products at the liquid-liquid (bleach solution) or liquid-solid (bleach powder) interface in a few minutes. Solubilization of the agents in the same medium as the bleach is not required. As shown in [the scheme below], HD is converted into a series of oxidation and elimination products. It is believed that the sulfoxide (HD-O) is formed first, followed by sulfone (HD-O $)$ formation. Subsequently, both oxidation products undergo elimination reactions in the strongly basic solution to produce the corresponding monovinyl and divinyl sulfoxides and sulfones, although small amounts of additional products are also present in the final solution.

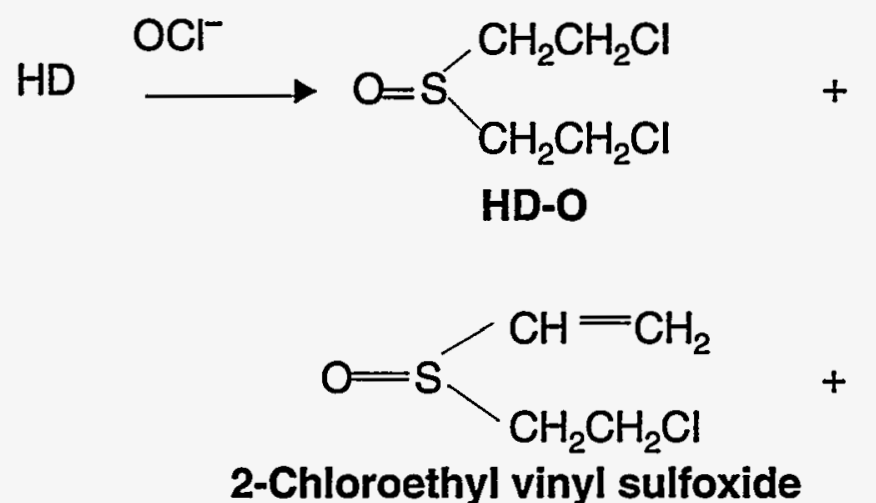<smiles>C=CS(=O)C=C</smiles>

Divinyl sulfoxide<smiles>O=S(=O)(CCCl)CCCl</smiles>

$\mathrm{HD}-\mathrm{O}_{2}$<smiles>C=CS(=O)(=O)CCCl</smiles>

2-Chloroethyl vinyl sulfone<smiles>C=CS(=O)(=O)C=C</smiles> 
According to Yang et al. (1992), the observed rates of oxidation by anionic oxidants (such as OCI) decrease as the polarity of the solvent decreases.

As shown above, information regarding the initial products of mustard oxidation is available; this comes from studies at low hypochlorite-to-mustard ratios, in dilute solution, at short times, or under other circumstances that permit isolation of somewhat reactive and unstable intermediates. When the reaction is pushed to the ultimate, complete mineralization can apparently occur. Evidently, researchers have not been successful in tracking the fate of identified products such as divinyl sulfone in the presence of hypochlorite, as these products are converted to sulfate, carbon dioxide, and water. In part, this reflects the instability of the intermediates. But it may also reflect the diversity of roles that various chlorine species may play. Depending on $\mathrm{pH}$ and on the concentrations of the species involved, the following oxidative chlorine species might be in equilibrium with $\mathrm{OCl}^{-}$(i.e., hypochlorite ion) (Rosenblatt 1975): $\mathrm{Cl}_{2}, \mathrm{Cl}_{3}{ }^{-}, \mathrm{HOCl}, \mathrm{Cl}_{2} \mathrm{O}$, and $\mathrm{H}_{2} \mathrm{OCl}^{+}$. Each may have its own spectrum of reactivity; for example, hypochlorite is a very potent nucleophile as compared to its basicity towards protons, and so one would expect it to attack sulfonium salts like the cyclic sulfonium salt, H-2TG and H-TG, as described in Section 5.1.3. Moreover, some of the reactive uncharged chlorine-containing species (perhaps the less polar ones) may have the ability to cross the aqueous-organic boundary, diffuse, and react with material in the organic phase. To gain insight into such behavior would require developing appropriate hypotheses and designing experiments.

If little is known about mechanisms of reaction of HD with chlorine species, even less is known about reactions of the sulfur-containing impurities of $\mathrm{H}$. Under conditions favoring the mineralization of $\mathrm{HD}$, it is quite probable that the extra, and rather labile, sulfurs of mustard polysulfides would be easily oxidized to sulfate. Other sulfurcontaining impurities, too, would probably be oxidized - if not to sulfate, then at least to relatively harmless sulfoxides, sulfones, or sulfonic acids. With decreasing ratios of hypochlorite to oxidizable sulfur and carbon, the possibility that some toxic species could escape destruction would increase. Nevertheless, given enough contact time, under the usual decontamination conditions, it is likely that $H$ would be completely detoxified - no less so than HD.

In summary, given sufficient contact, hypochlorite solutions are excellent decontaminants for $H$ and $H D$.

\subsection{Significance of Residual Products}

Decontamination solutions are by nature reactive and must be used in excess to ensure complete removal of the highly toxic substances against which they are used. To avoid the possibility of adverse effects on the environment or on potential human receptors, those excess amounts should always be neutralized following their employment; neutralization should be an integral part of the overall decontamination process. Unfortunately, among the residues from decontamination with bleach, chlorate ion is apt to be found (see Section 5.2.1); this ion is not readily destroyed by neutralizing agents (such as sulfite ion) that react so easily with hypochlorite.

Fluoride ion, an inorganic product of GB and GD hydrolysis, is both an essential nutrient and, at higher levels, somewhat toxic. The organic products of basic or hypochlorite-catalyzed hydrolysis of GB and GD, as well as one of the products of VX hydrolysis, are alkyl methylphosphonic acids; although essentially harmless, under certain conditions they could form toxic (cholinesterase-inhibiting) anhydrides. These alkyl methylphosphonic acids are degraded through catalysis by metals in the soil and by soil organisms, at site-specific rates, to methylphosphonic acid; this, like its precursors, is essentially harmless. Degradation of methylphosphonic acid to inorganic phosphate occurs only microbially and at a much slower rate (Kingery and Allen 1994). 
Some of the products of VX hydrolysis are considered quite toxic, which is why alkaline alcoholysis or treatment with hypochlorite is preferred for decontamination.

The products of mustard hydrolysis are harmless when water is present in large enough excess and contact with the aqueous decontaminant is sufficiently prolonged. At lower ratios of water to $H$ or $H D$, toxic intermediates would be of concern.

Alkaline chlorinolysis of VX with sufficient hypochlorite produces two organic products of relatively low toxicity, diisopropylamine and the alkyl methylphosphonic acid. At low $\mathrm{pH}$, the latter is also formed, along with diisopropyltaurine (2-dijsopropylaminoethanesulfonic acid), through the action of $\mathrm{Cl}_{2}$.

Alkaline chlorinolysis of $\mathrm{H}$ or $\mathrm{HD}$ with sufficient hypochlorite causes complete mineralization and is generally considered a much more rapid process than hydrolysis.

Contact with water would cause hydrolysis of the additive $N, N^{\prime}$-disopropylcarbodiimide to $N, N^{\prime}$-diisopropylurea and of the additive $\mathrm{N}, \mathrm{N}^{\prime}$-dicyclohexylcarbodiimide to $\mathrm{N}, \mathrm{N}^{\prime}$-dicyclohexylurea. Under conditions of chlorinolysis, these ureas could become $\mathrm{N}, \mathrm{N}^{\prime}$-dichlorinated. (Direct degradation of the carbodiimides by chlorine-containing oxidants to still other products is a possibility, but no information has been found on the subject.) The $N^{\prime}, N^{\prime}$-dichlorinated compounds would be reduced back to the corresponding ureas during neutralization.

Tributylamine, sometimes an additive for GB, would not be affected by hydrolysis. It would probably be oxidatively dealkylated to dibutylamine and butyraldehyde by hypochlorite (Rosenblatt and Burrows 1982).

It may be concluded that, depending on the exact conditions, chemical decontamination of the agents of concern can form a variety of residual products.

\subsection{ALTERNATIVE LIQUID DECONTAMINATION SYSTEMS}

The variety of possible decontaminants - other than the principal systems discussed above - that could be used to decontaminate various types of substrate materials is large; not all could be addressed in this review, but examples of those types applicable to equipment decontamination systems are presented below.

\subsection{DS-2}

Decontamination Solution 2 (DS-2) is a polar, nonaqueous, nonoxidizing liquid composed of $70 \%$ diethylenetriamine, $28 \% 2$-methoxyethanol, and $2 \%$ sodium hydroxide by weight. It is a general-purpose, ready-touse, reactive decontaminant with long-term storage stability and a large operating temperature range $\left(-26^{\circ}\right.$ to $52^{\circ} \mathrm{C}$ ). With this mixture, the half-lives for $\mathrm{GB}, \mathrm{VX}$, and $\mathrm{HD}$ were found to be $<30 \mathrm{~s},<7 \mathrm{~s}$, and $2.3 \mathrm{~s}$, respectively, at ambient temperature. Unfortunately, because of the low content of sodium hydroxide, DS-2 is subject to rapid depletion, and relatively large volumes must be used to ensure effective decontamination of appreciable quantities of agents. Moreover, it is corrosive to the skin, eyes, and lungs, as well as to paint, plastics, rubber, leather, and wood (Durst et al. 1988; Yang et al. 1992). Moreover, DS-2 is combustible. To minimize corrosion problems, the decontamination contact time of DS-2 with most painted surfaces is limited to $30 \mathrm{~min}$, followed by a water rinse (Yang et al. 1992). 
The reactive component of DS-2 is the strong nucleophile (or "superbase") $\mathrm{CH}_{3}-\mathrm{O}-\mathrm{CH}_{2}-\mathrm{CH}_{2}-\mathrm{O}^{-}$, whose activity is probably enhanced because the counterion, $\mathrm{Na}^{+}$, is complexed by the diethylenetriamine component (Durst et al. 1988; Yang et al. 1992). The main or only product of DS-2 with HD is divinyl sulfide, formed through consecutive elimination reactions (Durst et al. 1988; Yang et al. 1992):

$$
\mathrm{HD} \longrightarrow \mathrm{CH}_{2}=\mathrm{CH}-\mathrm{S}-\mathrm{CH}_{2}-\mathrm{CH}_{2}-\mathrm{Cl} \longrightarrow \mathrm{CH}_{2}=\mathrm{CH}-\mathrm{S}-\mathrm{CH}=\mathrm{CH}_{2}
$$

With G-agents and VX, fluoride or diisopropylaminoethylthio groups (respectively) are initially displaced by $\mathrm{CH}_{3}-\mathrm{O}-\mathrm{CH}_{2}-\mathrm{CH}_{2}-\mathrm{O}^{-}$to give<smiles>COCCOP(C)(=O)O[AlH2]</smiles>

In time, these diesters further decompose to other esters or part-ester anions that are essentially nontoxic (Yang et al. 1992).

Exposure to air or relatively large amounts of water decreases the efficacy of DS-2. Carbon dioxide is absorbed from the air to form carbonate salts that increase the solution's viscosity, and water causes reversion of $\mathrm{CH}_{3}-\mathrm{O}-\mathrm{CH}_{2}-\mathrm{CH}_{2}-\mathrm{O}^{-}$to $\mathrm{CH}_{3}-\mathrm{O}-\mathrm{CH}_{2}-\mathrm{CH}_{2}-\mathrm{OH}$. In the case of $\mathrm{HD}$, depletion of $\mathrm{CH}_{3}-\mathrm{O}-\mathrm{CH}_{2}-\mathrm{CH}_{2}-\mathrm{O}^{-}$prevents the consecutive elimination reactions shown above; instead, substitution with diethylenetriamine occurs to form, more slowly, amine derivatives such as the following (Yang et al. 1992):<smiles>NCCNCCNCCNCCSCCN</smiles>

Basic formulations related to DS-2 include $70 \%$ methyl cellosolve/30\% of a $50 \%$ aqueous sodium hydroxide solution and monoethanolamine. Both are effective against HD. Monoethanolamine, in particular, has the advantage of a high flash point, low toxicity, low cost, stability, and lack of corrosivity to metals (Durst et al. 1988). When combined with 4-N,N-dimethylaminopyridine (sometimes described as a "supernucleophile"), monoethanolamine has been employed for destruction of GB (Durst et al. 1988).

In summary, DS-2 and related materials can be quite effective but are costly and sometimes corrosive decontaminants. 


\subsection{Oxidizing Systems}

\subsubsection{Alkaline Hydrogen Peroxide and Peroxy Acids}

Whereas a significant fraction (13\%) of an $0.01 \mathrm{M}$ solution of $\mathrm{VX}$ in $0.1 \mathrm{M}$ sodium hydroxide is converted to the toxic EA 2192 (see Sections 3.4 and 5.1.2), adding 1\% hydrogen peroxide is sufficient to preclude formation of any EA 2192, with mainly the following transformation occurring:

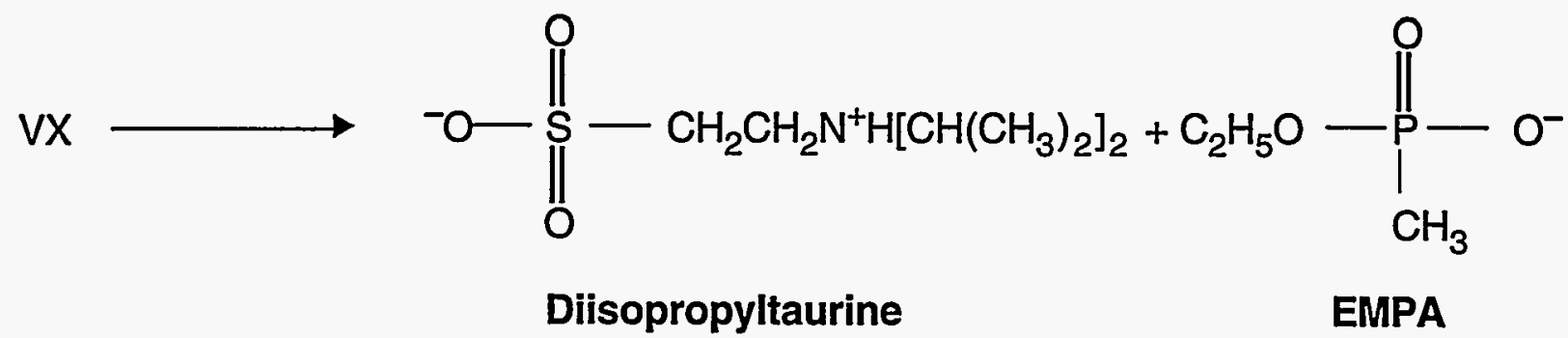

The reaction is also considerably faster in the presence of $1 \%$ hydrogen peroxide (half-life for VX disappearance $=42 \mathrm{~s}$ at $22^{\circ} \mathrm{C}$, as opposed to $1,860 \mathrm{~s}$ in the absence of the peroxide). Because this effect is due to initial nucleophilic attack on phosphorus by the anion of hydrogen peroxide $\left(\mathrm{pK}_{\mathrm{a}}=11.8\right)$, it only occurs at high $\mathrm{pH}$ and not in neutral solution. (Note that in a basic aqueous medium the solubility of VX is poor [Hovanec et al. 1993].) The reaction between EA 2192 and hydrogen peroxide under these conditions is much slower (Yang et al. 1993a). G-agents would be rapidly hydrolyzed not only because of catalysis by the hydroperoxide anion (Larsson 1958) but simply because of the high $\mathrm{pH}$.

Oxone is a commercial mixture, $2 \mathrm{KHSO}_{5}-\mathrm{K}_{2} \mathrm{SO}_{4}-\mathrm{KHSO}_{4}$, the solution of which has a pH of 2.3 at $20^{\circ} \mathrm{C}$. Oxidation of VX by Oxone formed N,N-diisopropylaminoethanesulfonic acid (diisopropyltaurine) and ethyl methylphosphonic acid almost exclusively. With a $0.01 \mathrm{M}$ solution of this oxidant and $5 \times 10^{-4} \mathrm{M} \mathrm{VX}$, the observed half-life for $\mathrm{VX}$ was $19 \mathrm{~min}$. At the low $\mathrm{pH}$ (high acidity) of the reaction mixture, $\mathrm{VX}$ dissolved readily and the nitrogen was shielded, through protonation, from oxidation to the $\mathrm{N}$-oxide or products thereof (Yang et al. 1990). EA 2192 was not formed at all, which might be expected because the initial oxidation of the sulfur made the P-S bond extremely vulnerable to hydrolytic cleavage. Because of the high effectiveness of Oxone towards VX, this oxidant was tested against $\mathrm{HD}$. In a solution of $0.05 \mathrm{M} \mathrm{HD}, 0.1 \mathrm{M}$ Oxone, and $15 \mathrm{vol} \% \mathrm{~N}$-methyl-2-pyrrolidone (added to help dissolve the HD), HD was oxidized immediately to the sulfoxide (see Section 5.2.3), which converted within an hour to the sulfone (Yang et al. 1992). Hovanec et al. (1993) have observed that $N$-methyl-2-pyrrolidone at a level of $<20 \%$ does little to improve the solubility of $\mathrm{HD}$ and that it causes the Oxone to decompose. Oxone does not oxidize G-agents, but it is acidic enough to catalyze their slow hydrolysis (Yang et al. 1992).

Like Oxone, certain other peroxygen-containing oxidants are effective against HD and VX, notably m-chloroperoxybenzoic acid and magnesium monoperoxyphthalate (Yang et al. 1992). It should be pointed out that organic peroxides tend to be dangerously unstable. 


\subsubsection{Aqueous Fichlor}

Fichlor (sodium $\mathrm{N}, \mathrm{N}^{\prime}$-dichloroisocyanurate monohydrate) is quite stable in water, as compared to calcium hypochlorite, though its stability is $\mathrm{pH}$-dependent. It has been used for laboratory-scale decontamination of VX (Durst et al. 1988). The products with VX are EMPA and diisopropyltaurine (Yang et al. 1992). Durst et al. (1988) record that Fichlor "was reported for destruction of HD, GD, and VX on paint surfaces and the test results were compared to those for other decontaminating agents." But Yang et al. (1992) observe that, "Since the pH of the Fichlor solution is about 6 , detoxification of G-agents by this method is too slow to be effective."

\subsubsection{Aqueous Chlorine Dioxide}

Durst et al. (1988) have cited a 1969 internal Edgewood Arsenal research report to the effect that chlorine dioxide, $\mathrm{ClO}_{2}$, reacts (rapidly) with VX to give carbon dioxide, carbonyl sulfide, sulfate ion, EMPA, and diisopropylamine. They have pointed out concerns with the "explosive nature" of the gas as a deterrent to large-scale work. However, chlorine dioxide is used extensively and safely on a large scale for paper pulp bleaching and for disinfecting municipal potable water supplies; the gas is generated in situ. There is considerable potential for chlorine dioxide to be used in the final step of the decontamination of equipment with basic aqueous solutions to ensure complete destruction of VX and any EA 2192 that might potentially be present in decontamination waste streams. Basic research on the reactivity of chlorine dioxide with amines (the class to which VX belongs) is summarized by Rosenblatt and Burrows (1982). Because of its small molecular size and low molecular weight, and because it is neither ionic nor very polar, chlorine dioxide might be able to penetrate into the interior of porous organic materials, such as paint or plastics, where it could react with absorbed agent. The potential exists (though no research has been done on this) for rapid chlorine dioxide reaction with mustard and related species (such as dithiane, thioxane, and thiodiglycol), though not with G-agents.

\subsubsection{MCBD Microemulsion and German C8 Emulsion}

The multipurpose chemical, biological decontaminant (MCBD) microemulsion consists of $60 \%$ water (the continuous phase), $7 \%$ tetrachloroethylene, $4 \%$ Fichlor, $28 \%$ of the surfactant $n$-cetyl trimethylammonium chloride, a small amount of the cosurfactant and phase transfer catalyst tetrabutylammonium hydroxide, $0.1 \%$ sodium 2-nitro-4-iodoxybenzoate (IBX, a nucleophilic catalyst for G-agent — but not VX — hydrolysis), and sodium borate buffer to maintain a pH of about 10 (Yang et al. 1992). This mixture was designed to decontaminate all agents of interest.

The German emulsion (C8) is composed, by weight, of $15 \%$ tetrachloroethylene (the continuous phase), $76 \%$ water, $1 \%$ anionic surfactant, and $8 \%$ calcium hypochlorite. Because the continuous phase is organic, this emulsion "is noncorrosive and as good a solvent as pure tetrachloroethylene for the thickened agents. In addition, C8 can penetrate into paint to dissolve and react with imbedded agent without damaging the paint. When the emulsion is sprayed, a thin, coherent film is formed on the surface to allow sufficient residence time for reaction with the agents" (Yang et al. 1992).

\subsubsection{DANC}

Typically, DANC (decontaminating agent, noncorrosive) consisted of about $7 \%$ of 1,3-dichloro5,5-dimethylhydantoin or of 1,1'-methylenebis(3-chloro-5,5-dimethylhydantoin), both of which are chlorinating agents, in 1,1,2,2-tetrachloroethane (Chemical and Biological Defense Information Analysis Center 1993); there 
were evidently several formulations. DANC was designed for use against $H / H D$, although it should also be effective against VX but not against G-agents. The chlorinating agent reportedly reacts with HD in aqueous solution "to give a sulfilimine derivative." Because 1,1,2,2-tetrachloroethane is toxic and has a corrosive effect on painted surfaces and rubber, DANC has become obsolete (Durst et al. 1988).

\subsubsection{Future Directions}

Yang et al. (1992) discuss decontaminants of the future, which would be noncorrosive; biodegradable; capable of penetrating agent thickeners; and effective against $H D, V X, G B$, and GD. Strong bases or calcium hypochlorite dissolved in mixtures of water with biodegradable $\mathrm{N}$-alkyl-2-pyrrolidones seem to fit the requirements. It would appear that the dielectric constants of $\mathrm{N}$-alkyl-2-pyrrolidones are high enough that these solvents should not decrease the rate-limiting formation of cyclic sulfonium salts by HD in aqueous mixtures. Also, these cyclic amides should resist oxidation, chlorination, and hydrolysis. An example of one such decontaminant (decontaminating agent: multipurpose [DAM]) is $4 \%$ (by weight) of calcium hypochlorite in an equivolume mixture of $\mathrm{N}$-cyclohexyl-2pyrrolidone and water. (According to Hall [1994], the mixture is not stable and may undergo exothermic decomposition.) The DAM development project was terminated both because of deficiencies in DAM and because the majority of serious problems associated with DS-2 have been corrected (Harlacker et al. 1993).

\subsection{ADVANTAGES AND DISADVANTAGES OF THE VARIOUS SYSTEMS}

One disadvantage of the major decontaminants is their limited ability to penetrate many of the substrate materials (such as paint and plastics) in which the agents of concern might be found. This is especially true of water-based decontaminants. Sufficiently long contact of the decontaminants with such media, along with adequate liquid shearing, should permit diffusion of agent into the decontaminant.

Purely aqueous base has the advantage of introducing no potentially hazardous chemicals other than sodium hydroxide or carbonate, which can be easily neutralized to dilute brines. It would be most effective against GB and GD. With VX, dissolution would not be rapid, a very high concentration of hydroxide would be required to effect a reasonable reaction half-life (e.g., about $3 \mathrm{~min}$ at $\mathrm{pH} 13.5$ and $25^{\circ} \mathrm{C}$ ), and the toxic and stable EA 2192 would be formed; however, the latter, along with mercaptan, organic sulfide, organic disulfide, and amine, could probably be destroyed readily and rapidly by treating the collected waste with chlorine dioxide bubbled in as a gas. Provided there was sufficient base to neutralize evolved hydrochloric acid, $\mathrm{pH}$ would have virtually no effect on the rate of $H / H D$ hydrolysis. In any case, the rate of chemical reaction would be governed by the extremely low rate of solution in water. Aqueous base is not to be recommended for decontaminating VX (except if post-treatment is added to destroy the EA 2192 that would be present) or $\mathrm{H} / \mathrm{HD}$.

The efficacy of aqueous base towards $V X$ is notably enhanced by adding hydrogen peroxide. (This is probably not true of its reactivity with $\mathrm{H} / \mathrm{HD}$.) Sodium perborate may be used in place of hydrogen peroxide (Hovanec et al. 1993).

Sodium hydroxide in mostly alcoholic solution ( $90 \%$ alcohol or more) would be an effective but unnecessarily powerful decontaminant for $\mathrm{GB}$. It might have some advantage over purely aqueous base for $\mathrm{GD}$, which is less soluble in water than GB. It would be particularly effective against $V X$ for reasons of solubility because it reacts rapidly and because EA 2192 is not among the observable products. The presence of alcohol increases H/HD 
solubility but depresses the rate of hydrolysis. Costs of alcoholic solvents must also be considered. The toxicity of simple alcohols, such as methanol, is probably of little concern because they are quickly degraded by soil microorganisms. Solutions of sodium hydroxide in 90 to $100 \%$ alcohol would be recommended for GD and VX decontamination and would be highly effective (though unnecessarily costly) for GB. They would not be recommended for H/HD.

Somewhat alkaline aqueous hypochlorite solutions or slurries should be acceptably effective against G-agents (although constituting somewhat of an overkill), V-agents, and H/HD; they are, however, rather corrosive (Hovanec et al. 1993). Collected decontaminating solutions would have to be neutralized, probably with stoichiometric amounts of sulfite.

Acidic solutions of hypochlorous acid would react rapidly with $V X$ and be stoichiometrically more efficient than alkaline hypochlorite in converting the agent to harmless products. However, such solutions would tend to emit toxic and corrosive chlorine fumes that would have to be addressed by suitable engineering arrangements, including postdecontamination neutralization. Acidic chlorine solutions would not be very effective against $\mathrm{G}$-agents; they would probably chlorinate $\mathrm{H} / \mathrm{HD}$ to form products about which little is known.

Aqueous Fichlor is considered quite effective as a decontaminant for VX and perhaps for HD, but not for G-agents. As with other chlorinating decontaminants, the residual oxidizing power of excess Fichlor would have to be neutralized.

Chlorine dioxide rapidly detoxifies VX but does not react at all with G-agents. Its reactivity towards $H / H D$ and their derivatives has not been tested. Because chlorine dioxide is a gas, its solutions can emit toxic and corrosive fumes requiring engineering controls. Reputed explosion hazards can easily be minimized. Excess chlorine dioxide can be reduced to either chlorite or chloride ion.

DS-2 solution is capable of decontaminating all the agents, though it has a limited capacity; it dissolves or softens some polymers and coatings, and it is combustible.

The tetrachloroethylene-based, active-chlorine-containing emulsions seem to be effective against the agents of concern but are toxic and expensive.

DANC was designed to use against $H / H D$ but will also detoxify $V X$, though not GB or GD. It is damaging to many materials. The presence of 1,1,2,2-tetrachloroethane makes it toxic as well as costly.

The proposed new decontaminant, DAM, was thought to be effective, safe, and environmentally acceptable but is evidently too unstable to be kept for any length of time. It would probably also be expensive.

\subsection{TOXIC REBOUND}

The term "toxic rebound" is used primarily in connection with the generation of a small amount of GB when a brine containing the hydrolyzed salts from detoxification of GB with sodium hycloxide is spray dried (Epstein et al. 1977). The more concentrated the salt solutions are, the higher the acidity of the solution being spray dried and the higher will be the yield of GB. It was possible to generate low levels of $G B$ even by mixing pure fluoride and methylphosphonate solutions (rather than by using GB hydrolysates). Epstein et al. (1977) observed that under 
the spray-drying conditions in use, high concentrations of carbon dioxide were in contact with the material being treated, thus increasing the acidity of the brines. Heating the spray-dried solids also formed GB. The reformation phenomenon is of concern only when concentrations of the participating chemical species are high and heat is applied; it should not occur when these species are in dilute aqueous solution (especially high pH) or sparsely distributed among soil particles. Harris et al. (1982) developed an expression for the equilibrium between fluoride, isopropyl methyiphosphonate ion, hydroxide ion, and GB with the objective of defining conditions under which the aqueous $G B$ equilibrium concentration would not exceed $10^{-8} \mathrm{M}$, which they considered a safe limit:

$$
[\mathrm{GB}]=10^{-19}\left[\mathrm{~F}^{-}\right]\left[\mathrm{MP}^{-}\right] /\left[\mathrm{OH}^{-}\right]^{2}
$$

At pH 7, then, $[\mathrm{GB}]=10^{-5}\left[\mathrm{~F}^{-}\right]\left[\mathrm{IMP}^{-}\right]$, and, to conform to the safety criterion, $\left[\mathrm{F}^{-}\right]\left[\mathrm{IMP}^{-}\right]<10^{-8} / 10^{-5}=10^{-3} \mathrm{M}^{2}$. This would indicate an initial safe $\mathrm{GB}$ concentration of $(0.001)^{0.5}=0.032 \mathrm{M}$, or $4.5 \mathrm{~g}$ per liter of decontaminating solution. For $\mathrm{pH} 8$, that value would be increased a hundredfold. Dispersion of the $\mathrm{GB}$ hydrolysate in groundwater would dramatically reduce the potential level of reformed GB because the concentrations of both fluoride and methyiphosphonate would be decreased. Complexation of fluoride with soil minerals would further diminish the potential for $\mathrm{GB}$ reformation.

In addition to the explanation for the detection of $G B$ in brines resulting from GB hydrolysis, there is the strong possibility, demonstrated experimentally, of GB forming in neutralized or slightly acidic chloroform — but not methylene chloride - extracts of brines containing fluoride and isopropyl methylphosphonate (Beaudry et al. 1993). This represents an artifact in the analysis of brines by means of extraction followed by chromatography.

High concentrations of alkyl methylphosphonates (from hydrolysis of G-agents or VX) in dry soil might form somewhat toxic anhydrides; this would not occur to a serious degree in aqueous solution.

It is extremely unlikely that VX, once hydrolyzed, would form again under any conditions. However, one of the major hydrolysis products, diisopropylaminoethanethiol, would easily be air-oxidized to a reputedly vesicant disulfide. One sure way to prevent the occurrence of the latter product (as well as of EA 2192) is to decontaminate with chlorine, hypochlorite, or chlorine dioxide.

Thiodiglycol, the hydrolysis product of HD, can form HD by reaction with hydrochloric acid. In fact, a preparative method for HD consists of holding a mixture of one volume of thiodiglycol with three volumes of concentrated hydrochloric acid at $60^{\circ} \mathrm{C}$ for $30 \mathrm{~min}$ and collecting the heavy oil that precipitates (Bent 1947). The equilibrium concentration of HD is far lower near neutral $\mathrm{pH}$, even when chloride ion is present (as it would especially be in certain saline soils). Unfortunately, the complex equilibria involved here have apparently not been adequately researched. It may be surmised that, over time, there should be a tendency to form irreversibly such products as oxathiane, 1,2-dichloroethane, and dithiane, thereby gradually lowering the potential for forming HD. It is true, as has already been reported in Section 3.5.2, that mustard can be formed (presumably in small yield) when its decomposition products - 1,4-dithiane and excess 1,2-dichloroethane - are heated in a sealed tube. However, such a reaction would not occur in the open because the volatile chlorocarbon would escape too quickly. Reformation of HD, then, is not at all likely under the conditions of basic hydrolysis, although more possible (to a small degree) at neutral $\mathrm{pH}$. Oxidation with excess hypochlorite makes such a reaction utterly impossible.

Toxic rebound is primarily a problem with large-scale decontamination activities and has little real-world relevance to the delisting process. Use of hypochlorite decontamination, moreover, completely precludes toxic rebound for $H D$ and $V X$. 


\subsection{REFERENCES}

Bartlett, P.D., and C.G. Swain, 1949, Kinetics of Hydrolysis and Displacement Reactions of $\beta, \beta^{\prime}-$ Dichlorodiethyl Sulfide (Mustard Gas) and $\beta$-Chloro- $\beta$-hydroxydiethyl Sulfide (Mustard Chlorohydrin), J. Am. Chem. Soc., 71:1406-1415 (as cited by Yang et al. 1986).

Beaudry, W.T., J.H. Buchanan, D.K. Rohrbaugh, J.B. Samuel, L.L. Szafraniec, and J.R. Ward, 1993, Analysis of Decontamination Solutions of G Agents to Detect Reformalion of Agent, ERDEC-TR-005, Edgewood Research, Development and Engineering Center, Aberdeen Proving Ground, MD 21010, January. AD-A264308.

Bell, E.V., G.M. Bennett, and A.L. Hock, 1927, Decomposition of Some Halogenated Sulphides, and the Nature of the "Polymeric" Ethylene Sulphides, J. Chem. Soc., 1803-1809.

Bent, H.E., 1947, The Laboratory Preparation of Mustard Gas, Science, 106. 374-375.

Bodek, I., W.J. Lyman, W.F. Reehl, and D.H. Rosenblatt, 1988, Environmental Inorganic Chemistry: Properties, Processes, and Estimation Methods, Pergamon Press, New York.

Britton, K.B., and C.L. Grant, 1988, Prediction of Octanol-Water Partition Coefficients of Organophosphonates. Evaluation of Structure-Function Relationships, Special Report 88-11, U.S. Army Corps of Engineers Cold Regions Research \& Engineering Laboratory, Hanover, NH, August.

Brooks, M.E., W.T. Beaudry, P.C. Bossle, R.E. Herd, J.M. Lochner, S.G. Pleva, J.H. Reeder, D.K. Rohrbaugh, T.E. Rosso, L.J. Szafraniec, and L.L. Szafraniec, 1994, Operation Safe Removal: Spring Valley, Washington, D.C., Analytical Results: January-February 1993, ERDEC-SP-008, Edgewood Research, Development and Engineering Center, Aberdeen Proving Ground, MD 21010-5423, July. AD-A267804.

Carpenter, T.J., and T.E. Hill, 1988, Methods for Demolition of Building E5625, prepared by Battelle Columbus Division, Columbus, Ohio, for the Chemical Research, Development and Engineering Center, Aberdeen Proving Ground, MD, under Contract DAAA15-87-D-0011, Task 6, November.

Chemical and Biological Defense Information Analysis Center (CBIAC), 1993, Nomenclature Guide for the Chemical Defense Materials Database (CDMD), Version 4.1, Edgewood, MD, August.

Clark, D.N., 1989, Review of Reactions of Chemical Agents in Water (Task 80), Final Report, prepared by Battelle Columbus Division, Columbus, Ohio, for the U.S. Army Medical Research and Development Command, Fort Detrick, Frederick, MD, under Army Project No. 88PP8847. AD-.4213287.

Committee on Alternative Demilitarization Technologies, 1993, Alternative Technologies for the Destruction of Chemical Agents and Munitions, Board on Army Science and Technology, Commission on Engineering and Technical Systems, National Research Council, Washington, DC.

Cooper, W.A., 1990, A Data Base on Persistent CW Agenis on Terrain, CRDEC-TR-204, Chemical Research, Development and Engineering Center, Aberdeen Proving Ground, MD. AD-B149 284. 
Dacre, J.C., and W.D. Burrows, 1988, Recommended Field Drinking Water Criteria for Chemical Agent Sulfur Mustard, Technical Report 8816, U.S. Army Biomedical Research \& Development Laboratory, Fort Detrick, Frederick, MD, December. AD-A221745.

D'Agostino, P.A., and L.R. Provost, 1985, The Identification of Compounds in Mustard Hydrolysate, Suffield Report No. 412, Defence Research Establishment, Suffield, Canada, April. CB-0008053.

Demek, M.M., G.T. Davis, W.H. Dennis, Jr., A.L. Hill, R.L. Farrand, N.P. Musselman, R.J. Mazza, W.D. Levine, D.H. Rosenblatt, and J. Epstein, 1970, Behavior of Chemical Agents in Seawater, Edgewood Arsenal Technical Report EATR 4417, Edgewood Arsenal Research Laboratories, Edgewood Arsenal, MD. AD-873242.

Dennis, W.H., Jr., L.A. Hull, and D.H. Rosenblatt, 1967, Oxidations of Amines. IV. Oxidative Fragmentation, J. Org. Chem., 32:3783-3787.

Durst, H.D., E.W. Sarver, H.W. Yurow, W.T. Beaudry, P.A. D'Eramo, D.M. Jackson, H. Salem, L.L. Szafraniec, F.P. Ward, and J.R. Ward, 1988, Support for the Delisting of Decontaminated Liquid Chemical Surety Materials as Listed Hazardous Waste from Specific Sources (State) MD02 in COMAR 10.51.02.16-1, CRDEC-TR009, Chemical Research, Development and Engineering Center, Aberdeen Proving Ground, MD, November. AD-A271648.

Edgewood Arsenal, 1968, Purchase Description, Chemical Agent, GB, Redistilled 196-21-86, FSC 1365, June 14.

Edgewood Arsenal, 1974, Chemical Agent Data Sheets, Volume I, Department of the Army, Aberdeen Proving Ground, MD, December. AD-B028222.

Epstein, J., V.E. Bauer, M. Saxe, and M.M. Demek, 1956, The Chlorine-Catalyzed Hydrolysis of Isopropyl Methylphosphonofluoridate (Sarin) in Aqueous Solution, J. Am. Chem. Soc., 78:4068-4071.

Epstein, J., J.J. Callahan, and V.E. Bauer, 1974, The Kinetics and Mechanisms of Hydrolysis of Phosphonothiolates in Dilute Aqueous Solution, Phosphorus, 4:157-163.

Epstein, J., G.T. Davis, L. Eng, and M.M. Demek, 1977, Potential Hazards Associated with Spray Drying Operations, Environ. Sci. Technol., 11:70-75.

Eskanow, K., 1978, Study on the Reaction of Methyl-O-Pinacolin-Phosphine Fluoride, Soman, with Calcium Hypochlorite in Aqueous Solution, Biul. Wojsk. Akad. Tech., 27:119-127 (1978); Chem. Abstr., 90:44410w (1979).

Fuson, R.C., R.E. Foster, and R.D. Lipscomb, 1946a, Levinstein Mustard Gas. VI. The Mode of Formation, J. Org. Chem., 11:504-509.

Fuson, R.C., R.D. Lipscomb, B.C. McKusick, and L.J. Reed, 1946b, Thermal Conversion of Mustard Gas to 1,2-bis(2-Chloroethylthio)ethane and bis[2-(2-Chloroethylthio)-ethyl] Sulfide, J. Org. Chem., 11:513-517. 
Fuson, R.C., C.C. Price, D.M. Burness, R.E. Foster, W.H. Hatchard, and R.D. Lipscomb, 1946c, Levinstein Mustard Gas. IV. The bis(2-Chloroethyl) Polysulfides, J. Org. Chem., 11:487-498.

Hall, D., 1994, Personal communication with D.H. Rosenblatt, Stability of N-alkylpyrrolidone/ hypochlorite mixtures, Dugway Proving Ground, Dugway, UT. December 19.

Harlacker, S.R., V.D. Auber, D.W. Macfarlane, T.M. Sotamayor, T.N. Nguyen, P.W. Bartram, J.W. Hovanec, J. Albizo, and V. Henderson, 1993, Demonstration and Validation Phase Test and Evaluation of the Decontaminating Agent: Multipurpose (DAM), ERDEC-TR-125, Edgewood Research, Development and Engineering Center, Aberdeen Proving Ground, MD, November. AD-B181883.

Harris, J.M., K. DeBruin, J.E. Gebhart, B.C. Garrett, and T.M. Prociv, 1982, GB.NaOH Neutralization Mechanism and Analytical Procedures Evaluation, Final Report, March-May 1982, DRXTH-SE-CR-82161, prepared for the U.S. Army Toxic and Hazardous Materials Agency under Contract No. DAAG29-81-D-0100, by Battelle Columbus Laboratories, Columbus, OH, July. AD-B067290.

Headquarters, Departments of the Army, Navy, and Air Force, 1990, Potential Military Chemical/Biological Agents and Compounds, Army Field Manual No. 3-9, Commandant, U.S. Army Chemical School, ATTN: ATZNCM-NF, Fort McClellan, AL, December.

Healy, T.V., 1948, Kinetics of the Hydrolysis of Pinacolyl Methanefluorophosphonate, Porton Technical Paper No. 79, Porton Down, UK, November.

Hovanec, J.W., L.L. Szafraniec, J.M. Albizo, W.T. Beaudry, V.D. Henderson, Y.-C. Yang, B.K. Maclver, and L. Procell, 1993, Evaluation of Standard and Alternative Methods for the Decontamination of VX and HD in Chemical Agent Disposal Facilities, ERDEC-TR-054, Edgewood Research, Development and Engineering Center, Aberdeen Proving Ground, MD, April. AD-A265 870.

Kingery, A.F., and H.E. Allen, 1993, Extraction and Chromatographic Development of Selected Organophosphorus Compounds from Soil and Aqueous Media, Final Report, prepared for the U.S. Army Environmental Center under Contract No. DAAL03-86-D-0001 by the University of Delaware, Newark, DE, January.

Kingery, A.F., and H.E. Allen, 1994, Environmental Fate of Alkyl Methylphosphonates Arising from Chemical Surety Material (CSM) and Potential Non-CSM Sources in Soil and Aqueous Media, Final Report, prepared for the U.S. Army Environmental Center under Contract No. DAAL03-86-D-0001 by the University of Delaware, Newark, DE, March.

Kingery, A.F., and H.E. Allen, 1995, The Environmental Fate of Organophosphorus Nerve Agents: $A$ Review, Toxicology and Environmental Chemistry, 47:155-184.

Kinnear, A.M., and J. Harley-Mason, 1943, The Composition of Levinstein H, Porton Report 2537, Military Intelligence Division, Great Britain, September.

Larsson, L., 1958, A Kinetic Study of the Reaction of isoPropoxy-methyl-phosphoryl Fluoride (Sarin) with Hydrogen Peroxide, Acta Chem. Scand., 12:723-730. 
Lyman, W.J., and C.P. Loreti, 1987, Prediction of Soil and Sediment Sorption for Organic Compounds, Final Report, Arthur D. Little, Inc., Cambridge, MA, prepared for the Monitoring and Data Support Division, Office of Water Regulations and Standards, U.S. Environmental Protection Agency, under Contract No. 68-01-6951, Task 15.

Lyman, W.J., W.F. Reehl, and D.H. Rosenblatt, 1990, Handbook of Chemical Property Estimation Methods: Environmental Behavior of Organic Compounds, American Chemical Society, Washington, DC.

MacNaughton, M.G., and J.H. Brewer, 1994, Environmental Chemistry and Fate of Chemical Warfare Agents, Final Report, SwRI Project 01-5864, Southwest Research Institute, San Antonio, TX, March.

Ogston, A.G., E.R. Holiday, J. St. L. Philpot, and L.A. Stocken, 1948, The Replacement Reactions of $\beta, \beta^{\prime}-$ Dichlorodiethyl Sulphide and of Some Analogues in Aqueous Solution: The Isolation of $\beta$-Chloro- $\beta^{\prime}-H y d r o x y$ Diethyl Sulphide, Trans. Faraday Soc., 44:45-52.

Penski, E.C., 1993, The Properties of Di-(2-chloroethyl) Sulfide. I. Vapor Pressure Review and Analysis, Technical Report ERDEC-TR-043, Edgewood Research, Development and Engineering Center, Aberdeen Proving Ground, MD, April. AD-A267059.

Preston, J.M., and V. Starrock, 1983, Partial Vapor Pressures and Activity Coefficients of GB and GD in Aqueous Solution, Report 893, Chemical Defence Section, Protective Sciences Division, Defence Research Establishment, Ottawa, Canada, September. AD-A140644.

Rohrbaugh, D.K., 1994, Personal Communication with D.H. Rosenblatt, Analyses of mustard gas from an old munitions sample and from a sample of stored distilled mustard, Edgewood Research, Development and Engineering Center, November.

Rosenblatt, D.H., 1975, "Chlorine and Oxychlorine Species Reactivity with Organic Substances," in D.J. Johnson, ed., Disinfection: Water and Wastewater, Ann Arbor Science, Ann Arbor, MI.

Rosenblatt, D.H., and E.P. Burrows, 1982, "Oxidation of Amines," in S. Patai, ed., The Chemistry of Functional Groups, Supplement F: The Chemistry of Amino, Nitroso and Nitro Compounds and Their Derivatives, Part 2, Chapter 25, Interscience Publications, John Wiley \& Sons, New York.

Rosenblatt, D.H., T.A. Miller, J.C. Dacre, I. Muul, and D.R. Cogley, eds., 1975, Problem Definition Studies on Potential Environmental Pollutants. II. Physical, Chemical, Toxicological, and Biological Properties of 16 Substances, Technical Report 7509, U.S. Army Medical Bioengineering Research and Development Laboratory, Fort Detrick, Frederick, MD. AD A030428.

Rosenthal, R.W., R. Proper, and J. Epstein, 1956, The Distribution of Some Phosphonofluoridates between Organic Solvents and Water, J. Phys. Chem., 60:1,596-1,598.

Sage, G.W., and P.H. Howard, 1989, Environmental Fate Assessments of Chemical Agents HD and VX, CRDEC-CR-034, prepared by Syracuse Research Corporation, Syracuse, NY, for the Chemical Research, Development and Engineering Center, Aberdeen Proving Ground, MD, June. AD-B135352. 
Samuel, J.B., E.C. Penski, and J.J. Callahan, 1983, Physical Properties of Standard Agents, Candidate Agents, and Related Compounds at Several Temperatures (U), Special Publication ARCSL-SP-83015, Chemical Systems Laboratory, Aberdeen Proving Ground, MD, June.

Small, M.J., 1983, Soil Detection Limits for Potential Chemical Warfare-Related Contaminants at Fort McClellan Alabama, Technical Report 8208, U.S. Army Medical Bioengineering Research and Development Laboratory, Fort Detrick, Frederick, MD, May. AD-B077091L.

Small, M.J., 1984, Compounds Formed from the Chemical Decontamination of $H D, G B$, and VX and their Environmental Fate, U.S. Army Medical Bioengineering Research and Development Laboratory, Fort Detrick, Frederick, MD, Technical Report 8304, June. AD-A149515.

Szafraniec, L.J., L.L. Szafraniec, W.T. Beaudry, and J.R. Ward, 1990, On the Stoichiometry of Phosphonothiolate Ester Hydrolysis, CRDEC-TR-212, U.S. Army Chemical Research, Development and Engineering Center, Aberdeen Proving Ground, MD, July. AD-A225952.

Szafraniec, L.L., W.T. Beaudry, and Y.-C. Yang, 1993, Hydrolysis of VX and S-2-(Diisopropylamino)ethyl Methylphosphonothioic Acid (EA 2192) in Super-Alkaline Solution, Proceedings, 1992 ERDEC Scientific Conference on Chemical Defense Research, Aberdeen Proving Ground, MD, November 17-20, 1992.

U.S. Army, 1964, Military Specification. Chemical Agent, VX, Mill-C-51105A(MU) (as cited by Small 1983).

U.S. Army, 1969, Military Specification. Chemical Agent, GB, MIL-C-10758D(MU) (as cited by Small 1983).

U.S. Environmental Protection Agency, 1986, Superfund Public Health Evaluation Manual, Appendix C, EPA 540/1-86/060, Office of Emergency and Remedial Response, Office of Solid Waste and Emergency Response, U.S. Environmental Protection Agency, Washington, DC, October.

Yang, Y.-C., J.R. Ward, and T. Luteran, 1986, Hydrolysis of Mustard Derivatives in Aqueous AcetoneWater and Ethanol-Water Mixtures, J. Org. Chem., 51:2756-2759.

Yang, Y.-C., L.L. Szafraniec, W.T. Beaudry, and J.R. Ward, 1987, Sulfonium Chlorides Derived from 2Chloroethyl Sulfides. I. Formation and Magnetic Resonance Identification in Water, CRDEC Technical Report TR88008, Chemical Research, Development and Engineering Center, Aberdeen Proving Ground, MD, October. AD-A187594.

Yang, Y.-C., L.L. Szafraniec, W.T. Beaudry, and D.K. Rohrbaugh, 1990, Oxidative Detoxification of Phosphonothiolates, J. Am. Chem. Soc., 112:6621-6627.

Yang, Y.-C., J.A. Baker, and J.R. Ward, 1992, Decontamination of Chemical Warfare Agents, Chem. Rev., 92:1729-1743.

Yang, Y.-C., L.L. Szafraniec, W.T. Beaudry, and C.A. Bunton, 1993a, Perhydrolysis of Nerve Agent VX, J. Org. Chem., 58:6964-6965. 
Yang, Y.-C., L.L. Szafraniec, and C.A. Bunton, 1993b, Nucleophilic Substitution of O,S-Diethyl Methylphosphonothiolate: The Selectivity of P-S- to P-O Bond Cleavage, Proceedings, 1992 ERDEC Scientific Conference on Chemical Defense Research, Aberdeen Proving Ground, MD, November 17-20, 1992.

Yang, Y.-C., L.L. Szatraniec, W.T. Beaudry, J.B. Samuel, and D.K. Rohrbaugh, 1994, Hydrolysis of VX: 'Activation Energies and Acid Catalysis (Oral Presentation), 1994 Scientific Conference on Chemical and Biological Defense Research, Aberdeen Proving Ground, MD, November 15-18.

Yurow, H.W., 1981, Decontamination Methods for HD, GB and VX. A Literature Survey, ARCSL-SP80032, AD B057399L (as cited by MacNaughton and Brewer 1994). 


\section{APPENDIX A}

\section{ENVIRONMENTAL FATE OF GB, VX, AND HD}

\section{A-1.0 INTRODUCTION}

The history of outdoor testing of agents GB, VX, and H/HD at DPG, which was discontinued in the 1960s, suggests that unconfined soil in agent test areas may have been contaminated with one or more of these agents. In addition, decontaminated materials may have been landfilled. It may be assumed that soils that originally contained agent may not have been treated to decontaminate them. On the other hand, they have not been in a continually moisture-free condition that might have protected them from hydrolysis. The purpose of this appendix is to describe the processes whereby the agents that may have been present originally might have degraded or dispersed. In the case of unconfined soil, the more water-soluble agents, their products, or their impurities could have then migrated away (while continuing to decompose) from the original site. Such migration usually results from dissolution and vertical (downward) movement in recharge water in the unsaturated zone or through nearly horizontal flow as dissolved material in the groundwater. Further, more volatile agents or breakdown products are capable of diffusing as vapors in the unsaturated zone until they escape to the soil surface and are dispersed by the wind.

\section{A-2.0 GB AND ASSOCIATED COMPOUNDS}

\section{A-2.1 GB}

GB undergoes loss from unconfined soils by evaporation, leaching, and hydrolysis. The initial hydrolytic reaction is:<smiles>CC(C)OP(C)(=O)[OH+]CC(C)OP(C)(=O)O</smiles>

For the disappearance of GB from soil open to the air, Small (1984) cited a study by Puzderliski (1980). Samples of soil were placed in 7-cm-diameter, open crystallizing flasks. On each sample, drops of GB were placed corresponding to a nominal surface density of $50 \mathrm{~g} / \mathrm{m}^{2}$, a rather heavy loading. The flasks were buried at ground level in outdoor soil where they were exposed to weathering. During the exposure period, samples were assayed. (The methods of assay were not well documented.) The time frame of interest was the period, $\tau$, required for the agent density to decrease to $0.033 \mathrm{mg} / \mathrm{m}^{2}$, i.e., by a factor of 1500 , somewhat over 10 halflives. Puzderliski derived the values of $\tau$ shown in Table A-1. 


\section{Table A-1. Persistence Times Predicted for GB Droplets on Soil ( $\tau$, hours)}

\begin{tabular}{ccccc} 
Temperature $\left({ }^{\circ} \mathrm{C}\right)$ & Calm, dry & Windy, dry & Light rain & \multicolumn{2}{c}{ Heavy rain } \\
\cline { 2 - 3 } & 274 & 238 & 434 & 279 \\
25 & 8.9 & 7.8 & 14.2 & 9.1 \\
\hline
\end{tabular}

"Closed container" studies essentially preclude evaporative or leaching effects; any decrease in content of a contaminant in the soil may be attributed to chemical interaction in the soil, such as hydrolysis, chemisorption, air oxidation, or soil-catalyzed reactions, with no displacement of equilibria through removal of products. Contaminated samples are stored in the containers at room temperature and periodically assayed (Small 1983). Sass et al. (1953) conducted a closed-container study of GB clecomposition in loam of pH 6.5 and in humus, $\mathrm{pH} 4.5$, at room temperature, which one may consider to be $21^{\circ} \mathrm{C}$. The percent GB remaining after given periods was determined (Table A-2). Percent GB vs. time in this study was generally linear for the first $24 \mathrm{~h}$. Especially in the moist loam, the degradation rate was considerably faster than it would have been in water at the same $\mathrm{pH}$ and temperature; thus, in water at $\mathrm{pH} 6.5$ and $21^{\circ} \mathrm{C}$, according to Larsson's equation (see below), the half-life is calculated as $394 \mathrm{~h}$. When soil containing $1 \%$ moisture was contaminated with GB, $13 \%$ could be recovered in 3 days, $2.6 \%$ in 7 days, and $0.02 \%$ in 35 days (USATECOM undated). A model developed for the fate of GB in Lakewood Sand soil indicated a half-life of about $13 \mathrm{~h}$ for what is presumed to have been $50 \mathrm{~mL}$ of aqueous $\mathrm{GB}$ (initially $4 \mathrm{mg} / \mathrm{L}$ ) shaken with $2 \mathrm{~g}$ of the soil at room temperature (about $21^{\circ} \mathrm{C}$ ) (Kingery and Allen 1994).

\section{Table A-2. Percent GB Remaining at Indicated Time after Application}

$\begin{array}{lccccc}\text { Soil (\% Moisture) } & 12 \text { hours } & \frac{24 \text { hours }}{28} & \frac{48 \text { hours }}{92 \text { hours }} & \text { 168 hours } \\ \text { Humus (2.9) } & 56 & 28 & 9 & 2 & \text { Nil } \\ \text { Humus (36.8) } & 42 & \text { Nil } & \text { Nil } & -- & -- \\ \text { Loam (1.4) } & 59 & 27 & 14 & 12 & 5 \\ \text { Loam (12.8) } & 40 & \text { Nil } & -- & -- & --\end{array}$

The half-life for $\mathrm{GB}$ in water decreases linearly with increasing $\left[\mathrm{OH}^{-}\right]$from about $\mathrm{pH} 6.5$ upward and decreases linearly with increasing $\left[\mathrm{H}_{3} \mathrm{O}^{+}\right]$from about $\mathrm{pH} 4$ downward. In the $\mathrm{pH}$ 4-6.5 interval, aqueous $\mathrm{GB}$ is at its most stable, with a half-life at $25^{\circ} \mathrm{C}$ of about $238 \mathrm{~h}$ (see graphic presentation by Kingery and Allen 1994); the half-life at $\mathrm{pH} 3$ is about $18 \mathrm{~h}$. For $\mathrm{pH}$ values above 6.5, the following equation (Kingery and Allen 1995, as derived from Larsson 1957) may be used to estimate half-life in fresh water: $\log t_{1 / 2}$ (hours) $=5039 / \mathrm{T}-\mathrm{pH}-8.035$, where $T$ is temperature (degrees Kelvin). The presence of magnesium and calcium ions in seawater considerably accelerates GB hydrolysis; thus, at $\mathrm{pH} 7.7$ and $15^{\circ} \mathrm{C}$, the experimental half-life is $2.65 \mathrm{~h}$ (Epstein 1970), compared to the estimate of $56.5 \mathrm{~h}$ by Larsson's equation for water free of catalytic metal ions. Other metallic ions also catalyze the hydrolysis of GB. 
Minute amounts of GB might remain at equilibrium in the soil-water system, but the chances that detectable quantities of agent are present as the result of agent dissemination in a former military testing program are exceedingly small. It may be concluded that under the worst plausible conditions, dispersed GB in contact with relatively dry (but not totally water-free) soil would not be detectable in the soil after about 15 half-lives, with the half-life seldom exceeding about 2 days. Thus, soil originally contaminated with dispersed GB should be free of detectable agent after a month or less.

\section{A-2.2 GB Hydrolysis Products}

Fluoride ion $\left(\mathrm{F}^{-}\right)$, present as its salts, is nonvolatile and, in aqueous solution, is not retarded through sorption mechanisms as it is transported through the soil. The concentration of fluoride ion in soils worldwide is in the range of $20-700 \mathrm{mg} / \mathrm{kg}$, with a median value of $200 \mathrm{mg} / \mathrm{kg}$ (Bodek et al. 1988).

Soil sorbs isopropyl methylphosphonic acid (IMPA) to a significant degree (Kingery and Allen 1994); this implies that, depending on the soil type, leaching may be retarded by the soil to some extent. The hydrolysis rate for IMPA in aqueous solution at ambient temperature is extremely slow; yet, in certain soil-water systems, appreciable hydrolysis to methylphosphonic acid (MPA) takes place. For example, $50 \mathrm{~mL}$ of aqueous IMPA ( $4 \mathrm{mg} /$ ) shaken with $2 \mathrm{~g}$ of Fort McClellan clay loam soil had a half-life of $2.9 \mathrm{~h}$ (presumably at about $21^{\circ} \mathrm{C}$ ); however, aqueous IMPA shaken with sandy clay loam from Dugway Proving Ground or sandy loam from Rocky Mountain Arsenal showed no observable hydrolysis (Kingery and Allen 1994). Thus, it would be possible that MPA would be found in the vicinity of former GB dissemination as a secondary hydrolysis product of the agent. Moreover, MPA is degraded by some microorganisms to inorganic phosphate; but the process is usually quite slow and may not occur everywhere (Kingery and Allen 1994). Aqueous IMPA and MPA were routinely analyzed in water down to a level of $0.5 \mu \mathrm{g} / \mathrm{L}$ by ion chromatography (Kingery and Allen 1993). It may be concluded that the most likely long-lived products of GB hydrolysis in soils would be fluoride ion and MPA.

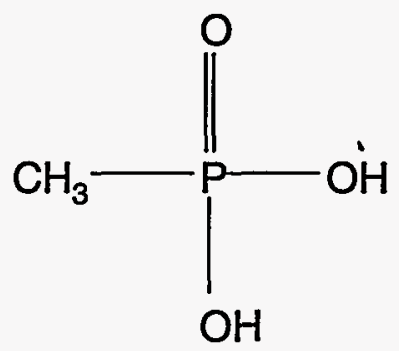

\section{MPA}

\section{A-2.3 GB Impurities and Stabilizers}

Methylphosphonic difluoride, a potential impurity of GB, rapidly hydrolyzes to MPA (see above) and fluoride ion on exposure to water. 
Another GB impurity, diisopropyl methylphosphonate (DIMP), which is infinitely miscible with water (Major 1990), undergoes extremely slow aqueous hydrolysis to IMPA (see above) and isopropyl alcohol. By extrapolation of results from high-temperature hydrolysis, it was estimated that the half-life of DIMP in groundwater at $10^{\circ} \mathrm{C}$ would be about 687 years (Rosenblatt et al. 1975). The fairly high boiling point of DIMP, $174^{\circ} \mathrm{C}$ (Rosenblatt et al. 1975), suggests that the compound would not readily disappear from soil or groundwater by evaporation. The presence of DIMP in Rocky Mountain Arsenal groundwater over several decades tends to confirm the perception that DIMP disappears very slowly from the environment.

Diisopropyl carbodiimide (DIPC), which was added as a stabilizer for weapons-grade GB, is hydrolyzed to N,N'-diisopropylurea (DIPU). Williams and Ibrahim (1981) measured the observed pseudo-first-order rate constant (units of $\mathrm{s}^{-1}$ ) at $25^{\circ} \mathrm{C}$ and $1 \mathrm{M}$ ionic strength, over a range of $\mathrm{pH}$ values, to obtain the equation

$$
\mathrm{k}=63\left[\mathrm{H}^{+}\right]+0.0011\left[\mathrm{OH}^{-}\right]
$$

From the equation, one calculates that the half-life at $\mathrm{pH} 7$ would be $31.6 \mathrm{~h}$; the longest half-life, at $\mathrm{pH} 9.4$, would be about $3,600 \mathrm{~h}$.

The GB stabilizer tributylamine, which boils at $213^{\circ} \mathrm{C}$ (Weast 1979 ), is not expected to volatilize readily. 'It cannot hydrolyze.

In summary, aside from compounds that are also products of GB hydrolysis, the most likely long-lasting environmental contaminants arising from GB stabilizers and impurities would be $\mathrm{N}, \mathrm{N}^{\prime}$-diisopropylurea, tributylamine, and DIMP.

\section{A-3.0 VX AND ASSOCIATED COMPOUNDS}

\section{A-3.1 VX}<smiles>CCOP(C)(=O)[Se]CC(C)N(CC)C(C)C</smiles> 
It is likely that VX undergoes loss from unconfined soils mainly by leaching and to a lesser extent by hydrolysis and evaporation. Three major initial hydrolytic reactions can occur (Epstein et al. 1974):
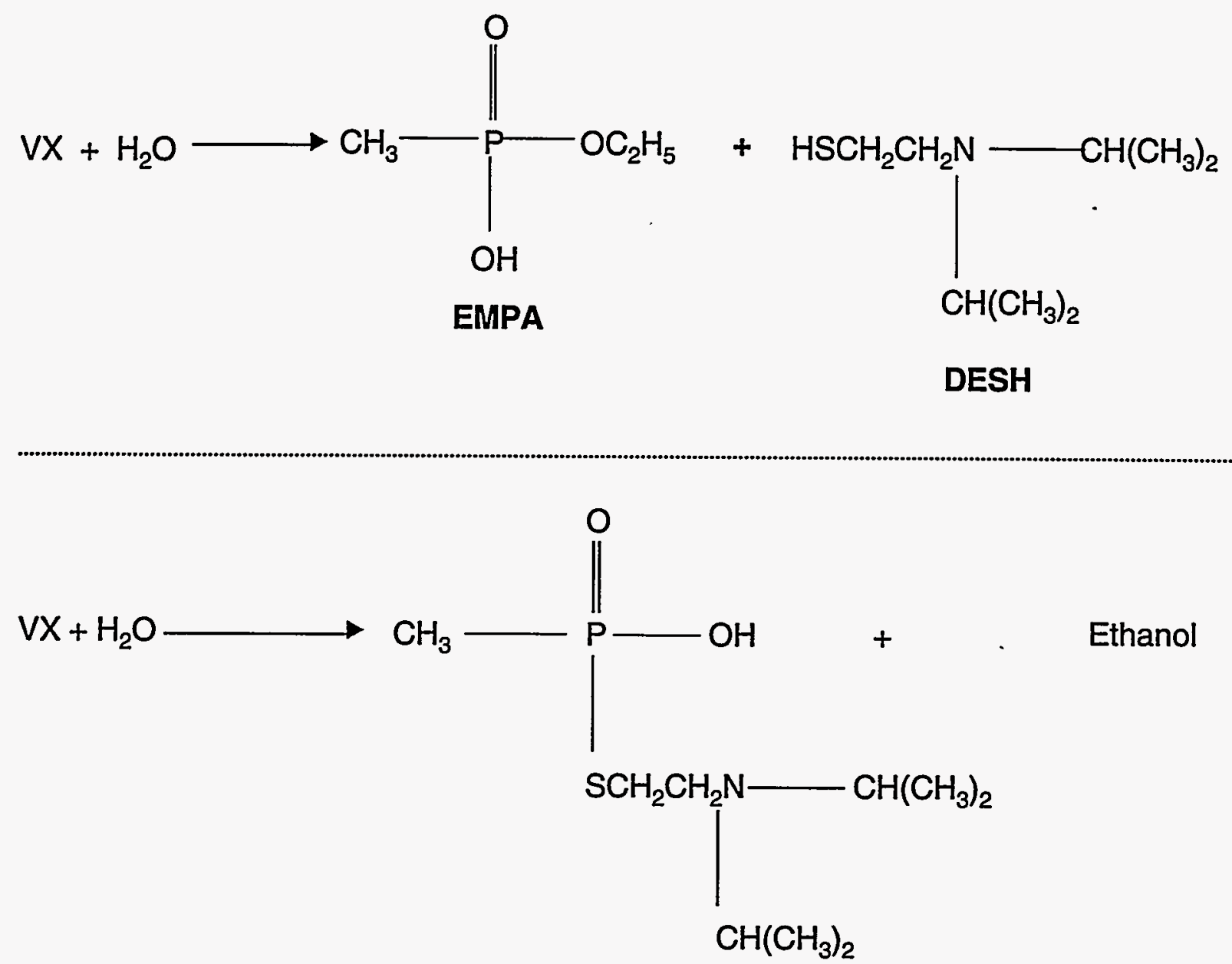

\section{EA 2192}

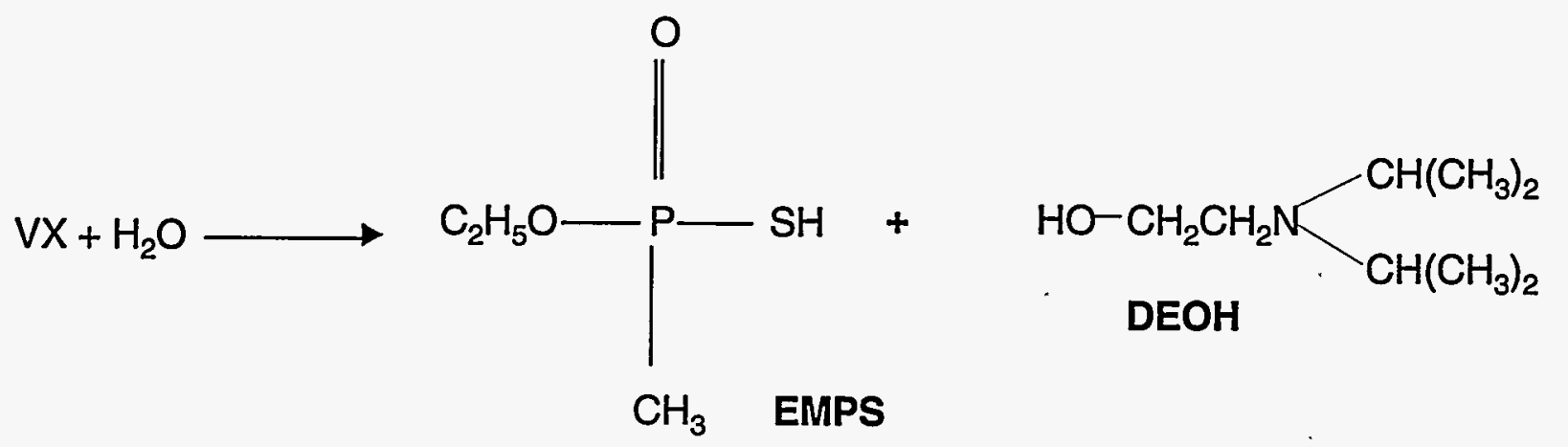


In addition, a cyclic imonium intermediate in the last of the above reactions can interact with DESH to form

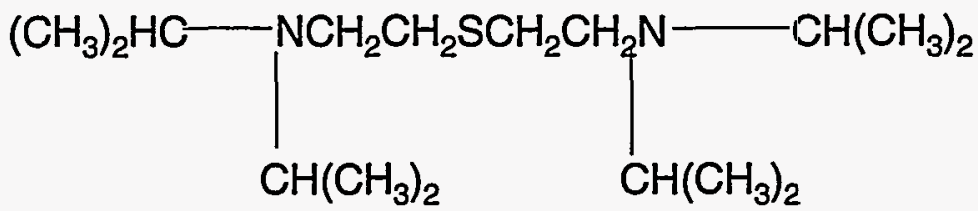

$(D E)_{2} S$

DESH is rapidly air-oxidized (Kaaijk and Frijlink 1977) to the environmentally stable disulfide (DES) ${ }_{2}$ or EA 4196.

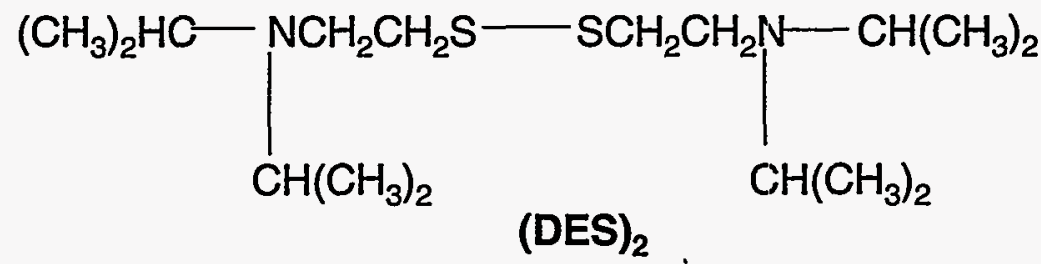

Finally, under environmental conditions, it appears that VX can react with the anion of EMPA to form the anion of DESH plus a cholinesterase inhibitor, the pyrophosphonate DDP (Small 1983):

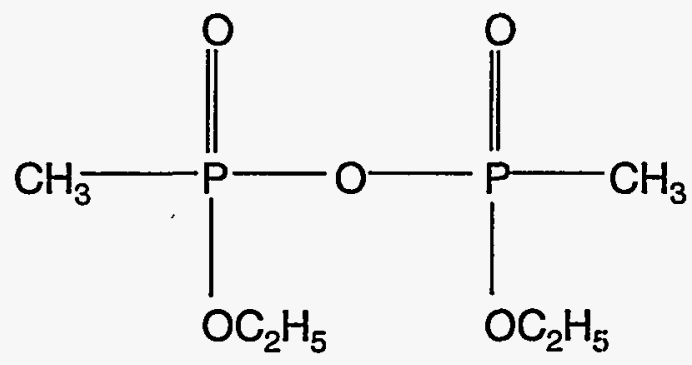

\section{Diethyl dimethylpyrophosphonate (DDP)}

For the disappearance of VX from soil open to the air, Small (1983) cited a study by Demek and Epstein (1959) that describes a small-scale 1957-1958 study of the fate of VX on Carroll Island soil plots. Samples of soil were tested 17 to 52 days after VX application; about three orders of magnitude decrease in VX soil content was observed. Small (1984) cited a report by Griffiths et al. (1979) on analysis of samples taken from the Dugway Proving Ground V-Grid area. At some time before 1969, VX had been tested at this site and soil samples had shown VX levels as high as $6 \mathrm{mg} / \mathrm{g}$. The 1979 tests at depths down to $102 \mathrm{~cm}$ indicated no VX at detection levels as low as $0.4 \mu \mathrm{g} / \mathrm{g}$. The degradation product MPA (see Section A-2.2) was found at concentrations ranging from 14.9 to $23 \mu \mathrm{g} / \mathrm{g}$; no $(\mathrm{DES})_{2}$ was detected.

Epstein et al. (1959) conducted a closed-container study (see definition above) of VX in soil. In these tests, $0.1 \mathrm{~g}$ of $\mathrm{VX}$ was added to $10 \mathrm{~g}$ samples of Carroll Island soil (fine silly loam, $\mathrm{pH} 6.5, \mathrm{SOC}=0.8 \%$ ) in glassstoppered flasks. Moisture content was $4.5 \%, 20 \%$, or $50 \%$. With little effect by percent moisture, the VX level dropped to $2.5-7.2 \%$ of its initial value in 14 days, as measured by cholinesterase inhibition. The recorded rate of disappearance of VX decreased with time, but this could have been due to the formation of cholinesterase- 
inhibiting products (e.g., EA 2192). A follow-on study with different soils essentially confirmed the results (Demek and Epstein 1959). Studies at the Netherlands' TNO Laboratories involved application of $200 \mathrm{mg} / \mathrm{kg}$ of VX to soil (Verweij and Boter 1976; Kaaijk and Frijlink 1977). After 3 weeks, only $0.1 \%$ of the applied VX was detectable. EA2192 was observed within a day after VX introduction to the soil but was found to degrade about as rapidly as VX. EMPA was the main initial phosphorus-containing product, and it slowly degraded to MPA. In USATECOM studies, when soil containing $1 \%$ moisture was contaminated with VX, $21 \%$ could be recovered in 3 days and $10 \%$ in 15 days (USATECOM undated).

The half-lives for disappearance of $V X$ at $25^{\circ} \mathrm{C}$ in aqueous solution have been reported by Epstein et al. (1974) as shown in Table A-3 (where some of the values were actually determined for the diethylamino analog of VX, which has virtually identical hydrolytic behavior).

\section{Table A-3. $\quad$ Hydrolysis Half-Lives for VX}

$\begin{array}{lc}2.0 & 2,520 \\ 4.0 & 2,257 \\ 6.0 & 2,381 \\ 7.0 & 996 \\ 8.0 & 184 \\ 9.0 & 63 \\ 10.0 & 40.5 \\ 11.0 & 15 \\ 12.0 \text { (approximately } 0.01 \mathrm{M} \mathrm{NaOH}) & 2.5 \\ 12.65 & 0.525 \\ 12.9 & 0.279 \\ 13.5 & 0.0529\end{array}$

Source: Epstein et al. (1974)

Because $\mathrm{VX}$ is a base, the $\mathrm{pH}$ resulting from its dissolution in water is sufficient to initiate its own hydrolysis. However, the acid generated by that reaction would gradually lower the $\mathrm{pH}$, so that the apparent half-life would decrease with time. Yang et al. (1990) estimated $80 \mathrm{~h}$ as the "half-life for the spontaneous hydrolysis" of VX at $20^{\circ} \mathrm{C}$. Szafraniec et al. (1990) made a $0.5 \%$ solution of VX in unbuffered water; the initial $\mathrm{pH}$ was 9.0 , and this dropped to 7.5 in the course of hydrolysis." The overall first-order rate constant was $0.0121 \mathrm{~h}^{-1}$, so that the half-life was $57 \mathrm{~h}$. Cleavage fractions were P-O, 0.54 (product EA 2192); P-S, 0.36; and S-C, 0.10. Thus, cleavage to produce EA 2192 was dominant under these conditions.

With the exercise of a certain amount of judgment, it may be concluded from the foregoing that under the worst plausible conditions, dispersed VX in contact with relatively dry (but not totally water-free) soil would not be detectable in the sample after about 3 months.

\section{A-3.2 VX Hydrolysis Products}

Information on most VX hydrolysis products is sparse. 
The hydrolysis product ethyl methylphosphonate may be assumed to have an environmental fate very similar to that of isopropyl methylphosphonate (see Section A-2.3).

As noted above, the hydrolysis product DESH is rapidly air-oxidized (Kaaijk and Frijlink 1977) to the environmentally stable (DES) $)_{2}$, which is rather tightly bound to the soil. It is reasonable to assume that (DE) $)_{2} S$ is also tightly bound.

Verweij and Boter (1976) reported the rapid hydrolysis of DDP $\left(t_{1 / 2}=1 \mathrm{~h}\right)$.

Under very alkaline conditions, the half-lives (in minutes) of VX and EA 2192 can be expressed as $t_{1 / 2}=2.17 /\left(\left[\mathrm{OH}^{-}\right]^{1.2}\right)$ and $t_{1 / 2}=835 /\left[\mathrm{OH}^{-}\right]^{1.6}$, respectively (Szafraniec et al. 1993). This indicates that EA 2192 should be considerably more stable in water than VX. Nevertheless, it appears to degrade as readily as VX in soil (see above).

It is concluded that the most long-lasting products of VX decomposition in weathered soil samples would be $(D E S)_{2}$ and MPA.

\section{A-4.0 HD AND ASSOCIATED COMPDUNDS}

\section{A-4.1 $\mathrm{HD}, \mathrm{Cl}-\mathrm{CH}_{2}-\mathrm{CH}_{2}-\mathrm{S}-\mathrm{CH}_{2}-\mathrm{CH}_{2}-\mathrm{Cl}$}

The following reactions of HD with water are observed almost exclusively when the ratio of water to HD is relatively high (Rosenblatt et al. 1975):

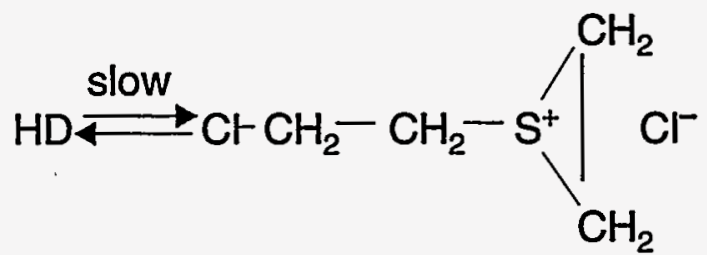<smiles>ClCCO[14CH2]OCCCSCCCl</smiles>
Mustard chlorohydrin<smiles>OCCSCCO</smiles>
Thiodiglycol

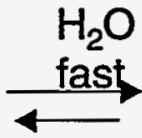<smiles>CCC</smiles><smiles>[S+][S-]</smiles><smiles>[GeH3-]</smiles>
fast

If chloride ion is present, as it is in seawater, for example, the hydrolysis reaction is retarded because chloride ion reacts with the cyclic sulfonium intermediates to reform $\mathrm{HD}$. Strong nucleophiles, for example thiosulfate, also react with the cyclic intermediates, competing with water or hydroxide for them, and thereby diminishing the yield of thiodiglycol (Ogston et al. 1948). 
In addition to the foregoing, there are other reactions in water-containing media. These involve alkylation of sulfide to linear sulfonium ions and dealkylation of the latter, leading to a large number of quasi-stable sulfonium ion intermediates (Yang et al. 1987), such as H-2TG, H-TG, and CH-TG. lons of this type retain much of the toxicity of mustard, including its vesicancy (Yang et al. 1987). Thus, reaction of HD with limited volumes of water can result in the loss of HD without corresponding loss of toxicity. Most analytical procedures used to examine soil or groundwater cannot detect ionic products such as these.

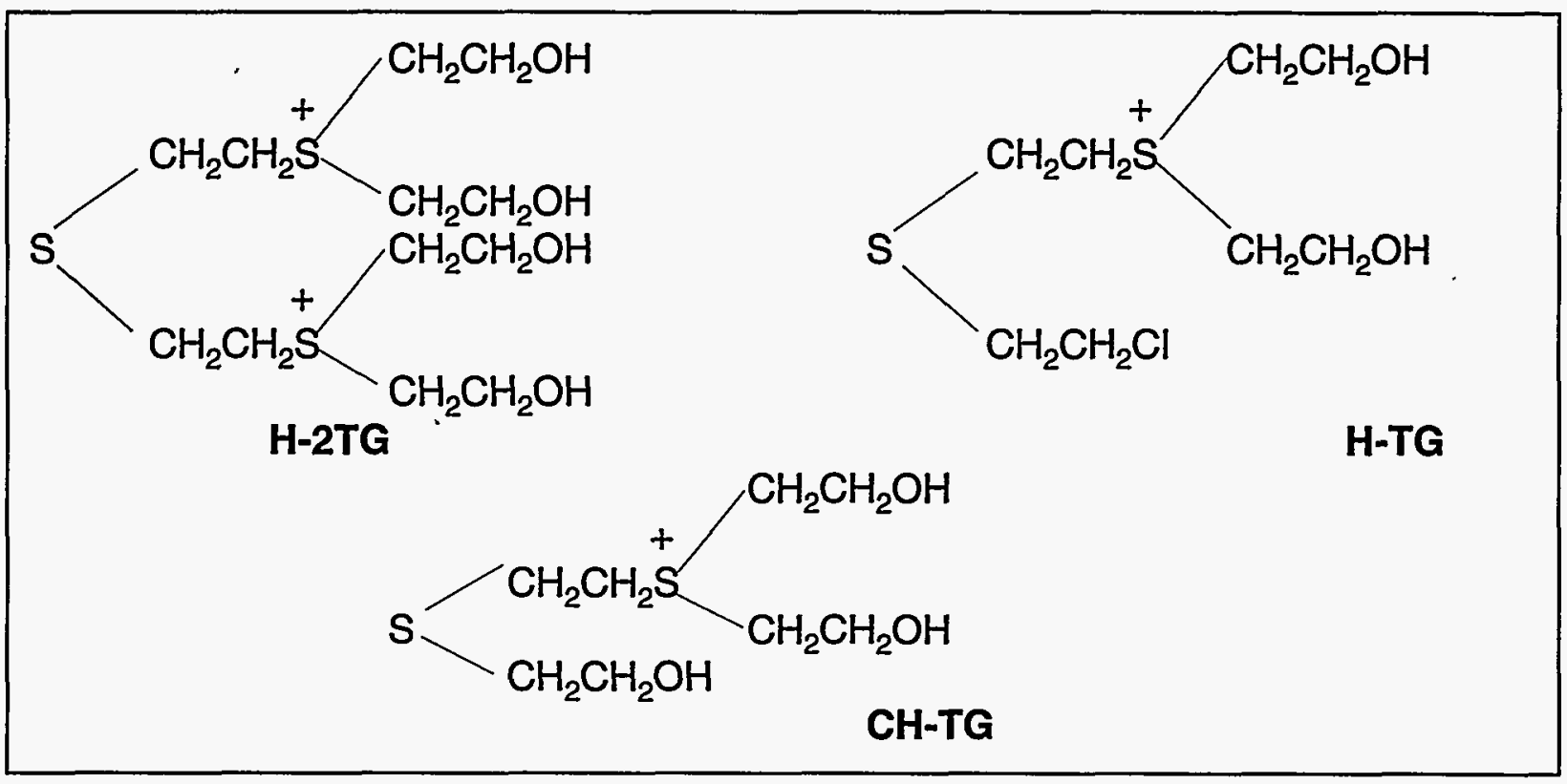

Finally, some end products from the series of alkylation and dealkylation reactions are readily measured in either organic or aqueous media. Aside from thiodiglycol (mentioned above), 1,4-oxathiane is formed when water is present. In dry HD, thermochemical reactions (most likely via alkylation and dealkylation) lead to 1,4dithiane and 1,2-dichloroethane (Bell et al. 1927). The latter, especially, is fairly volatile, boiling at $83^{\circ} \mathrm{C}$ (Weast 1979); in the open, it quite likely volatilizes over a period of time, displacing any slow equilibrium that might tend to reform HD.

Despite the rapidity with which the hydrolysis reaction occurs (once the HD is in aqueous solution), there is reason to believe that a tendency exists, in quiescent conditions, for HD to polymerize at the HD/water interface, interfering with transfer of $H D$ to the aqueous solution and thus shielding the bulk agent from hydrolysis reactions (MacNaughton and Brewer 1994). Hence, the fact that bulk HD (or $\mathrm{H}$ ) can persist deep in the soil or under relatively quiescent water for years may be due to encapsulation by oligomeric degradation products of limited hydrolysis, which are related to the linear sulfonium ions shown above. Small (1984) points out that each $-\mathrm{SC}_{2} \mathrm{H}_{4}$ - unit of increase in oligomer or polymer chain length would increase the octanol-water partition coefficient by a factor of 1.6; there would be some corresponding decrease in the aqueous solubility of the oligomer (which could itself be quite toxic). Samples of soil or groundwater taken near an encapsulated HD mass might show no trace of the active agent. The Committee on Alternative Demilitarization Technologies (1993) states: "The chemical problem is that the intermediate products are cyclic or oligomeric sulfonium salts, which are relatively unreactive and which moreover have the potential for slowly reforming mustard." Yang et al. (1987) express the belief that "the enduring toxicity of mustard gas in the environment can hardly be explained unless additional transformations of mustard gas into stable products of similar toxicity exist." 
The impurities found in $\mathrm{H}$, such as the polysulfides, might be expected to hinder the already slow dissolution of the agent, and, if they dissolved in water, to react more slowly with water than HD (or not at all). One impurity, 1,2-bis(2-chloroethylthio)ethane ( $\mathrm{Cl}-\mathrm{CH}_{2}-\mathrm{CH}_{2}-\mathrm{S}-\mathrm{CH}_{2}-\mathrm{CH}_{2}-\mathrm{S}-\mathrm{CH}_{2}-\mathrm{CH}_{2}-\mathrm{Cl}$ ), is about five times as vesicant as $\mathrm{HD}$ itself; others, such as 1,8-dichloro-3-oxa-6-thiaoctane $\left(\mathrm{Cl}-\mathrm{CH}_{2}-\mathrm{CH}_{2}-\mathrm{S}-\mathrm{CH}_{2}-\mathrm{CH}_{2}-\mathrm{O}-\mathrm{CH}_{2}-\right.$ $\mathrm{CH}_{2}-\mathrm{Cl}$ ), are probably about as toxic as $\mathrm{HD}$. Yet others, perhaps including the HD polysulfides, might be considerably less vesicant.

Small (1983) has cited field plot and shell explosion tests in which the time required for the air concentration of $H D$ to drop to $10 \%$ of the initial value varied from $5 \mathrm{~h}$ to 10 days. If one assumed that such measured $H D$ concentrations in air corresponded directly to those in the soil, it would follow that soil HD levels were reduced $90 \%$ in the same time range. For the disappearance of HD from soil open to the air, Small (1984) cited the study by Puzderliski (1980). Samples of soil were placed in 7-cm-diameter open crystallizing flasks. On each sample, drops of HD were placed corresponding to a nominal surface density of $50 \mathrm{~g} / \mathrm{m}^{2}$, a rather heavy loading. The flasks were buried at ground level in outdoor soil where they were exposed to weathering. During the exposure period, samples were assayed. (The methods of assay were not well-documented.) The time frame of interest was the period, $\tau$, required for the agent density to decrease to $0.033 \mathrm{mg} / \mathrm{m}^{2}$, i.e., by a factor of 1500 , somewhat over 10 half-lives. Puzderliski derived the values of $\tau$ shown in Table A-4.

\section{Table A-4. Persistence Times Predicted for HD Droplets on Soil ( $\tau$, hours)}

\begin{tabular}{ccccc} 
Temperature $\left({ }^{\circ} \mathrm{C}\right)$ & Calm, dry & Windy, dry & Light rain & Heavy rain \\
\hline 0 & 1,530 & 1,743 & 2,215 & 1,122 \\
25 & 41.5 & 7.3 & 51.2 & 30.5 \\
\hline
\end{tabular}

Small (1984) comments that, "If HD droplets were applied to a soil surface, but not deliberately incorporated into the soil, vaporization could be the main route of HD loss. If the soil were extremely wet, hydrolysis might occur to an appreciable extent. If droplets were considerably below the soil surface, conditions similar to that of a droplet in quiescent water might prevail, and HD would persist (as HD or in oligomeric form)."

With the exercise of a certain amount of judgment, it may be concluded from the foregoing that even under cold weather conditions, fine droplets of HD in contact with surface soil would not be detectable after about a year. However, buried HD pockets of sufficient mass might survive for greater lengths of time and be difficult to detect.

\section{A-4.2 HD Hydrolysis Products}

Thiodiglycol, the major hydrolysis product of $H D$, is quite polar, being infinitely miscible with water and fairly high-boiling $-280^{\circ} \mathrm{C}$ at atmospheric pressure (Nemeth 1989), $164^{\circ} \mathrm{C}$ at 20 torr, and $133^{\circ} \mathrm{C}$ at 1 torr (Weast 1979); the octanol/water partition coefficient is 0.83 (Major 1989), also indicative of quite high polarity. Though it does not hydrolyze further, thiodiglycol can undergo environmental biodegradation. Two bacterial strains isolated from "local soil" (presumably at the Edgewood Area of Aberdeen Proving Ground) were able to use thiodiglycol as a sole source of carbon for growth: Pseudomonas pickettii strain SH18 and Alkaligenes xylosoxidans ssp. xylosoxidans strain SH42. In $72 \mathrm{~h}$, the SH42 culture metabolized at least $97 \%$ of the organic starting material (hydrolyzed HD) to inorganic products. In the case of the $\mathrm{SH} 18$ culture, there was a $16 \%$ production of thiodiglycol sulfoxide, a product of "dead end" metabolism (Harvey et al. 1992). 
1,4-Oxathiane melts at $-17^{\circ} \mathrm{C}$ and boils at $147-150^{\circ} \mathrm{C}$ (Berkowitz et al. 1978). The octanol/water partition coefficient is 5.9 (Major 1989), indicating a compound of fairly high polarity. Berkowitz et al. (1978) calculate an aqueous solubility of approximately $167,000 \mathrm{mg} / \mathrm{L}$. A vapor pressure of 5.3 torr at $25^{\circ} \mathrm{C}$ was estimated (Berkowitz et al. 1978). 1,4-Oxathiane is a groundwater contaminant often associated with production and demilitarization of $\mathrm{H}$ or HD, probably from hydrolytic decomposition (Roberts and Hartley 1992).

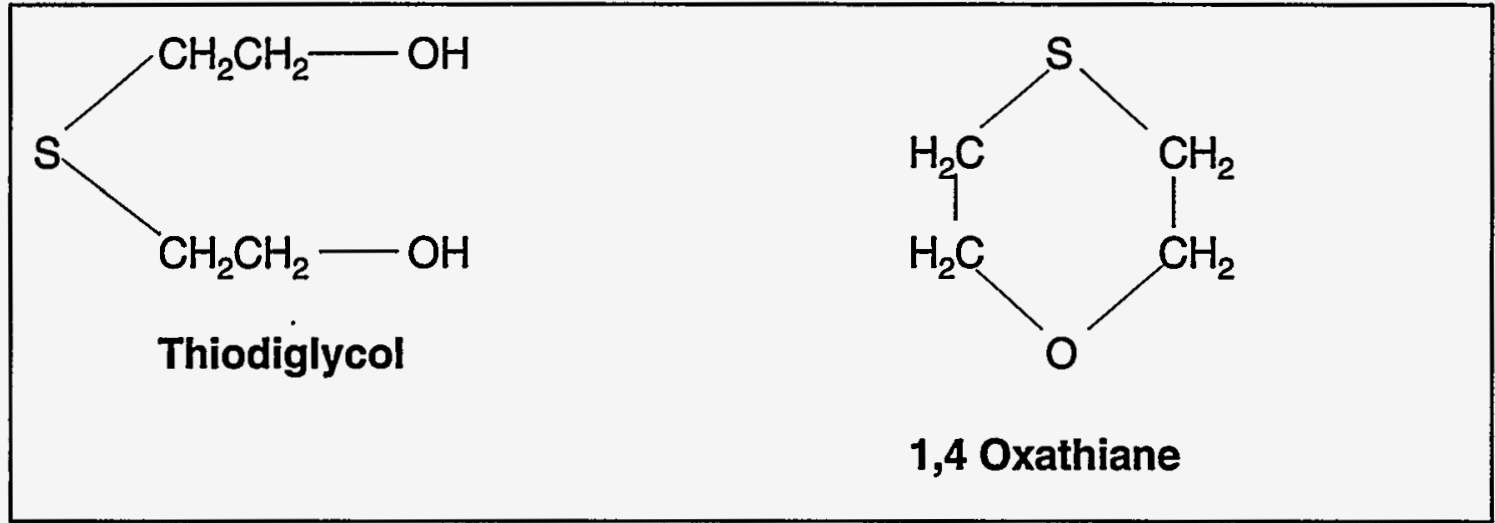

In summary, well-dispersed HD should be hydrolyzed in the environment mainly to thiodiglycol and 1,4-oxathiane.

\section{A-4.3 HD Impurities}

1,4-Dithiane melts at $111-112^{\circ} \mathrm{C}$ and boils at $199-200^{\circ} \mathrm{C}$ (Weast 1979). The octanol/water partition coefficient is 71 (Major 1989), indicating a compound of considerably lower polarity than 1,4-oxathiane. Berkowitz et al. (1978) estimate an aqueous solubility of $11,800 \mathrm{mg} / \mathrm{L}$ and report an empirical vapor pressure equation of:

$$
\log P(\text { torr })=7.99-(2,410 / T(K))
$$

Thus, the vapor pressure at $25^{\circ} \mathrm{C}$ is approximately 0.8 torr. 1,4-Dithiane is a groundwater contaminant associated with $\mathrm{H}$ or HD storage and deposits; the occurrence of 1,4-dithiane is thought to result from mustard degradation (presumably thermal), because its concentration in HD increases with storage time (Roberts and Hartley 1992; Berkowitz 1982).

1,2-Dichloroethane is a product of the thermal decomposition of HD but by no means unique to that source. It is low-melting $\left(-35^{\circ} \mathrm{C}\right)$ and low-boiling $\left(83^{\circ} \mathrm{C}\right)$, with a vapor pressure of 79 torr at $20^{\circ} \mathrm{C}$. Water solubility is $8,524 \mathrm{mg} / \mathrm{L}$. The octanol/water partition coefficient of 30 indicates that it is not very polar. However, it is not expected to adsorb well to soil, in which it should exhibit high mobility. 1,2-Dichloroethane does not undergo environmental biodegradation to any great extent; most of it in soil or groundwater evaporates. Once in the atmosphere, it can travel long distances, eventually degrading through the action of photochemically formed hydroxyl radicals, with an atmospheric half-life of about a month (Howard 1990). One may conclude that 1,2-dichloroethane initially associated with environmental HD would tend to escape, primarily by evaporating. 


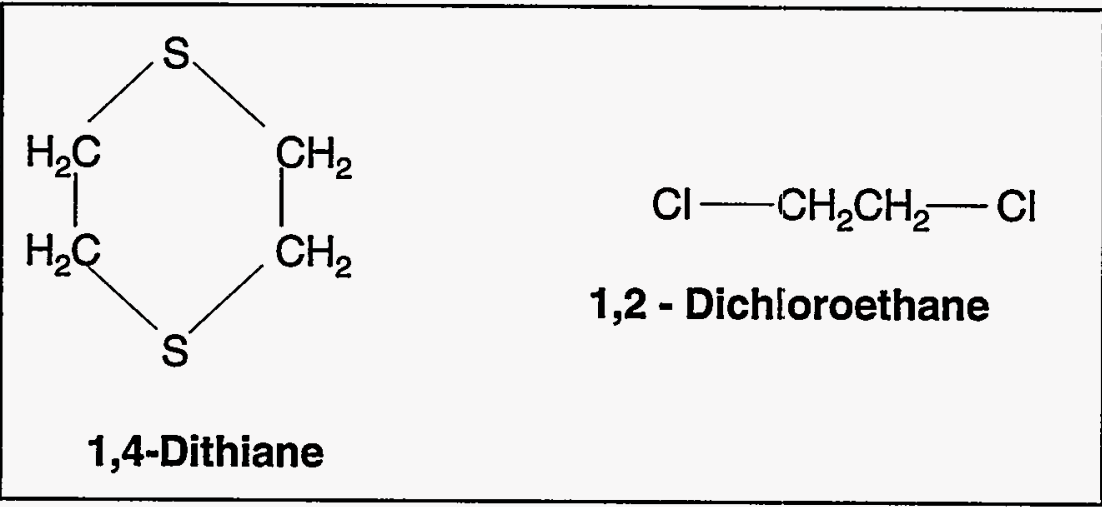

\section{A-5.0 EMISSION OF CONTAMINANTS FROM SOIL, TIME-AVERAGED FLUX ANALYSIS}

Worst-case scenarios have been examined for the emission of agents GB, VX, and HD from soil in a landfill or other open disposal site. These estimates disregard chemical degradation, chemical binding to soil components (mineral or organic matter), and leaching as mechanisms for attenuation despite strong indications of such effects (see above). The basic model (Small 1993) is an adaptation of the equations developed by the EPA (Office of Remedial Response 1988); it takes into account the presence in soil of both air-filled and waterfilled voids, as well as organic matter, which is especially important for the sorption of organic compounds of low polarity. The model assumes the initial presence of a layer of uniformly contaminated soil overlain by a layer of clean soil; diffusion of the contaminant occurs only upward.

Equation factors (Table A-5) include (1) site/soil/scenario-related default values and (2) contaminant-specific variables derived from information in the main text. For specific situations, better values - if available - may be substituted for site/soil/scenario-related default values. Contaminant-specific values for required variables are included in Table A-6. The emission model provides an output of $Q_{a v}=$ time-averaged source strength, expressed in units of $\mathrm{mg} / \mathrm{d}$.

At scenario time zero, the contaminant (agent) starts to diffuse upward through the initially uncontaminated soil layer. It follows a tortuous path, continuously partitioning between the solid phase (mainly soil organic matter, though there is some sorption to soil minerals), pore water, and soil air. The following expressions are used to calculate $Q_{\mathrm{av}}$ (where default values are inserted as appropriate):

$$
\begin{gathered}
D_{e i}=\left(K_{H} \times D_{a} \times \epsilon^{10 / 3}\right) /(\theta+\epsilon)^{2}=\left(K_{H} \times D_{a} \times 0.03802 / 0.16\right) \\
=0.2376 \times K_{H} \times D_{a} \\
K_{d a}=K_{d}+\epsilon / \rho=K_{d}+(0.375 / 1.4)=K_{d}+0.268 \\
K_{d j}=\left(\rho \times K_{d a}\right)+\theta+\left(\epsilon K_{H}\right)=\left(1.4 \times K_{d a}\right)+0.025+\left(0.375 K_{H}\right)
\end{gathered}
$$

and

$$
\begin{aligned}
Q_{a v}= & \left(2,000 A C_{a} D_{e j}\right) /\left\{K_{d a}\left(d_{o}+\left[d_{o}^{2}+2 D_{e i} t / K_{d j}\right]^{1 / 2}\right)\right\} \\
= & \left(2 \times 10^{7} D_{e i}\right) /\left\{K_{d a}\left(1+\left[1+180 D_{e j} / K_{d j}\right]^{1 / 2}\right)\right\}
\end{aligned}
$$




\section{Table A-5. Factors in the Time-Averaged Flux Analysis}

Symbol

Definition

Value

1. Site/Soil/Scenario-Related Default Values

A

Assumed area of contaminated soil parcel $\left(\mathrm{m}^{2}\right)$

10,000

$d_{0}$

Initial depth of top of contaminated soil

layer $(\mathrm{m})$

$h_{0} \quad$ Initial depth of bottom of contaminated soil layer (m)

3

$\mathrm{C}_{\mathrm{a}}$

Initial agent concentration (dry soil) (mg/kg)

1.0

t

Emission duration time (days)

90

$\epsilon$

Air-filled soil void fraction (dimensionless)

Water-filled soil void fraction (dimensionless)

$\rho \quad$ Bulk density of undisturbed soil $(\mathrm{kg} / \mathrm{L})$

$f_{\infty c}$

Fraction of organic carbon in soil

(dimensionless) (used only to determine $\mathrm{K}_{\mathrm{d}}$ )

$T \quad$ Prevailing temperature (degrees Kelvin)

(used only to determine $D_{a}$ and $K_{h}$ )

\section{Contaminant-Specific Values}

$\mathrm{D}_{\mathrm{a}} \quad$ Diffusivity of contaminant in air $\left(\mathrm{m}^{2} / \mathrm{d}\right)$ (Value $=$ $8.64 \times \mathrm{D}_{\mathrm{a}}$ expressed in $\mathrm{cm}^{2} / \mathrm{s}$.)

$\mathrm{K}_{\mathrm{H}} \quad$ Henry's Law constant for contaminant (dimensionless) (can be obtained by dividing Henry's Law constant in $\mathrm{atm}-\mathrm{m}^{3} / \mathrm{mol}$ by $8.2 \times 10^{-5} \times \mathrm{T}$ )

$\mathrm{K}_{\mathrm{oc}} \quad$ Partition coefficient for contaminant between soil organic carbon and water, (mg/kg organic carbon) $\div$ (mg/L) [in L/kg]

$\mathrm{K}_{\mathrm{d}} \quad$ Partition coefficient for contaminant between soil and water $=\mathrm{K}_{\mathrm{OC}} \times f_{\mathrm{OC}}(\mathrm{mg} / \mathrm{kg}) \div(\mathrm{mg} / \mathrm{L})[$ in L/kg] 
Table A-6. Contaminant-Specific Values and Derived 90-Day Average Flux Rates for a Hypothetical Scenario

$\begin{array}{lllc}\text { Factor }^{2} & \underline{G B} & \underline{V X} & \underline{H D} \\ \mathrm{D}_{\mathrm{a}}, \mathrm{m}^{2} / \mathrm{d} & 0.68 & 0.49 & 0.63 \\ \mathrm{~K}_{\mathrm{oc}} & 2.8 & 15.1 & 100 \\ \mathrm{~K}_{\mathrm{d}} & 0.056 & 0.30 & 2.0 \\ \mathrm{~K}_{\mathrm{H}} & 1.62 \times 10^{-5} & 2.92 \times 10^{-7} & 8.94 \times 10^{-4} \\ \mathrm{Q}_{\mathrm{av}}, \mathrm{mg} / \mathrm{d} & 80 & 0.6 & 589\end{array}$

${ }^{a} D_{a}, K_{o C}$, and $K_{H}$ are derived from tables in the main text.

Although $h_{0}$ does not appear in the foregoing calculations, it is used in determining the time, $t_{d r y}$, to exhaustion of the contaminant (i.e., when emission stops):

$$
\begin{aligned}
t_{d r y} & = & {\left[K_{d j}\left(h_{o}{ }^{2}-d_{o}{ }^{2}\right)\right] /\left[2 D_{e i}\right] } \\
\text { If } t>t_{d r y} \text {, then } Q_{a v} & = & {\left[A \times\left(h_{0}-d_{o}\right) \times C_{a} \times \rho \times 10^{3}\right] / t } \\
& = & 2.8 \times 10^{7} / t, m g / d
\end{aligned}
$$

Calculations for mustard (HD) average emissions are provided as an example:

$$
\begin{array}{rll}
\mathrm{D}_{\mathrm{ei}} & = & 0.2376 \times \mathrm{K}_{\mathrm{H}} \times \mathrm{D}_{\mathrm{a}}=0.2376 \times 0.000894 \times 0.63 \\
& = & 0.0001338 \\
\mathrm{~K}_{\mathrm{da}} & = & \mathrm{K}_{\mathrm{d}}+0.268=2+0.268=2.268 \\
\mathrm{~K}_{\mathrm{d}} & = & \left(1.4 \times \mathrm{K}_{\mathrm{da}}\right)+0.025+\left(0.375 \mathrm{~K}_{\mathrm{H}}\right) \\
& = & (1.4 \times 2.268)+0.025+\left(0.375 \times 8.94 \times 10^{-4}\right) \\
& = & 3.1752+0.025+0.0003=3.201 \\
\mathrm{Q}_{\mathrm{av}} & =\left(2 \times 10^{7} \mathrm{D}_{\mathrm{ei}}\right) /\left\{\mathrm{K}_{\mathrm{da}}\left(1+\left[1+180 \mathrm{D}_{\mathrm{ei}} / \mathrm{K}_{\mathrm{dj}}\right]^{1 / 2}\right)\right\} \\
& =\quad\left(2 \times 10^{7} \times 0.0001338\right) /\{2.268(1+[1+180 \times \\
& \left.\left.0.0001338 / 3.201]^{1 / 2}\right)\right\} \\
& = & (2676) /(4.545)=589 \mathrm{mg} / \mathrm{d}
\end{array}
$$

Under the assumed conditions, $t_{d r y}$ is much larger than $t$. Note that the value of $Q_{a v}$ increases with decreasing $\mathrm{d}_{0}$.

For a worst-case continuation of the foregoing scenario, assume that the wind is blowing unidirectionally towards a human receptor situated at a short distance downwind of the soil repository. The wind velocity is 
$4 \mathrm{~m} / \mathrm{s}$ (roughly $10 \mathrm{mph}$ ), blowing across a 100-m edge of the repository (which measures $100 \times 100 \mathrm{~m}$ ); the contaminant is distributed to a height of $2 \mathrm{~m}$. Thus, on average, the volume filled by the contaminant is

$$
4 \mathrm{~m} / \mathrm{s} \times 86,400 \mathrm{~s} / \mathrm{d} \times 2 \mathrm{~m} \times 100 \mathrm{~m}=69,120,000 \mathrm{~m}^{3} / \mathrm{d}
$$

The average exposure concentration is therefore

$$
(589 \mathrm{mg} / \mathrm{d}) /\left(6.9 \times 10^{7} \mathrm{~m}^{3} / \mathrm{d}\right)=8.5 \times 10^{-6} \mathrm{mg} / \mathrm{d} \text { or } 0.0085 \mu \mathrm{g} / \mathrm{m}^{3} \text {. }
$$

It must be emphasized that empirical evidence, as well as the measured reactivity of the agents of concern with water, would suggest that the above calculations grossly exaggerate potential exposures.

\section{A-6.0 REFERENCES}

Bell, E.V., G.M. Bennett, and A.L. Hock, 1927, Decomposition of Some Halogenated Sulphides, and the Nature of the "Polymeric" Ethylene Sulphides, J. Chem. Soc., 1803-1809.

Berkowitz, J.B., 1982, Literature Review - Problem Definition Studies on Selected Chemicals. Final Report. Volume IV. Site Specific Evaluation of Selected Organic Pollutants at Rocky Mountain Arsenal as of 1979, Contract No. DAMD17-77-C-7037 with U.S. Army Medical Research and Development Command, Arthur D. Little, Inc., Cambridge, MA, March.

Berkowitz, J.B., M.M. Goyer, J.C. Harris, W.J. Lyman, R.A. Horne, L.H. Nelken, J.E. Harrison, and D.H. Rosenblatt, 1978, Literature Review - Problem Definition Studies on Selected Chemicals. Final Report. Volume 11. Chemistry, Toxicology and Potential Environmental Effects of Selected Organic Pollutants, Contract No. DAMD17-77-C-7037 with U.S. Army Medical Research and Development Command, Arthur D. Little, Inc., Cambridge, MA, June.

Bodek, I., W.J. Lyman, W.F. Reehl, and D.H. Rosenblatt, 1988, Environmental Inorganic Chemistry: Properties, Processes, and Estimation Methods, Pergamon Press, New York.

Committee on Alternative Demilitarization Technologies, 1993, Alternative Technologies for the Destruction of Chemical Agents and Munitions, Board on Army Science and Technology, Commission on Engineering and Technical Systems, National Research Council, Washington, DC.

Demek, M., and J. Epstein, 1959, Project Little Seven Studies. III. Further Studies on the Behavior of VX in Soil, CWLR 2301, Chemical Corps Research and Development Command, Army Chemical Center, MD (as cited by Small 1983).

Epstein, J., M. Demek, B.L. Harrison, and J. Kolmerton, 1959, Project Little Seven Studies. II. Studies on the Behavior of VX in Soils, CWLR 2291, Chemical Corps Research and Development Command, Army Chemical Center, MD (as cited by Small 1983). 
Epstein, J., J.J. Callahan, and V.E. Bauer, 1974, The Kinetics and Mechanisms of Hydrolysis of Phosphonothiolates in Dilute Aqueous Solution, Phosphorus, 4:157-163.

Epstein, J., 1970, Rate of Decomposition of GB in Seawater, Science, 170:1396-1398.

Griffiths, T.A., M.J. Houle, V. Wallace, and F.D. Bagley, 1979, Extraction and Analysis of Soil Samples from V-Grid at Dugway Proving Ground, Letter Report DPG-I-135A, Dugway Proving Ground, UT (as cited by Small 1984).

Harvey, S.P., J.J. DeFrank, J.J. Height, C.M. Kutchey, W.T. Beaudry, L.L. Szafraniec, J.J. Valdes, and A.M. Chakrabarty, 1992, "Biodegradation of Mustard," in Reeves, P.J., ed., Proceedings of the 1990 U.S. Army Chemical Research, Development and Engineering Center Scientific Conference on Chemical Defense Research, 13-16 November 1990, CRDEC-SP-034, U.S. Army Chemical Research, Development \& Engineering Center, Aberdeen Proving Ground, MD, pp. 727-734.

Howard, P.H., 1990, Handbook of Environmental Fate and Exposure Data for Organic Chemicals, Lewis Publishers, Chelsea, MI.

Kaaijk, J., and C. Frijlink, 1977, Degradation of S-2-Diisopropylaminoethyl O-Ethyl Methylphosphonothioate in Soil. Sulphur-Containing Products, Pestic. Sci., 8:510-514 (as cited by Small 1983).

Kingery, A.F., and H.E. Allen, 1993, Extraction and Chromatographic Development of Selected Organophosphorus Compounds from Soil and Aqueous Media, Final Report, prepared for the U.S. Army Environmental Center under Contract No. DAAL03-86-D-0001 by the University of Delaware, Newark, DE, January.

Kingery, A.F., and H.E. Allen, 1994, Environmental Fate of Alkyl Methylphosphonates Arising from Chemical Surety Material (CSM) and Potential Non-CSM Sources in Soil and Aqueous Media, Final Report, prepared for the U.S. Army Environmental Center under Contract No. DAAL03-86-D-0001 by the University of Delaware, Newark, DE, March.

Kingery, A.F., and H.E. Allen, 1995, The Environmental Fate of Organophosphorus Nerve Agents, Toxicol. Env. Chem., 47:155-184.

Larsson, L., 1957, The Alkaline Hydrolysis of Isopropoxy-Methyl-Phosphonyl Fluoride (Sarin) and Some Analogues, Acta Chem. Scand., 11:1131-1142.

MacNaughton, M.G., and J.H. Brewer, 1994, Environmental Chemistry and Fate of Chemical Warfare Agents, Final Report, SwRI Project 01-5864, Southwest Research Institute, San Antonio, TX, March.

Major, M.A., 1989, Octanol Water Partition Coefficients of Surface and Ground Water Contaminants Found at Military Installations, Technical Report 88-10, U.S. Army Biomedical Research and Development Laboratory, Fort Detrick, Frederick, MD.

Major, M.A., 1990, U.S. Army Biomedical Research and Development Laboratory, Ft. Detrick, Frederick, MD, Miscibility of DIMP with water, personal communication to D.H. Rosenblatt, December 4. 
Nemeth, G., 1989, RCRA Facility Assessment Report - Edgewood Area - Aberdeen Proving Ground, Maryland No. 39-26-0490-90, Waste Disposal Engineering Division, U.S. Army Environmental Hygiene Agency, Aberdeen Proving Ground, MD, November.

Office of Remedial Response, 1988, Superfund Exposure Assessment Manual, OSWER Directive 9285.5-1, EPA/540/1-88/001, U.S. Environmental Protection Agency, Washington, DC, April.

Ogston, A.G., E.R. Holiday, J. St. L. Philpot, and L.A. Stocken, 1948, The Replacement Reactions of 6,6'-Dichlorodiethyl Sulphide and of Some Analogues in Aqueous Solution: The Isolation of 8-Chloro-8'Hydroxy Diethyl Sulphide, Trans. Faraday Soc., 44:45-52.

Puzderliski, A., 1980, Persistence of Drops of Sarin and Yperite in Soil, Naueno-Technicki Pregled, 30:18-23. (Translation from the Serbo-Croation, AD A124201) (as cited by Small 1984).

- Roberts, W.C., and W.R. Hartley, 1992, Drinking Water Health Advisory: Munitions, Lewis Publishers, Boca Raton, FL.

Rosenblatt, D.H., T.A. Miller, J.C. Dacre, I. Muul, and D.R. Cogley, eds., 1975, Problem Definition Studies on Potential Environmental Pollutants. Il. Physical, Chemical, Toxicological, and Biological Properties of 16 Substances, Technical Report 7509, U.S. Army Medical Bioengineering Research and Development Laboratory, Fort Detrick, Frederick, MD. AD A030428.

Sass, S., T.N. Zenk, and R.A Hilliard, 1953, Stability of Agents in Soils (GA, GB, GF, EA1211, Paraoxon, EA 1370), CRLR 247, Chemical Corps Chemical and Radiological Laboratories, Army Chemical Center, MD.

Small, M.J., 1983, Soil Detection Limits for Potential Chemical Warfare-Related Contaminants at Fort McClellan Alabama, U.S. Army Medical Bioengineering Research and Development Laboratory, Fort Detrick, Frederick, MD, Technical Report 8208, May. AD-B077091L.

Small, M.J., 1984, Compounds Formed from the Chemical Decontamination of HD, GB, and VX and their Environmental Fate, U.S. Army Medical Bioengineering Research and Development Laboratory, Fort Detrick, Frederick, MD, Technical Report 8304, June. AD-A149515.

Small, M.J.,1993, The Pollutant Hazard Assessment System, Version 3: Documentation and Users Manual, Technical Report 9302, U.S. Army Biomedical Research and Development Laboratory, Fort Detrick, Frederick, MD, May.

Szafraniec, L.J., L.L. Szafraniec, W.T. Beaudry, and J.R. Ward, 1990, On the Stoichiometry of Phosphonothiolate Ester Hydrolysis, CRDEC-TR-212, U.S. Army Chemical Research, Development and Engineering Center, Aberdeen Proving Ground, MD, July.

Szafraniec, L.L., W.T. Beaudry, and Y.-C. Yang, 1993, Hydrolysis of VX and S-2(Diisopropylamino)ethyl Methylphosphonothioic Acid (EA2192) in Super-Alkaline Solution, Proceedings, 1992 ERDEC Scientific Conference on Chemical Defense Research, Aberdeen Proving Ground, MD, Nov. 17-20, 1992. 
USATECOM, undated, Environmental Impact Statement for the Study of the Fate of Agent and Residues in Vegetation and Soil, USATECOM Project 5-CO-483-000-015, Deseret Test Center, Fort Douglas, UT.

Verweij, A., and H.L. Boter, 1976, Degradation of S-2-Diisopropylaminoethyl O-Ethyl Methylphosphonothioate in Soil. Phosphorus-Containing Products, Pestic. Sci., 7:355-362 (as cited by Small 1983).

Weast, R.C., 1979, CRC Handbook of Chemistry and Physics, CRC Press, Inc., Boca Raton, FL.

Williams, A., and I.T. Ibrahim, 1981, A New Mechanism Involving Cyclic Tautomers for the Reaction with Nucleophiles of the Water-Soluble Peptide Coupling Agent 1-Ethyl-3-(3-(dimethylaminopropyl) carbodiimide (EDC), J. Am. Chem. Soc., 103: 7090-7095.

Yang, Y.-C., L.L. Szafraniec, W.T. Beaudry, and J.R. Ward, 1987, Sulfonium Chlorides Derived from 2-Chloroethyl Sulfides. I. Formation and Magnetic Resonance Identification in Water, CRDEC Technical Report TR-88008, Chemical Research, Development and Engineering Center, Aberdeen Proving Ground, MD, October.

Yang, Y.-C., L.L. Szafraniec, W.T. Beaudry, and D.K. Rohrbaugh, 1990, Oxidative Detoxification of Phosphonothiolates, J. Am. Chem. Soc., 112:6621-6627. 


\title{
APPENDIX B
}

\section{ABSORPTION AND DESORPTION OF CHEMICAL AGENTS ON POLYMERIC MATERIALS}

\section{B-1.0 INTRODUCTION}

This Appendix seeks to provide an understanding of the absorption and desorption of liquid chemical agents in polymeric substrate materials. Such phenomena relate to the ability of decontaminants applied to substrate surfaces to reactively decompose and remove the agents. The polymeric substrate materials of special interest are:

\author{
Alkyd paints (on metal) \\ Polyurethane paints (on metal) \\ Butyl rubber \\ Neoprene rubber \\ Polystyrene \\ Polymethyl methacrylate \\ Chemically protective fabric (materials not specified)
}

Unfortunately, no direct evidence concerning the absorption or desorption of the chemical agents with these specific substances has been located in the open (peer-reviewed journal) literature, but a moderate amount of relevant information is available in military documents.

Substrates are usually tested with liquid agent contamination densities of up to $10 \mathrm{~g} / \mathrm{m}^{2}$ nominal surface density (Southern Research Institute 1992). This density should be put into common perspective. The application of one-coat wall paint corresponds to an approximate surface density of 1 gallon per $300 \mathrm{ft}^{2}$. If one assumes that the mass density of paint is $1 \mathrm{~g} / \mathrm{cm}^{3}$, after conversions of weight and area, the paint application corresponds to a surface density of $136 \mathrm{~g} / \mathrm{m}^{2}$, about 14 times that planned for agent. Moreover, if the density of agent is about $1.1 \mathrm{~g} / \mathrm{cm}^{3}$, a $10 \mathrm{~g} / \mathrm{m}^{2}$ uniform surface density would have a depth of $0.009 \mathrm{~mm}$. In comparison, the average plastic trashbag is about 0.8 mil or $0.020 \mathrm{~mm}$, approximately twice as thick. Because agent is applied as discrete droplets, the initial agent film on a substrate is likely to be rather uneven.

\section{B-2.0 ABSORPTION INTO POLYMERIC SUBSTRATE MATERIALS}

In this discussion, polymeric substrate materials are assumed to be nonporous. For a liquid substance or permeant to be absorbed into a polymeric material, it must "dissolve" in the polymer and then diffuse through the polymeric structure (Perkins and Tippit 1985). The absorption process is usually studied in terms of the kinetics of reaching equilibrium under isothermal conditions. Two parameters are involved: the solubility of the permeant in the polymer at equilibrium and the diffusion coefficient (characteristic of the kinetics of permeant movement into the polymer).

The question of polymer-liquid solubility has been extensively studied, and the extent of solubility can be qualitatively predicted by considering the solubility parameters $(\delta)$ for the polymer and liquid. This parameter is defined as the square root of the ratio of molar energy of evaporation to molar volume (Grulke 1989). This parameter is cited in units of either $\left(\mathrm{cal} / \mathrm{cm}^{3}\right)^{0.5}$ or $(\mathrm{MPa})^{0.5}$; here, $\left(\mathrm{cal} / \mathrm{cm}^{3}\right){ }^{0.5}$ will be assumed unless otherwise specified. 
For nonpolar liquids and vapors, and in the absence of hydrogen bonding, the Hildebrand-Scatchard regular solution theory has been used as a starting point to determining if a noncrystalline polymer dissolves in a liquid (Blanks and Prausnitz 1964). The theory involves computing the free energy of mixing, in which the solubility parameters for the system liquid and polymer appear. If these parameters differ by less than 1.7 to 2.0 (Billmeyer 1971), polymer dissolution in liquid may be expected.

Hansen (1969) extended this theory to the problem of permeability of solvent in polymer. He postulated that the solubility parameter could be treated as the vector sum of four components, of which three were considered most important: those of dispersive forces, permanent dipoles, and hydrogen-bonding attributes. These parameters have been measured for hundreds of solvent compounds and many polymeric materials and are tabulated in standard references (Barton 1983, 1990; Grulke 1989) and in computer databases (Shuely 1993). For convenience, parameters collected for compounds mentioned in this appendix are listed in Table B-1. Alkyd paint solubility parameters are also available.

\section{Table B-1. Solubility Parameter Data for Chemical Agents, Solvents,} and Polymeric Materials

\begin{tabular}{|c|c|c|c|c|c|}
\hline Permeant & $\delta^{a}$ & Source & Polymer & $\delta^{\mathbf{a}}$ & Source \\
\hline GB & $9.0^{b}$ & Pfau et al. 1987 & Polymethyl methacrylate & $9.1,5.1,3.7,11.1$ & Barton 1983 \\
\hline GD & $8.6^{b}$ & Pfau et al. 1987 & Polystyrene & $10.4,2.8,1.3,10.6$ & Barton 1983 \\
\hline$v x$ & $8.5^{b}$ & Pfau et al. 1987 & Neoprene & $9.5,1.5,1.3,9.7$ & Barton 1990 \\
\hline HD & $9.5,3.8,2.4,10.5^{c}$ & Shuely and McNeely, 1992 & Butyl Rubber & $7.8,1.1,1.6,8.0$ & Barton 1990 \\
\hline Toluene & $8.8,0.7,1.0,8.9^{c}$ & Barton 1983 & Polypropylene & $8.2^{b} \quad N$ & Michaels et al. 1968 \\
\hline Methylcyclo- & & & Styrene-Butadiene Rubber & $8.6,1.7,1.3,8.9$ & Barton 1983 \\
\hline hexane & $7.8,0.0,0.5,7.8^{c}$ & Barton 1983 & Polyethylene & $8.6,0.0,0.0,8.6$ & Barton 1983 \\
\hline n-Heptane & $7.5,0.0,0.0,7.5^{c}$ & Barton 1983 & PVC & $8.9,3.7,2.1,9.9$ & Barton 1983 \\
\hline Methyl acetate & $7.5,3.5,3.7,9.1^{c}$ & Barton 1990 & & & \\
\hline
\end{tabular}

\footnotetext{
a Values given in order. dispersive, polar, $H$-bonding, and total.

b No component values available from reference.

c Data in $(\mathrm{MPa})^{1 / 2}$, converted by the author $\left[1(\mathrm{Mpa})^{1 / 2}=2.046\left(\mathrm{cal}^{1 / \mathrm{cm}^{3}}\right)^{1 / 2}\right]$.
}

Shuely (1993) presents a detailed procedure to predict if a chemical agent is soluble in a given polymer. A solubility parameter database with selected polymers was assembled for liquids known to be soluble or insoluble. A three-dimensional surface (the dimensions representing dispersion, polarity, and hydrogen-bonding aspects of the solubility parameter), which encloses the polymer's solubility space, can be constructed. To assess a candidate liquid for permeability, the liquid's location in solubility parameter space is determined to be inside or outside the polymer's solubility space. The theory does not suffice to estimate saturation solubility for agent. Mangaraj et al. (1987) present a method to estimate phosphonofluoridate agent solubility and diffusion coefficients in polymers based on experimental results with several simulant liquids. Perkins and Tippit (1985) indicate some progress in correlating permeation rate and breakthrough times to the vector distance from the "center" of the polymer's solubility space to the permeant. 


\section{B-2.1 Methods and Models}

When a solid is immersed in a liquid or vapor containing an absorbable substance, the relationship between the amount of the substance that sorbs into the solid and the concentration of the substance in the liquid or vapor phase at a fixed temperature is called an absorption isotherm. Absorption isotherms can be measured with permeant in the liquid or vapor state. Generally, thin films of polymer are used, although for vapor experiments, powdered materials may be employed (Berens 1985). Liquid absorption isotherms can be developed by immersing the polymer sample in liquid. At selected time intervals, the sample is removed from the liquid, blotted dry, and weighed. The vapor absorption isotherm tests have been performed with the sample attached to a calibrated quartz spring in a test cell, which is filled with vapor permeant that is maintained at a preselected pressure. The increase of polymer weight due to absorption is indicated by the elongation of the spring, which can be followed visually. More recently, gravimetric devices such as recording microbalances have been developed to follow the weight gain with time.

The test results are expressed as a curve of weight gain vs. elapsed time. The ratio of weight gain to polymer sample weight approaches an asymptotic value, which is the saturation solubility for the permeant. The saturation solubility of a permeant in a given polymer depends on whether the permeant is applied as a liquid or vapor, on the temperature, and - for vapor contact - on the vapor pressure. Solubility is also a function of polymer structure. Crystalline nonpolar polymers and cross-linked polymers resist the permeation of otherwise soluble nonpolar permeants. For example, in work by Long (1965), solubility predictions with polymers of differing crystalline content were obtained by adjusting for the crystalline content.

The saturation solubilities for permeant liquid and saturated vapor are expected to be equal due to thermodynamic considerations. However, the solubility at lower permeant activities may be considerably lower than expected from Henry's Law. Berens (1985) experimentally determined absorption isotherms for several permeants in polyvinyl chloride (PVC), either at saturated conditions or with unsaturated vapor or diluted liquid (in nondiffusing solvent). As an example, the weight gain of PVC in contact with liquid toluene (activity $=1$ ) was about $55 \%$ of initial polymer sample weight. At an activity of 0.75 (either toluene vapor at $75 \%$ of saturated vapor pressure or a toluene-polyethylene glycol solution that produces the same pressure), the weight gain was only $16 \%$; at an activity of 0.5 , the weight gain was just $8 \%$. Berens (1985) explains the relation in terms of the Flory-Huggins equation: $\ln (P / P 0)=\ln (V 1)+V 2+x V_{2}^{2}$. In this equation, $P / P 0$ is the activity, $V 1$ is the volume fraction of permeant in polymer at equilibrium conditions, $V 2$ is the volume fraction of polymer at equilibrium conditions, and $x$ is the Flory interaction parameter, which in this application is a curve-fitting parameter. Usually, $X$ provides a semiqualitative criterion to predict if a solvent softens a polymer or causes polymer swelling and is a function of both the solvent and polymer. Values of $X$ for selected systems are also tabulated (Barton 1983; Grulke 1989).

Several models, based on mathematical solutions to the diffusion equation, can be used for data analysis. The simplest model is one-dimensional diffusion, in which the diffusion coefficient of the permeant within the polymer is independent of permeant concentration. In experiments that fit this model, the initial part of the curve exhibits a linear uptake-(time $)^{1 / 2}$ behavior. A pseudosaturation time is determined by extrapolation of the line (uptake vs. [time] $^{1 / 2}$ ) to the estimated saturation solubility. If half this time is called $t_{1 / 2}$ sat, the diffusion coefficient is computed as $D=0.0492 \mathrm{~L}^{2} / \mathrm{t}_{1 / 2}$ sat, where $L$ is the thickness of the polymer parallel to the direction of diffusion. In Naylor (1989), this is called Case I sorption. Case I sorption is often encountered with permeants into polymeric materials above the glass transition point (Crank 1956). 
A more complicated situation arises if the diffusion coefficient is a function of permeant concentration within the polymer. This situation was encountered by Long (1965), who studied the permeation of toluene, $n$-heptane, and methyicyclohexane in polypropylene, and by Berens (1985), whose work is described above. In this case, the weight gain-time relation tends to be more linear. The condition of a linear weight gain-time relation has been called Case II sorption (Naylor 1989).

Long (1965) estimated a zero-concentration diffusion coefficient, $D_{0}$, for the model $D=D_{0} e^{a C}$, where

$D$ is the diffusion coefficient for a specific concentration of permeant in polymer,

$\mathrm{C}$ is the point concentration, and

$a$ is a constant for a given temperature and polymer-solvent system.

$D_{\mathrm{o}}$ was determined from data obtained by desorbing a polymer sample that had been equilibrated with the saturated vapor of a permeant. The polymer sample of thickness $L$ was suspended on a quartz spring in an enclosed case. Vacuum was applied to an outlet, and as desorption occurred, the polymer weight (as measured from the elongation of the spring) was obtained. After an extended time period, the slope of the In (weight) vs time curve should approach $\pi^{2} \mathrm{D}_{d} \mathrm{~L}^{2}$. At room temperature, the diffusion coefficient of liquid toluene was estimated as $3 \times 10^{-6} \mathrm{~cm}^{2} / \mathrm{sec}$, while $D_{0}$ was computed to be $1.5 \times 10^{-9} \mathrm{~cm}^{2} / \mathrm{sec}$.

One major difference between the two models is the concentration profile of permeant in the polymer. For Case I sorption, the profile has been determined and presented in dimensionless figures (see Crank 1956) (Section B-3). The polymer is saturated just inside the surface, and the concentration decreases monotonically towards zero at greater depths. In Case II sorption, the profile approaches a "step" function (depending upon the model relation for $D$ and the fit parameter). The permeant diffuses into the polymer as a "front," and, at any time in the process, the transition from saturated to near-zero concentration in polymer occurs over a short thickness interval. Experimental observations show that the nearly saturated portion of the polymer will swell considerably, while the nearly dry portion has normal dimensions. Berens (1985) observes that at low activity levels, absorption into PVC was described by the Case I sorption model, but as the activity increased, the isotherms tended towards Case II sorption behavior. For example, Case I sorption isotherms were determined for toluene at activities of 0.75 or lower.

In short, under some conditions an agent may show a gradually decreasing concentration profile as it penetrates a polymer substrate, the forward edge of the migrating agent.

\section{B-2.2 Diffusion of Chemical Agents}

Pfau et al. (1987) studied the absorption of saturated vapors of the chemical agents GB, GD, VX, and HD in low-density polyethylene (LDPE) and styrene-butadiene rubber (SBR). Their data are reviewed here, and the intake per $\mathrm{m}^{2}$ area is estimated for a $1-\mathrm{h}(3,600-\mathrm{s})$ exposure to illustrate the extent of permeation of liquid at a $10 \mathrm{~g} / \mathrm{m}^{2}$ surface density. The results calculated from these data appear in Table B-2. 


\begin{tabular}{lllllll}
\hline Table B-2. & \multicolumn{6}{c}{ Agent Permeation Estimated for 1-Hour Exposure to Saturated Vapor } \\
\hline Agent/Polymer & GB/LDPE & GB/SBR & GD/LDPE & GD/SBR & HD/LDPE & VX/LDPE \\
\hline $\mathrm{D}\left(\mathrm{cm}^{2} / \mathrm{s}\right)$ & & & & & & \\
Solubility $(\mathrm{g} / \mathrm{g})$ & $1.3 \times 10^{-8}$ & $4.9 \times 10^{-8}$ & $1.3 \times 10^{-9}$ & $8.7 \times 10^{-9}$ & $3.1 \times 10^{-9}(\mathrm{a})$ & $3.8 \times 10^{-9}(\mathrm{a})$ \\
$\mathrm{t}_{1 / 2} \mathrm{sat}(\mathrm{s})$ & 0.003 & 0.12 & 0.016 & 0.23 & $0.022(\mathrm{a})$ & $0.062(\mathrm{a})$ \\
$\mathrm{L}(\mathrm{cm})$ & 39,200 & 29,800 & 500,000 & 113,000 & 180,000 & 146,000 \\
fraction, $1 \mathrm{~h}$ & 0.10 & 0.17 & 0.11 & 0.14 & $0.11(\mathrm{~b})$ & $0.11(\mathrm{~b})$ \\
Agent sorbed $(\mathrm{g})$, in $1 \mathrm{~h}$ & 0.214 & 0.6246 & 0.06 & 0.126 & 0.1 & 0.011 \\
\hline
\end{tabular}

Estimated by the author.

b Assumed thickness.

Source: Based on data of Pfau et al. (1987).

GB and GD diffusion coefficients and solubility values are presented in Table 2 of the report by Pfau et al. (1987). Because polymer thickness data are not provided, the "Case I" equation discussed above is used to back-calculate the thickness $L$. The term "fraction, $1 \mathrm{~h}$ " is the ratio of $(3,600)^{1 / 2} /(\text { tsat })^{1 / 2}$ and indicates the extent of total absorption that is attained in $1 \mathrm{~h}$. (Note that tsat $=2 \times t_{1 / 2}$ sat.) The weight of agent sorbed in one hour is the product: (saturation solubility) $\times L \times 10,000 \times$ (fraction, $1 \mathrm{~h}$ ). The polymer is assumed to have unit density. For HD and VX, absorption curves are presented by Pfau et al. (1987), but the solubility and the diffusion coefficient are not estimated. Estimates of these factors and saturation time in Table B-2 were made by the authors of the present document. The LDPE test material for HD and VX experiments was assumed to be $0.11 \mathrm{~cm}$ thick.

The results in Table B-2 should be considered tentative because agent vapor-polymer data have been applied to an agent liquid-polymer scenario. The present authors consider this a valid approach for two reasons. First, Long (1965) indicates that, for liquids with low permeation rates, the liquid and vapor permeation rates should be equal. Second, liquid agent does not cover the entire surface, and the areas unexposed to liquid would be subject to vapor penetration from evaporating liquid. The analysis does suggest that a significant amount of agent could permeate into either SBR or LDPE in $1 \mathrm{~h}$.

It can be seen that the capacity of substrate polymers to absorb agents varies widely.

\section{B-3.0 DESORPTION}

Once an external supply of permeant is removed from a polymeric substance that has absorbed a permeant, desorption can take place. The transport mechanism of permeant away from the surface plays the major role in controlling the rate of desorption, as does the dependence of the diffusion coefficient on concentration.

The simplest situation is that of a polymer fully saturated with permeant, where Case I sorption applies, that is suddenly exposed to an external environment where the exiting vapors are instantly dispersed. A practical example would be agent-saturated polymer immersed in a decontamination liquid that is not soluble in the polymer. In terms of the Fickian diffusion equation, $\partial C / \partial t=-D \partial^{2} C / \partial x^{2}$ (where $x$ is the length dimension), the boundary conditions prevailing during absorption are simply reversed. Thus, desorption should proceed, at least in theory, as did absorption, with the same mass of permeant removed in the same time as it took for that mass to absorb. In practice, there is hysteresis (a lag of effect when the direction of action is reversed), with the desorption rate somewhat lower than that of absorption. Experimental observations to this effect are discussed by Crank and Park (1968); in one example, that of methyl acetate in polymethyl acrylate, the slope of the mass desorbed-(time) ${ }^{1 / 2}$ line was 0.8 that of the absorption line. 
For a partially saturated polymer, the situation is more complex; the concentration profile of permeant in polymer at the start of desorption is not uniform. Crank (1956) provides dimensionless profiles for contours of $4 \mathrm{D} t \mathrm{~L}^{2}$. The HD/LDPE data from Table $\mathrm{B}-2$ give a contour value of 0.0037 . The nearest exemplar profile, for 0.005 (Crank 1956), indicates the following:

Distance inside Surface, $\mathrm{cm}$
0.0
0.006
0.011
0.016

\begin{tabular}{c} 
Percent Saturation \\
\hline 100 \\
30 \\
4 \\
0.4
\end{tabular}

As HD diffuses from the polymer, the driving gradient will decrease rapidly because the interior layers are not saturated. Moreover, there is still a gradient inwards, so HD will continue to penetrate the polymer to greater depths. In this case, the desorption rate should be considerably below the rate for a fully saturated polymer sample.

Crank (1956) also presents dimensionless desorption curves for the case in which permeant exiting the surface is subject to less-than-instantaneous dispersion according to the relation: - D $\partial \mathrm{C} / \partial \mathrm{x}=\alpha(\mathrm{Co}-\mathrm{Cs})$, where Cs is the permeant concentration just within the polymer and $\mathrm{Co}$ is the ambient external concentration of permeant. The parameter $\alpha$ has units of length/time. If the external environment is permeant-free air, $\alpha$ may be looked upon as an exchange coefficient.

If the diffusion coefficient is concentration dependent, the rate of desorption is less than that of the absorption that preceded it. Crank (1956) has illustrative curves for the exponential model, $D=D_{0} e^{a C}$, discussed in Section B-2.1, as well as for other diffusion-concentration models.

In summary, diffusion of an agent out of a polymeric substrate may require considerably more time than its diffusion into the substrate.

\section{B-4.0 IMPLICATIONS}

The models described above are useful guides for the design of experiments to determine quantitative absorption relationships between the agents of concern and the organic substrates of special interest. The solubility parameters in Table B-1 provide information on polymethyl methacrylate, polystyrene, neoprene rubber, butyl rubber, and the four agents. The nonpolar Hildebrand-Scatchard theory, as cited by Billmeyer (1971), would indicate that the agents are soluble in these polymers to an appreciable extent $\left[1 \delta_{\text {agent }}-\delta_{\text {polymer }} l\right.$ $<2$ ]. A better assessment can be made when the dispersive, polar, and hydrogen bonding components of agent solubility parameters are obtained. The work by Pfau et al. (1987) indicates that the agents will diffuse into SBR, a substance similar in solubility parameter characteristics to the other rubbers of special interest. The desorption from such materials, even when the materials are treated with decontaminants, may not suffice to remove all diffused (imbibed) agent in the time frame of concern.

It is quite likely that time constraints will render the complete decontamination of sorbed agents from thick layers of polymer highly impractical. 


\section{B-5.0 REFERENCES}

Barton, A.F.M., 1983, CRC Handbook of Solubility Parameters and Other Cohesion Parameters, CRC Press, Inc., Boca Raton, FL.

Barton, A.F.M., 1990, CRC Handbook of Polymer-Liquid Interaction Parameters and Solubility Parameters, CRC Press, Inc., Boca Raton, FL.

Berens, A.R., 1985, Prediction of Organic Chemical Permeation through PVC Pipe, J. Amer. Waterworks Assn., November, pp. 57-64.

Billmeyer, F.W., Jr., 1971, Textbook of Polymer Science, Wiley Interscience, John Wiley and Sons, New York, NY.

Blanks, R.F., and J.M. Prausnitz, 1964, Thermodynamics of Polymer Solubility in Polar and Nonpolar Systems, I\&EC Fundamentals, 3(1):1-7.

Crank, J., 1956, The Mathematics of Diffusion, Oxford University Press, London, UK.

Crank, J., and G.S. Park, 1968, Diffusion in Polymers, Academic Press, New York, NY.

Grulke, E.A., 1989, "Solubility Parameter Values," in J. Brandrup and E.H. Immergut, eds., Polymer Handbook, Chapter 7, Third Edition, Wiley Interscience, John Wiley and Sons, New York, NY.

Hansen, C.M., 1969, The Universality of the Solubility Parameter, I\&EC Prod. Res. Dev., 8(1):2-11.

Long, R.B., 1965, Liquid Permeation through Plastic Films, I\&EC Fundamentals, 4(4):445-451.

Mangaraj, D., J.P. Pfau, M. Luttinger, F. Block, and W.S. Magee, 1987, An Approach to Estimating the Permeation of Phosphonofluoridates into a High Polymer Matrix Part 1. Development of the Approach, Polymer Eng. Sci., 27:1338-1343.

Michaels, A.S., W.R. Veith, and H.H. AlCahay, 1968, The Solubility Parameter of Polypropylene, J. Appl. Poly. Sci., 12:1621-1624.

Naylor, T. deV., 1989, "Permeation Properties," in C. Booth and C. Price, eds., Comprehensive Polymer Science, Volume 2, Polymer Properties, Chapter 20, Pergamon Press, New York, NY.

Perkins, J., and A.D. Tippit, 1985, Use of Three-Dimensional Solubility Parameters to Predict Glove Permeation, Am. Ind. Hyg. Assoc. J., 46(8):455-459.

Pfau, J.P., R.E. Sharpe, D. Manjaraj, J.D. Booton, F. Block, and W.S. Magee, 1987, An Approach for Estimating the Permeation of Chemical Warfare Agents into a High Polymer Matrix Part II. Verification of the Approach, CRDEC-CR-87090, Chemical Research, Development and Engineering Center, Aberdeen Proving Ground, MD, June, DTIC AD-B113662L. 
Shuely, W.J., 1993, Test Methodology for Development of Corrosion Resistant Polymeric Materials: Predictive and Experimental Methods for Chemical Resistance Screening, 12th Biennial Managing Corrosion with Plastics Symposium, Baltimore, MD, November 1-4.

Shuely, W.J., and J.J. McNeely, 1992, Material Selection Guide Derived from Material-Chemical Compatibility Database: Feasibility Based on Database and Predictive Model Evaluation, CRDEC-TR-397, Chemical Research, Development and Engineering Center, Edgewood, MD, September. DTIC AD-A266508.

Southern Research Institute, 1992, Waste Sampling Test Report, Final Report, Contract DAAA15-89D-0004, Task Order No. 11, SRI-APC-92-552-6840-45, Project 6840-45/XXVI, by Southern Research Institute, Birmingham, AL. 